\title{
Regulator preferences and managers' manipulation choices
}

Citation for published version (APA):

Heese, J. (2014). Regulator preferences and managers' manipulation choices. [Doctoral Thesis, Maastricht University]. Datawyse / Universitaire Pers Maastricht. https://doi.org/10.26481/dis.20140613jh

Document status and date:

Published: 01/01/2014

DOI:

10.26481/dis.20140613jh

Document Version:

Publisher's PDF, also known as Version of record

\section{Please check the document version of this publication:}

- A submitted manuscript is the version of the article upon submission and before peer-review. There can be important differences between the submitted version and the official published version of record.

People interested in the research are advised to contact the author for the final version of the publication, or visit the DOI to the publisher's website.

- The final author version and the galley proof are versions of the publication after peer review.

- The final published version features the final layout of the paper including the volume, issue and page numbers.

Link to publication

\footnotetext{
General rights rights.

- You may freely distribute the URL identifying the publication in the public portal. please follow below link for the End User Agreement:

www.umlib.nl/taverne-license

Take down policy

If you believe that this document breaches copyright please contact us at:

repository@maastrichtuniversity.nl

providing details and we will investigate your claim.
}

Copyright and moral rights for the publications made accessible in the public portal are retained by the authors and/or other copyright owners and it is a condition of accessing publications that users recognise and abide by the legal requirements associated with these

- Users may download and print one copy of any publication from the public portal for the purpose of private study or research.

- You may not further distribute the material or use it for any profit-making activity or commercial gain

If the publication is distributed under the terms of Article $25 \mathrm{fa}$ of the Dutch Copyright Act, indicated by the "Taverne" license above, 


\title{
Regulator Preferences and \\ Managers' Manipulation Choices
}

\author{
Jonas Heese
}


(c) Jonas Heese 2014

All rights reserved. No part of this publication may be reproduced, stored in a retrieval system, or transmitted in any form or by any means, electronic, mechanical, photocopying, recording or otherwise, without the prior permission in writing from the author.

ISBN 9789461593405 


\title{
Regulator Preferences and Managers' Manipulation Choices
}

\author{
DISSERTATION \\ to obtain the degree of Doctor at Maastricht University, \\ on the authority of the Rector Magnificus, Prof. Dr. L.L.G. Soete, \\ in accordance with the decision of the Board of Deans, \\ to be defended in public \\ on Friday, June 13, 2014 at 10.00 hours \\ Jonas Heese
}

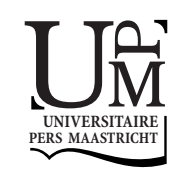




\section{Promoter}

Prof. Dr. Frank Moers

\section{Co-Promoter}

Prof. Dr. Ranjani Krishnan (Michigan State University, United States)

\section{Assessment Committee}

Prof. Dr. Ann Vanstraelen (Chair)

Prof. Dr. Margaret Abernethy (University of Melbourne, Australia)

Prof. Dr. Martin Carree

Prof. Dr. Naomi Soderstrom (University of Melbourne, Australia)

This dissertation benefited from the financial support granted by Maastricht University's Graduate School of Business and Economics and the Limburg University Fund (SWOL). 



\section{Acknowledgements}

Pursuing my PhD has, by all means, been a challenging, inspiring and rewarding experience. I could study topics I am interested in, had the opportunity to learn new things and exchange ideas on a daily basis and, most important, had the chance to meet wonderful people from all over the world. I am grateful to those people who not only joined me in moments of success during the last four years, but also supported me in times of doubt and frustration. I am very glad to have the opportunity to thank all of these people.

I would like to thank my promoter Prof. Dr. Frank Moers for his constant support and critical evaluation of my work throughout the last four years. Looking back, I have learned a lot not only from our inspiring research discussions but also from the more challenging moments of an academic life such as the rejections of our paper. All of these experiences have helped me tremendously to improve as a scholar and Frank's support has been invaluable in this process. Also, I am indebted to my co-promoter and co-author Prof. Dr. Ranjani Krishnan. I am grateful that Ranjani gave me the opportunity to visit Michigan State University twice and supported me throughout my whole PhD and especially during my job market endeavors. Working with Ranjani has been a constant source of inspiration and motivation, and an invaluable learning experience.

I also would like to thank the members of my assessment committee Prof. Dr. Margaret Abernethy, Prof. Dr. Martin Carree, Prof. Dr. Naomi Soderstrom and Prof. Dr. Ann Vanstraelen for taking the time to evaluate my dissertation and providing me with timely and helpful feedback. I especially want to thank my co-authors Maggie and Naomi for their continuous support. Maggie gave me the opportunity to visit the University of Melbourne and ensured that my visit was a great learning experience for me. Naomi supported me tremendously during my job market and really pushed our paper forward.

I was fortunate to be part of a wonderful department at Maastricht University: The Accounting and Information Management (AIM) department. I will miss the collegial atmosphere among all members of that department, the supportive environment and the personal as well as research-related chats. I especially appreciated the support of Prof. Dr. Roger Meuwissen and Prof. Dr. Philip Vergauwen, who in their function as department heads as well as dean, always provided me with a solution for any kind of administrative as well as financial constraint I might have. I also would not want to miss the numerous informal get-togethers with Isabella Grabner and Frank, among others. I also really enjoyed my conversations with Alexander Brüggen during and after work, which have often been spiced up by his great sense of humor. I am also thankful for the help of Annelies Renders in preparing for my job market.

I am also highly indebted to my fellow PhD colleagues for making my life in Maastricht much more enjoyable. First of all, I want to thank my two long-term 
officemates, friends and paranymphs Patrick and Thomas not only because of all the fun we had during accounting courses, conferences, numerous parties, trips to various countries and so forth, but also because both of you provided me with helpful feedback throughout my whole $\mathrm{PhD}$. From the first day of my $\mathrm{PhD}$ when I entered the office B2.23, which soon became a social hub of the university, seeing Patrick criticizing Thomas for setting up yet another committee, I knew I had met two great persons. Patrick's attempts to learn German which ultimately resulted in a new language, Thomas' creativity in organizing parties as well as our mutual song composition, will, among other things, always remind me of this great time we had. I truly believe that the three of us have set new standards for professional as well as social engagement and I am honored to have been part of that infernal trio. I also want to thank Christoph for later enriching our team with his great personality and the willingness to repeat our mistakes. I extend my gratitude towards Lars with whom I shared an apartment in Maastricht and had great discussions about the greater things in life. I am moreover thankful for having Nadine as a colleague. Her good mood and genuinely good nature have made the department a better place and enriched every social activity. Ron has also been an invaluable source of humor and fun during all types of activities. I am also thankful to Ronny for the numerous social activities and for his great hospitality when I visited him and his family in Perth. Special thanks are also extended to Simone for all the enjoyable conversations and her great jokes. Moreover, Abiot, Anant, Britt, Isabell, Judith, Julius, Lars, Lei, Mona, Norbert, and Réka, all enriched my life in Maastricht.

I am also thankful for meeting all the great people during my visits in Melbourne and Michigan; particularly, Bill, Jackie, James and Martin. They have made my visits truly memorable experiences.

I am especially grateful for all the support from my friends Daniel, Fabian, Moritz, Ralf, Richard, Rouven, Sebastian, Tim, and Volker. I am proud and happy that we still meet regularly, exchange ideas and have a lot of fun.

I also would like to thank my parents and my brother for their life-long support. I am deeply grateful for their tremendous support and their unlimited trust and confidence in me. May they regard the completion of this dissertation as a reward for their years of dedication.

Finally, the person I am most indebted to is Elina. Elina has not only made my life much more joyful during the last years, but she has also provided me with feedback on my work, encouraged me to spend months in Melbourne and Michigan, supported me during my job market, and cheered me up during all downs that are part of a PhD. I feel very fortunate to have enjoyed such unconditional support throughout all these years from Elina and for the wonderful time we have spent together. 


\section{Table of Contents}

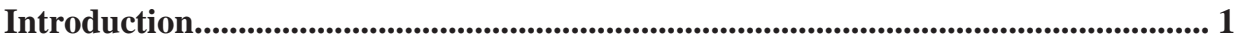

1.1. Theories and Empirical Evidence of Regulatory Behavior ......................................

1.2. Managers' Behavior under Regulatory Scrutiny ...................................................

1.3. The Interplay between Regulator Preferences and Organizational Motives for Revenue Manipulation ..................................................................................

1.4. The Role of Revenue Manipulation in the Trade-Off Decision between Performance Management Strategies .................................................................. 7

1.5. Government Preferences, SEC's Enforcement Actions and Firms'

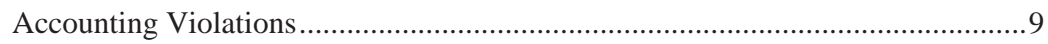

1.6. Outline of the Dissertation ................................................................................. 11

The Interplay between Regulator Preferences and Organizational Motives for

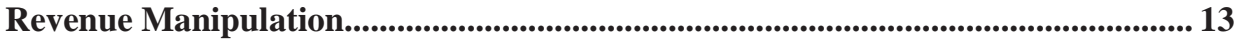

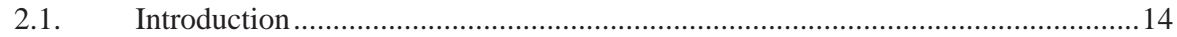

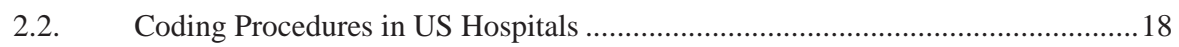

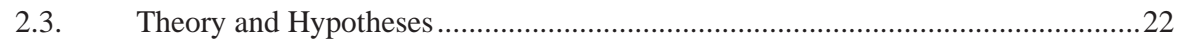

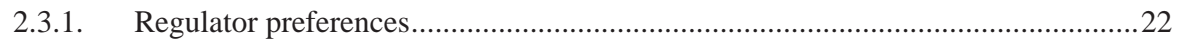

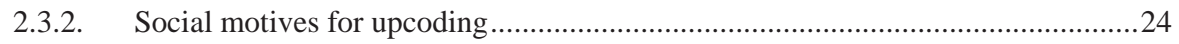

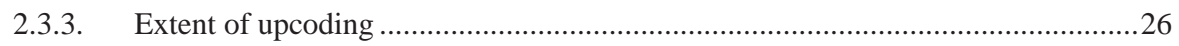

2.3.4. Pecuniary motives for revenue manipulation ........................................................26

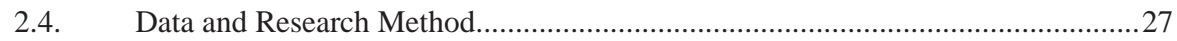

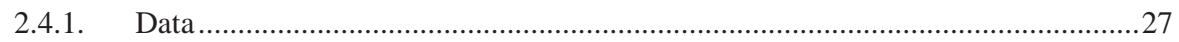

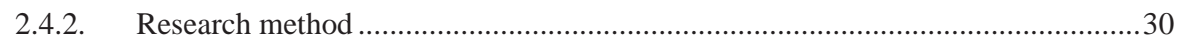

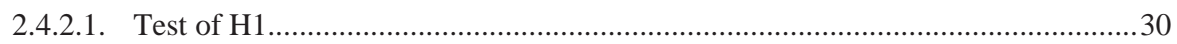

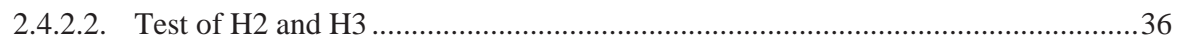

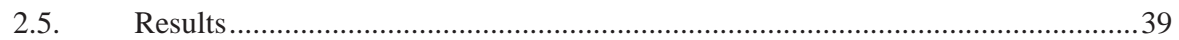

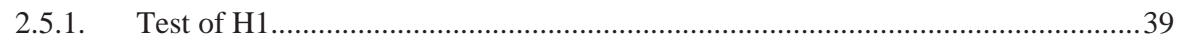

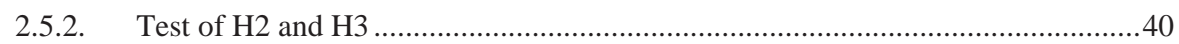

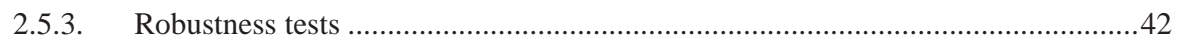

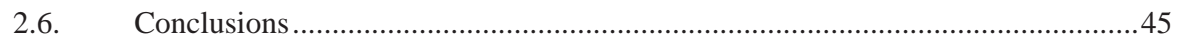

The Role of Revenue Manipulation in the Trade-Off Decision between

Performance Management Strategies ...................................................................... 49

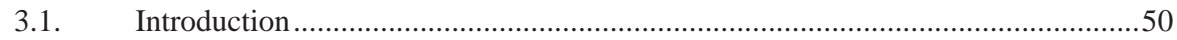

3.2. Revenue Manipulation and Prior Earnings Management Literature.........................53

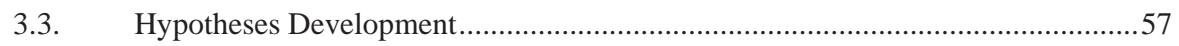

3.3.1. Constraints for performance management strategies ..............................................5

3.3.1.1. Constraints associated with real activities manipulation .......................................58

3.3.1.2. Constraints associated with accrual-based earnings management ...........................59

3.3.1.3. Constraints associated with revenue manipulation ................................................60

3.3.1.4. The direct trade-off decision between different performance management

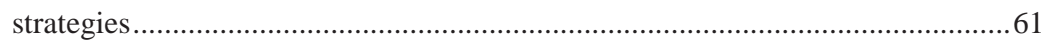

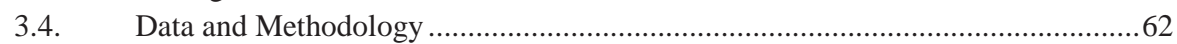

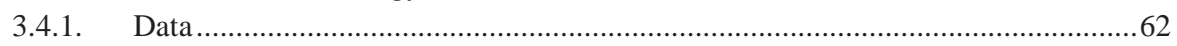

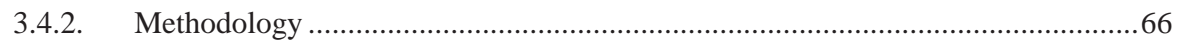


3.4.2.1. Measurement of revenue manipulation ..................................................................66

3.4.2.2. Measurement of real activities manipulation..........................................................66

3.4.2.3. Measurement of accrual-based earnings management ..........................................67

3.4.2.4. The trade-off between revenue manipulation, real activities manipulation and accrual-based earnings management ...................................................................68

3.4.2.5. Costs associated with real activities manipulation ..................................................6

3.4.2.6. Costs associated with accrual-based earnings management ...................................69

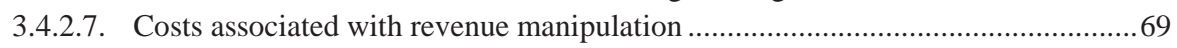

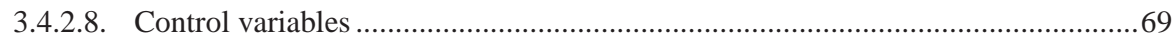

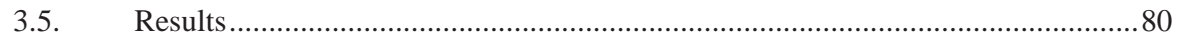

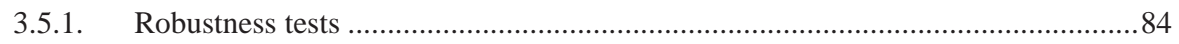

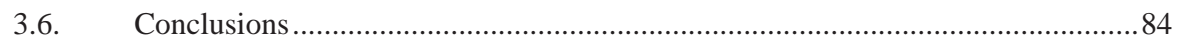

\section{Government Preferences, SEC’s Enforcement Actions and Firms’ Accounting}

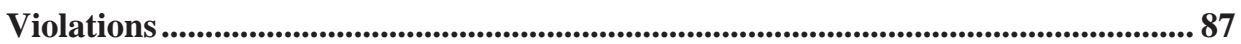

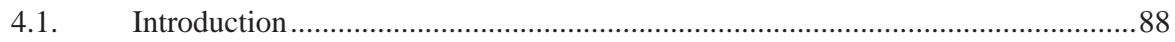

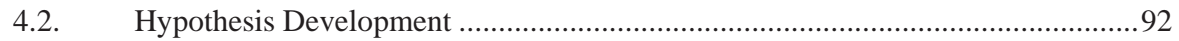

4.2.1. Government preferences for labor-intense firms ................................................... 92

4.2.2. SEC behavior under government preferences ....................................................... 93

4.2.3. Government's pressure on SEC during election years ...........................................95

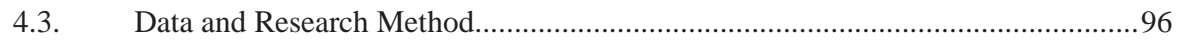

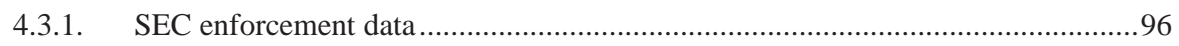

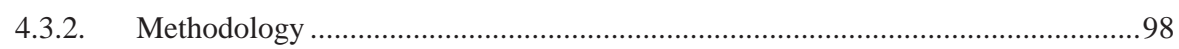

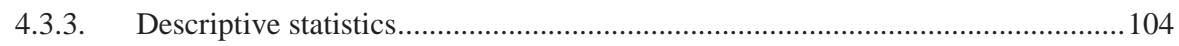

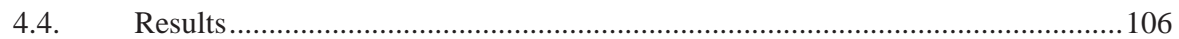

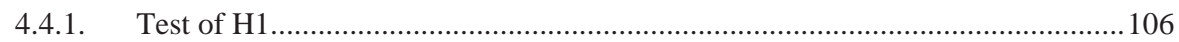

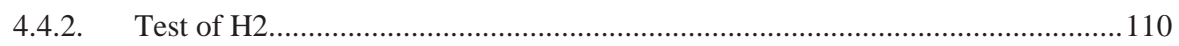

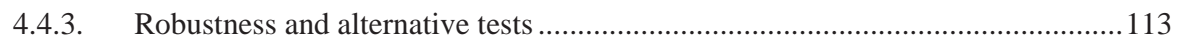

4.4.3.1. Accounting quality as alternative explanation for reduced SEC's enforcement actions against labor-intense firms...............................................113

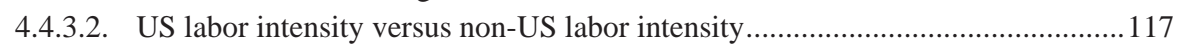

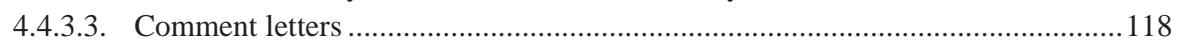

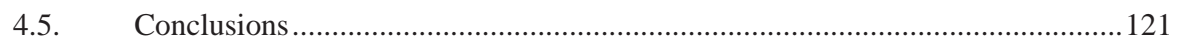

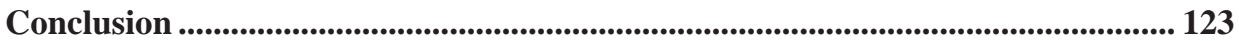

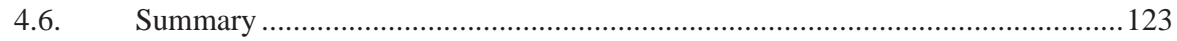

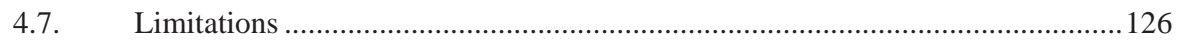

4.8. Contributions, Implications and Future Research..............................................127

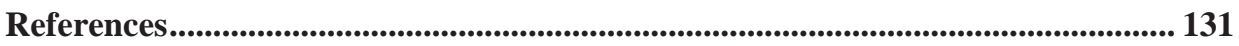

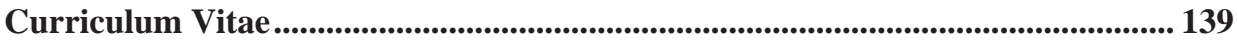





\section{Chapter 1}

\section{Introduction}

Over the last decade, high profile fraud scandals across several industries in the US have deteriorated the trust in the effectiveness of regulatory agencies. For instance, in the case of Enron, which was one of the largest bankruptcy cases in US business history, the Securities and Exchange Commission (SEC) together with the US Department of Justice have been blamed for not effectively scrutinizing Enron's misconduct of its accounting activities and failing to warn the public about the ongoing accounting manipulations (Culpan and Trussel 2005).

Regulatory agencies in the healthcare industry have also been confronted with huge criticism on their regulatory effectiveness. For instance, the Office of the Inspector General (OIG) of the US Department of Health and Human Services (HHS) has criticized that the efforts of the Centers for Medicare and Medicaid Services (CMS) to prevent improper payments stemming from so called upcoding, a form of overbilling, are not satisfactory (OIG 2005). This criticism has been severe since the General Accounting Office of the United States (GAO) has designated the Medicare program as a high-risk program because of its vulnerability to improper payments already at the beginning of the 1990s (GAO 2000). In particular, several studies by CMS, GAO and OIG conclude that improper payments ranged from $\$ 23.2$ billion in 1996 to $\$ 10.4$ billion in 2008, or $14 \%$ to $3.6 \%$ of Medicare's payments, respectively (GAO 2000; CMS 2008; OIG 2001a).

Fraud cases are often very costly for a large group of stakeholders. For instance, Enron's investors have suffered immensely because of the drop of the company's stock value from \$90 in September 2000 to nearly worthless in December 2001. In addition, most employees of Enron have lost their jobs as well as their lifetime retirement savings as a result of the company's collapse (Culpan and Trussel 2005). In the healthcare industry, HCA - The Healthcare Company, a US hospital chain, was convicted for unlawful billing practices and was sentenced to pay a fine of more than $\$ 840$ million in 2000 (Crennen 2013). In June 2006, Tenet, another US hospital chain, agreed to pay a total of $\$ 900$ million in fees to resolve claims it defrauded the federal government for overbilling Medicare during the 1990s (MNT 2006). As both of these hospital chains are listed for-profit organizations, investors have been affected by the loss in stock value. In addition, to finance the settlement, Tenet sold 11 hospitals in four states, threatening the access to medical care for people living in the affected areas.

Given that the costs of such fraud for both the firm and stakeholders are very high, the question arises why regulatory agencies often fail to unravel firms' fraudulent activities. Such failure seems to be contrary to the general assumption in the accounting 
and finance literature that regulatory agencies such as the SEC or CMS are neutral in their enforcement actions and therefore allocate their scarce resources to investigate those firms that are most likely to violate regulations and enforce firms' compliance with the regulations. Economists, however, have argued that regulators are not indifferent in their monitoring of firms' compliance with regulatory policies. In particular, regulators could be "captured” by the regulated, and operate for the interest of the firms that they are supposed to regulate (Stigler 1971). In addition, sociologists recognize that regulations are socially constructed and provide wide latitude to organizations as well as regulators regarding what constitutes satisfactory compliance (Edelman 1992; Edelman and Suchman 1997), providing regulators with a huge discretion in enforcement.

Therefore, theories in economics, political economy as well as sociology have long argued that enforcement by regulatory agencies can be biased. However, the literature on the drivers that affect regulatory behavior is not well developed (Kothari et al. 2010).

This dissertation builds on these theories that recognize that regulators exercise judgment in the enforcement of regulations and provides more detailed insights into the determinants of regulatory behavior. More precisely, it examines differences in regulatory behavior stemming from regulator's own preferences as well as government's interests across different types of firms. In addition, this dissertation investigates firms' reactions to such regulatory behavior. In particular, it examines whether managers adjust their manipulation choices depending on the regulatory scrutiny they face.

The first and second study of this dissertation, presented in chapter 2 and 3, investigate regulator preferences and hospital managers' motives as well as manipulation choices in the healthcare industry; an industry that is especially prone to fraud. The first study develops a case that what would appear to look like regulatory capture in some cases, could actually be a reflection of regulators' preferences for nonprofit hospitals' performance on social goals. In light of these regulator preferences, it also investigates whether nonprofit hospitals use upcoding, a form of overbilling, as a tool to subsidize their social goals. As the first study shows that upcoding is a powerful tool to manipulate an organization's performance, the second study investigates whether and how managers of for-profit hospitals adjust their use of different manipulation strategies as a consequence of market and firm characteristics as well as differences in regulatory scrutiny towards these manipulation strategies. The third study, presented in chapter 4 , extends the analysis of regulatory behavior from the healthcare sector to a large sample of listed firms and focuses on the role of government in affecting the behavior of regulatory agencies. In particular, the third study investigates whether SEC's enforcement actions are influenced by government's preferences for firms that contribute to the government's policy of fostering employment conditions and whether managers adjust their accounting choices as a result of these preferences. 
The following sections provide a more detailed overview of the relevant theories and each of the studies.

\subsection{Theories and Empirical Evidence of Regulatory Behavior}

While research in accounting and finance generally assumes that regulatory agencies are neutral in their enforcement actions, literature in economics and political science has developed various theories to investigate determinants of regulatory behavior more critically. The two main underlying theories of that literature are the "public interest" and the "regulatory capture" or the "interest group" theory (Laffont and Tirole 1991). According to the "public interest" theory, the government's role is to correct market imperfections such as monopoly pricing with the ultimate goal to maximize social welfare (Laffont and Tirole 1991). Consistent with this theory, economists posit that regulators have objective functions that seek to maximize the weighted average of consumer and producer surplus (Armstrong and Sappington 2007; Naughton 1989). Regulators can, however, incorporate their preferences into the objective function, which can include the regulators' interpretations of social welfare. As a consequence, the preference weights assigned to heterogeneous consumer groups and firms can vary based on the goals of the regulator (Naughton 1989).

In contrast, the "regulatory capture" or "interest group" theory emphasizes the active role of interest groups in the formation of public policy. According to the seminal studies of Stigler (1971) and Peltzman (1976), regulators act as self-interested utility maximizers that react to pressures from interest groups. These interest groups are perceived as being able to form coalitions more effectively than the general electorate when regulations will impose disproportionate costs or benefits on them. To avoid these costs or to gain these benefits these coalitions "capture” the regulatory agency or distort the formation of regulations in order to maximize their interests rather than social welfare.

The "regulatory capture" theory has been extended by Weingast and Moran (1983) who distinguish between the regulatory agency and the legislature. ${ }^{1}$ In particular, they note that Congress, representing the legislature, both exercises oversight over regulatory agencies as well as allocates resources to these agencies, providing congressmen with sufficient rewards and sanctions to create an incentive system for agencies. As a consequence of such an incentive system, agencies pursue congressional goals even though they receive little direct guidance from their overseers (Weingast and Moran

\footnotetext{
${ }^{1}$ Weingast and Moran (1983) assume that Stigler (1971) and Peltzman (1976) do not distinguish between the agency and the legislature presumably because of their close connection.
} 
1983). ${ }^{2}$ Thus, the congressional dominance theory provides insights into the relation between the legislature and regulatory agencies and provides a theory to explain how government preferences can affect regulatory agencies. To empirically test that theory, Weingast and Moran (1983) and Weingast (1984) investigate the behavior of two regulatory agencies, i.e., the Federal Trade Commission (FTC) and the SEC, respectively. They find evidence that both agencies implemented policy changes in alignment with congressional or political preferences. A number of recent studies provide further evidence in line with the "regulatory capture" theory. For instance, Correia (2009) and Yu and Yu (2011) show that firms with political connections or that engage in lobbying are less likely to be convicted by the SEC, suggesting that firms capture the regulatory agency via lobbying or political connections to derive benefits or avoid costs.

In addition to following its own interests or interests imposed by the legislature, the behavior of regulatory agencies can be impacted by the limited resources they are confronted with. For instance, the former SEC Commissioner Linda Thomsen has argued that the severe resource constraints faced by the SEC limits the SEC's possibility to investigate all firms that have potentially misstated their financial statements (Thomsen 2009). In line with these resource constraints, Kedia and Rajgopal (2011) find evidence consistent with the so called 'constrained cop' hypothesis. They show that the resource-constrained SEC is more likely to investigate firms located closer to its offices and interpret their findings as an indication that the SEC minimizes costs associated with its investigations. Thus, such resource constraints, which limit the regulator in its enforcement actions, make it even more likely that regulators adjust their decisions as to which firms to investigate and act based on their preferences.

\subsection{Managers' Behavior under Regulatory Scrutiny}

As a reaction to regulatory behavior, theory in the accounting literature suggests that managers are likely to adjust their manipulation decisions to the behavior of the regulator (Fischer and Verrecchia 2000). According to Fischer and Verrecchia (2000), managers' motivation to manipulate the firm's performance is that they can derive benefits from such manipulation after considering the costs associated with such manipulation. Such benefits can be, for instance, related to managers' bonuses, firm's stakeholders, firm's stock price or managers' career concerns (Healy and Wahlen 1999; Dechow and Skinner 2000; Fields et al. 2001). For instance, Bowen et al. (1995) and Burgstahler and Dichev (1997) state that by managing earnings, firms are able to

\footnotetext{
${ }^{2}$ An alternative, more bureaucratic view is that regulatory agencies work independently of the legislature. For instance, Wilson (1980) concludes that the policies of regulatory commissions are not under close scrutiny or careful control of either the White House or Congress.
} 
enhance their reputation with stakeholders, such as customers, suppliers, and creditors, and hence get better terms of trade. Graham et al. (2005) provide evidence that the manager's desire to hit the earnings target appears to be also driven by career concerns as the manager's inability to hit the earnings target is seen by the executive labor market as a potential managerial failure.

On the other hand, stricter enforcement by regulatory agencies or stiffer penalties for violations of those regulations increase the managers' costs associated with the manipulation choices, decreasing the extent of performance manipulation (Fischer and Verrecchia 2000). In line with this argument, Kedia and Rajgopal (2011) find that managers of firms located closer to SEC offices are less likely to misreport their financial statements as the SEC, due to its resource constraints, is more likely to investigate firms located closer to its offices. Thus, regulatory behavior is likely to affect managers' decisions about manipulating their firms' financial performance. ${ }^{3}$ To the extent that different manipulation choices are subject to scrutiny from different regulators, regulatory behavior is also likely to influence managers' trade-off decisions across different tools for manipulating a firm's performance.

\subsection{The Interplay between Regulator Preferences and Organizational Motives for Revenue Manipulation}

The first study of this dissertation, which can be found in chapter 2, investigates whether regulators are less likely to enforce regulations for nonprofit firms that have a higher performance on social goals and whether these organizations, in light of this lower regulatory enforcement, use revenue manipulation via upcoding as a tool to subsidize their social goals.

A broad literature has established that nonprofit firms' objective functions do not only include meeting a zero-profit goal, but also improving the welfare of a broad group of constituents (Hoerger 1991; Newhouse 1970; Pauly 1987). For instance, nonprofit hospitals seek to fulfill social goals such as medical education and providing care to the uninsured (Clement et al. 1994). Although nonprofits obtain some support for pursuing these social goals in the form of tax exemption, donations, or subsidies, by and large these social goals are unprofitable (Chen et al. 2009). Hospitals, however, can generate additional revenues via upcoding, a form of overbilling where an ailment is classified as more severe than it actually is. These additional resources can be used to supplement the cost of pursuing social goals, providing strong incentives for nonprofit hospitals to engage in that behavior.

\footnotetext{
${ }^{3}$ Instead of merely reacting to regulatory behavior, the political cost hypothesis developed by Watts and Zimmerman (1978) argues that managers can also actively interfere with the regulatory process by lobbying on accounting standards or enforcement of these standards based on their self-interest.
} 
While upcoding is potentially a powerful tool for generating additional resources, it can, however, be fraudulent and is thus subject to regulatory scrutiny. Regulators can detect upcoding in the normal course of audit, or when such behaviors are brought to the regulators' attention through actions of whistleblowers. On detection, the regulator can take actions to pursue sanctions against the hospital, which can result in significant reputational damage as well as financial costs in the form of penalties and losses. Economists argue that regulators could be "captured" by the regulated, and operate for the interest of the firms that they are supposed to regulate (Stigler 1971). Regulatory capture, however, may also serve the benefit of a larger group of stakeholders and might reflect regulators' preferences about how to maximize social welfare. Such preferences are then revealed in the process of regulatory enforcement. This differentiated enforcement of regulation is a mechanism for regulators to communicate their assessment of an organization's legitimacy, which provides leeway to the organization to reduce compliance without the fear of penalties.

Based on this argumentation, it is posited in this study that health care regulators recognize that nonprofit hospitals serve some customer groups that are unable to pay a price that covers the full-cost and provide costly medical education. These social preferences of regulators will manifest in the form of a reduction in enforcement of firms that manipulate their revenues if such firms have demonstrated higher performance on social goals. In essence, in a fixed-fee regulated market, regulators' reduced enforcement of firms with higher social performance allows these firms to obtain higher average prices to continue to meet their social goals.

The above question is empirically tested using the nonprofit hospital industry as a context. To investigate whether regulators are less stringent in enforcement of upcoding for nonprofit hospitals that have an established record of higher performance on two important social goals, i.e., charity care and medical education, a sample of 741 hospital-year observations from California nonprofit hospitals for the period 1996 to 1999 is used. Next, the hypothesized positive association between social motives and upcoding is tested, using a sample of 1,447 hospital-year observations from California nonprofit hospitals for the period 1999 to 2007. Given that the enforcement process reveals regulatory preferences, these different time periods are used as hospitals can only take regulatory preferences into account after they had the opportunity to observe the enforcement preferences. Upcoding is investigated using three different diagnosis related groups (DRGs) that have been identified by the US Department of Health and Human Services (1998) as being prone to upcoding (Silverman and Skinner 2004). ${ }^{4}$

The results confirm the predictions developed in this study. Hospitals with higher performance on social goals are less likely to be convicted for upcoding and use

\footnotetext{
${ }^{4}$ DRGs identify patients with similar conditions and processes of care and requiring similar resources for treatment.
} 
upcoding to subsidize the cost of social objectives such as charity care and medical education. These results hold after controlling for two important agency motives to manipulate revenues, i.e., to meet an income benchmark, and to obtain incentive compensation.

The study contributes to the accounting literature in the following ways. First, it helps to enhance the understanding of the complex social considerations surrounding regulation by showing that regulators reduce their enforcement for firms that perform activities that increase societal welfare. Although sociology theory has long articulated the endogeneity between regulators and organizations (Edelman and Suchman 1997), accounting research has not examined whether social preferences of the regulator drive enforcement efforts. Second, it provides evidence that in nonprofit settings, revenue manipulation via upcoding could be driven by a desire to cross-subsidize social goals. Finally, upcoding has been identified as a powerful method for revenue manipulation as it increases revenues but not costs, does not have to reverse in the future, and is difficult to detect. The study has also several policy implications as it suggests that regulators are likely to take the motives for financial manipulation into consideration while making decisions about which firms to pursue. In addition, the results identify upcoding as one potential reason for the high costs of health care in the US relative to other countries as hospitals that are not able to obtain resources to meet their social goals overbill the insured patients.

\subsection{The Role of Revenue Manipulation in the Trade-Off Decision between Performance Management Strategies}

The second study of this dissertation, which can be found in chapter 3, investigates the role of upcoding as a type of revenue manipulation (RM) in managers' choices of performance management activities. Building on the finding of the first study that revenue manipulation via upcoding is a powerful manipulation tool, this study investigates whether the possibility to use this tool decreases managers' application of other manipulation tools. In contrast to more traditional manipulation techniques, upcoding has significant advantages as it allows firms to increase revenues without (1) altering operations, (2) affecting costs directly or (3) facing the need to reverse in the future. Therefore, the second study investigates how managers make trade-off decisions between revenue manipulation and two traditional manipulation strategies, i.e., accrualbased earnings management (AEM) and real activities manipulation (RAM).

Studies in the accounting literature have extensively investigated firms' motives for managing their reported financial performance via accrual-based earnings management and real activities manipulation (Graham et al. 2005; Healy and Wahlen 1999) and have started to examine how firms make choices between these two strategies depending on the costs associated with each strategy (Zang 2012; Badertscher 2011). The application of both of these manipulation tools, however, is associated with significant costs. RAM requires changing the firm's underlying operating activities such 
as the timing or structuring of an operation to alter a firm's performance. AEM is conducted after fiscal year-end, does not generate direct cash flows and has to reverse. In addition, the application of RAM and AEM is constrained by many operational and financial circumstances such as the level of competition, a firm's financial health (Zang 2012), regulatory changes such as the Sarbanes-Oxley Act (SOX) (Cohen et al. 2008), and firms' accounting choices in prior periods (Baber et al. 2011; Barton and Simko 2002). As a consequence of such high costs, firms are likely to seek for alternative manipulation tools. Indeed, fraud scandals have indicated that firms' performance manipulation tools are not limited to these two manipulation techniques. Many firms operating in various industries engage in overbilling practices as a form of revenue manipulation (RM) to boost their performance. For instance, companies such as Lend Lease, a US construction company (Rashbaum 2012), and Holland \& Knight LLP, a US law firm (Koppel 2006), have all been found to have overbilled their clients by charging for fictitious working hours.

However, upcoding carries a considerable risk as its detection can lead to high reputational and financial costs including possible lawsuits. Thus, it is likely that managers will trade off between these three different strategies depending on the specific constraints they are facing. In order to assess how managers make choices between the three performance management strategies, the study examines the simultaneous use of these three tools for performance management and argues that managers apply revenue manipulation as an alternative manipulation tool when the costs for RAM and AEM are relatively high.

To test managers' trade-off decisions between these three strategies, 809 hospitalyear observations from California for-profit hospitals for the period 1997 to 2007 are used. Upcoding is investigated by using one DRG family that has been identified by the US Department of Health and Human Services (1998) as being prone to upcoding (Silverman and Skinner 2004), AEM by using discretionary accruals (Jones 1991) and RAM through cutting discretionary expenses in non-revenue generating and nonoperating activities (Eldenburg et al. 2011).

The results confirm that managers trade off between these three activities. In particular, throughout the year RM and RAM are direct substitutes and at the end of the fiscal year, hospital managers engage in less AEM the more RM has been applied throughout the year. Thus, the results indicate that the use of RM as an alternative manipulation tool directly decreases the hospital's need to apply RAM and AEM. In addition, the results suggest that the trade-off decisions are driven by the operational constraints the hospital is facing. When hospitals face constraints for RAM, hospitals prefer RM over AEM. When AEM is constrained by prior accounting choices and regulatory changes such as the passage of SOX, hospital managers resort to using more RM instead of RAM. On the other hand, hospitals that are constrained in applying RM apply RAM and AEM instead of RM. Overall, the results suggest that organizations that have the opportunity to engage in revenue manipulation are likely to make different 
trade-off decisions in their performance manipulation choices than organizations that have only RAM and AEM at their disposal.

The second study of the dissertation contributes to the accounting literature by providing a more complete picture of the types of performance management tools that firms use to manipulate their performance. This is important to get to more definitive conclusions about the application and effect of the various performance management strategies (Fields et al. 2001). It also provides additional insights into the costs that affect managers' decisions to choose one of the three performance manipulation tools over the other. As a consequence, these findings help to further understand which manipulation strategy firms choose depending on their operational environment.

The findings of this study inform regulators, auditors and investors by emphasizing the significant role of alternative, powerful instruments to manipulate financial performance, which can hardly be detected from financial reporting numbers. With respect to the health care industry, for auditors of hospitals' financial statements it might be important to incorporate the potential performance manipulation resulting from upcoding into their auditing processes in order to conduct a more thorough analysis of the hospitals' reported figures. This study also provides a set of conditions that auditors of medical claims should incorporate in their assessment of which hospitals to investigate and a potential method to identify hospitals with abnormal billing behavior.

\subsection{Government Preferences, SEC's Enforcement Actions and Firms' Accounting Violations}

The third study of this dissertation, which can be found in chapter 4, extends the analysis of regulatory behavior from the healthcare sector to a large sample of listed firms and focuses on the role of government in affecting the behavior of regulatory agencies. In particular, it investigates whether government's preferences for firms that contribute to the government's policy of fostering employment are likely to reflect in the SEC's decisions as to which firms to investigate.

Research in accounting and finance traditionally assumes that the SEC is a neutral regulatory agency that allocates scarce resources to investigate those firms that are most likely to violate Generally Accepted Accounting Principles (GAAP). Yet, economists such as Stigler (1971) and Peltzman (1976) have long argued that regulations and regulators are influenced by the government. Government's preferences are likely to reflect in the SEC's decisions as to which firms to investigate since the government decides on the resource allocations to the SEC (Bealing 1994; Weingast 1984), can actively intervene with an SEC investigation (Levitt and Dwyer 2003), appoints SEC Commissioners and can thus impact which political views are represented in the SEC (Noll 1971; Weingast 1984), and can also sanction the SEC and its employees by, for instance, affecting the careers of SEC Commissioners and other key employees. In addition, Kedia and Rajgopal (2011) find evidence consistent with the so called 
'constrained cop' hypothesis, indicating that the SEC's enforcement actions are influenced by its constrained resources.

As the government's goal is to maximize political support, which comes in the form of votes, it responds to both constituent and special interest pressure by adjusting its political decisions and measures accordingly (Stigler 1971). Given that employment conditions are proven to systematically affect future electoral outcomes (Hibbs 2006), the government has long favored a policy to promote these conditions by supporting not only large employers in absolute terms, but also smaller, labor-intense firms that contribute to future employment (Adams and Brock 1987b; Audretsch 2003; Caves 1976). As SEC enforcement actions can take down firms that are important for the government's policy of promoting employment, the SEC and its Commissioners are likely to face political pressure from the government to spare labor-intense firms from enforcement actions.

As a result, the SEC is likely to act in accordance with government's policy to foster employment and thus exercises judgment as to which firms to investigate. This judgment can potentially occur at several steps of the SEC investigation process. For instance, the SEC can allocate less resources to general reviews or informal and confidential investigations of labor-intense firms. In addition, before starting a formal investigation, the SEC Commissioners decide how the investigation proceeds and can thus reduce or even prevent enforcement actions against these firms.

To test whether the SEC reduces its enforcement actions for labor-intense firms, a sample of firms for the time period 1982 to 2012 that have been sanctioned by the SEC for violating GAAP as reported in Accounting and Auditing Enforcement Releases (AAERs) and all other public firms that did not receive an AAER over this period is used. The results provide evidence that labor-intense firms are less likely to be subject to an AAER. To test the robustness of these results, the study further examines whether a government's higher sensitivity to constituents' interests in election years further decreases the likelihood of enforcement actions against labor-intense firms. The results confirm this hypothesis providing further evidence that government's preferences for firms that support government's policies reflect directly in SEC's enforcement actions. All of these results hold after controlling for firms' accounting quality and two alternative explanations for firms' favorable treatment by the SEC, i.e., firms' location and lobbying activities. In addition, the study examines whether labor-intense firms have a higher accounting quality, which would explain fewer SEC investigations and convictions. Measuring accounting quality with all three specifications of the F-score as developed by Dechow et al. (2011), discretionary accruals using the modified Jones model as in Dechow et al. (2011) and the Dechow and Dichev (2002) model, and the incidence of restatements, the study finds consistent evidence across all models that labor-intense firms have a lower accounting quality than their less labor-intense peers. This finding suggests that fewer SEC enforcement actions against labor-intense firms cannot be explained by these firms having a higher accounting quality. Instead, the 
results indicate that labor-intense firms exploit this preferential treatment by the SEC by engaging in more aggressive accounting choices.

The study contributes to the accounting literature in the following ways. First, in line with a growing body of research (Correia 2009; Kedia and Rajgopal 2011; Yu and $\mathrm{Yu}$ 2011) the results suggest that the SEC is not neutral in its enforcement actions. Second, the findings suggest that the SEC's enforcement actions are systematically influenced by government's preferences independent of firms' attempts to impact SEC's enforcement actions via lobbying and political connections. Finally, the study provides evidence that firms adjust their accounting choices as a result of the preferential treatment by the SEC and hence informs regulators about potentially adverse effects of preferences in enforcement actions.

\subsection{Outline of the Dissertation}

Each of the following three chapters describes one of the three aforementioned studies of this dissertation in detail. The autonomous structure of each chapter allows the three studies to be read separately or in different order than presented in this book. Chapter 2 presents the study on the interplay between regulator preferences and organizational motives for revenue manipulation, whereas chapter 3 illustrates the role of revenue manipulation in the trade-off decision between performance management strategies. Chapter 4 focuses on the study investigating government preferences, SEC's enforcement actions and firms' accounting violations. Chapter 5 summarizes the main findings of all three studies, discusses their limitations, contributions and implications, and also provides directions for future research. 



\title{
Chapter 2
}

\section{The Interplay between Regulator Preferences and Organizational Motives for Revenue Manipulation ${ }^{5}$}

\begin{abstract}
We use regulatory and institutional theories to posit that regulators are less likely to enforce regulations for nonprofit firms that have higher performance on social goals. In light of this lower regulatory enforcement, nonprofits use revenue manipulation as a tool to subsidize their social goals. We use data from the US hospital industry and examine revenue manipulation via “upcoding”, i.e., classifying an ailment as more severe than it actually is to earn higher revenues without incurring commensurate costs. We first provide evidence that regulators are less stringent in enforcement of upcoding for nonprofit hospitals that have an established record of higher performance on two important social goals, i.e., charity care and medical education. Next, we use archival analysis based on 1,447 hospital-year observations for the period 1999-2007 and find systematic evidence of a positive association between upcoding and the two aforementioned social goals, after controlling for two important agency motives to manipulate revenues, i.e., to meet an income benchmark, and obtain incentive compensation. Our results suggest that revenue manipulation via upcoding allows nonprofits with higher performance on social goals to obtain higher average prices in a price-regulated market.
\end{abstract}

\footnotetext{
5 This chapter is based on a working paper co-authored with Ranjani Krishnan and Frank Moers.
} 


\subsection{Introduction}

It is acknowledged in the literature that nonprofit firms' objective functions include not only meeting a revenue or zero-profit goal, but also improving the welfare of a broad group of constituents (Hoerger 1991; Newhouse 1970; Pauly 1987). Nonprofit hospitals for example, seek to fulfill social goals such as medical education and providing access to care to the uninsured (Clement et al. 1994; Morrisey et al. 1996; Weisbrod 1988). Although nonprofits obtain some support for these social goals in the form of tax exemption, donations, or subsidies, by and large these social goals are unprofitable (Chen et al. 2009). Revenue manipulation via upcoding, i.e., classifying an ailment as more severe than it actually is, can facilitate the generation of incremental resources that could be used to supplement the cost of pursuing social goals. In this study, we explore whether nonprofit hospitals manipulate revenues to fund social goals, and whether such revenue manipulation behavior is implicitly supported by regulators.

Revenue manipulation through upcoding can be detected by regulators in the normal course of audit, or when such behaviors are brought to the regulators' attention through actions of whistleblowers. On detection, the regulator can take actions to pursue sanctions against the hospital, which can result in significant reputational damage as well as financial costs in the form of penalties and losses. However, neither economic theory, nor sociology posits that regulators are indifferent in their monitoring of firms' compliance of regulatory policies. Economists argue that regulators could be "captured" by the regulated, and operate for the interest of the firms that they are supposed to regulate (Stigler 1971). Sociologists recognize that regulations are socially constructed, dynamic, and provide wide latitude to organizations as well as regulators regarding what constitutes satisfactory compliance (Edelman 1992; Edelman and Suchman 1997). Although the object of regulatory capture is most often deemed to be for the express purpose of benefitting the regulated firms, or serving the political ambitions of the regulator, we argue that regulatory capture may also serve the benefit of a larger group of stakeholders. Furthermore, we develop the case that what would appear to look like regulatory capture in some cases, could actually be a reflection of regulators' preferences about how to maximize social welfare and that these preferences are revealed in the process of regulatory enforcement. Differentiated enforcement of regulation is a mechanism for regulators to communicate their assessment of an organization's legitimacy, which provides leeway to the organization to reduce compliance without the fear of penalties.

Specifically, we posit that health care regulators recognize that nonprofit hospitals serve some customer groups that are unable to pay a price that covers the full-cost. In addition, nonprofit teaching hospitals provide costly medical education. Although nonprofits obtain subsidies or donations, these are often inadequate to cover the revenue 
shortfall. Additionally, if the industry is price regulated and the price is set at a fixed fee per service, then there is no room for regulators to directly compensate firms with higher social performance through mechanisms such as two-part pricing. ${ }^{6}$ In such an instance, we posit that social preferences of regulators will manifest in the form of a reduction in enforcement of firms that manipulate their revenues if such firms have demonstrated higher performance on social goals. In essence, in a fixed-fee regulated market, regulators' reduced enforcement of firms with higher social performance acts as an implicit two-part price system that allows these firms to obtain higher average prices to continue to meet their social goals.

We empirically examine the above question using the nonprofit hospital industry as a context. Nonprofit hospitals face pressures from multiple stakeholders to not only operate efficiently but also to fulfill their nonprofit mission through expensive and largely uncompensated or undercompensated social goals. To fulfill these goals, hospitals are likely to explore upcoding. Upcoding provides hospitals with an attractive manipulation tool to increase revenues but not affect costs directly. The opportunity for hospitals to manipulate revenues arises from their available leeway in coding their patients into diagnostic related groups (DRGs). ${ }^{7}$ By "upcoding” a patient into a DRG that yields higher reimbursement from Medicare and other insurance providers, the hospital generates higher revenues without incurring any additional costs.

Upcoding does not involve actually changing the treatment protocol that the patient receives. The factor that makes such behavior feasible is the information asymmetry between the provider (i.e., the hospital) and the payers (i.e., Medicare or other insurance companies) as well as the patients. ${ }^{8}$ Most medical treatments involve considerable judgment on the part of the hospital and its staff regarding the optimal treatment protocol. Therefore, upcoding is difficult to detect and the hospital likely could make a case for its choice of DRG assignment to the patient. Because of this information asymmetry, upcoding provides an attractive tool for revenue manipulation in hospitals.

We identify two social motives that are likely to drive revenue manipulation in hospitals - charity care and medical education. Hospitals that provide higher charity care (charity hospitals) have a unique niche in their communities, which generally regard these hospitals as critical to protecting the welfare of residents by providing

\footnotetext{
${ }^{6}$ In two-part pricing, the firm sets a different price for different product groups or customers. These prices are in inverse proportion to the price elasticity of demand.

${ }^{7}$ DRGs identify patients with similar conditions and processes of care and requiring similar resources for treatment. Each DRG has a weight based on its relative costliness to the average for all DRGs. These weights are used for reimbursement by various programs including Medicare and other public and private insurance programs (Folland et al. 1997).

${ }^{8}$ The predominance of the nonprofit form in the hospital industry is attributed to the information asymmetry between the provider and the patient (Arrow 1963; Hansmann 1980).
} 
access to health care, especially for indigents who do not have the capacity to pay (Weisbrod 1988). However, indigent patients can be expensive for hospitals. An example is trauma care, which has a higher proportion of uninsured patients but is one of the most expensive departments in a hospital (Chen et al. 2009). Charity hospitals must continue to meet the communities' expectations of uncompensated care, while at the same time find resources to cover the cost of providing such care (Hirth 1997). In much the same manner, teaching hospitals have high costs and the revenues earned may not be sufficient to cover these costs. For comprehensive education of residents, teaching hospitals need to maintain a larger range of services, including unprofitable services. Revenue manipulation via upcoding can enable charity and teaching hospitals to continue to serve their missions of charity care and medical education.

Our theory about the interplay between regulatory preferences and revenue manipulation predicts different upcoding patterns at different points in time. Given that the enforcement process reveals regulatory preferences, hospitals can only take these preferences into account after they had the opportunity to observe the enforcement process. Thus, if the enforcement process reveals that hospitals with higher social performance have more leeway, then we would observe a positive association between social motives and upcoding after hospitals have had the opportunity to observe the enforcement process, but no such association before. To test this, we first examine whether hospitals with higher social performance indeed have reduced enforcement. We use 741 hospital-year observations from California nonprofit hospitals for the period 1996 to 1999 to empirically examine if hospitals with higher performance on social goals are less likely to be convicted for upcoding and find evidence in support of such an association. That is, when upcoding is likely to confer some benefits to the community at large, regulators are more lax about enforcement. We speculate that regulators may consider upcoding as a two-part pricing system. Because insured patients have lower price elasticity of demand than do uninsured patients, the two-part pricing mechanism that is produced as a result of the upcoding could be considered by regulators as welfare enhancing. Reduced regulatory sanctions allow hospitals with higher performance on social goals to use upcoding as a mechanism to obtain higher prices for the same treatment basket.

Next, we examine the hypothesized positive association between social motives and upcoding. In particular, we argue that because the likelihood of detection and/or the imposed consequences upon detection are affected by the motives for upcoding, hospitals will adjust their upcoding strategies depending on the type of objectives that they pursue. We predict that when revenue manipulation is driven primarily by social objectives, upcoding will be prevalent amongst a greater number of DRGs. This is because hospitals which have higher performance on social goals recognize that they have a legitimacy advantage with regulators and utilize this advantage. We control for two conventional economic motives for revenue manipulation that have been identified in prior accounting literature. These include meeting a zero profit earnings target (Leone 
and Van Horn 2005), and increasing incentive compensation tied to financial performance (Eldenburg et al. 2011).

We use 1,447 hospital-year observations from California nonprofit hospitals for the period 1999 to 2007 to test our hypothesis regarding the association between social goals and revenue manipulation. We investigate upcoding in three different DRG families that have been identified by the US Department of Health and Human Services (1998) as being prone to upcoding (Becker et al. 2005; Silverman and Skinner 2004). ${ }^{9}$

Our results indicate that hospitals use revenue manipulation to subsidize the cost of social objectives such as charity care and medical education. A higher proportion of indigent patients is associated with greater upcoding as is a larger magnitude of residents per hospital bed. Furthermore, we also find weak evidence of revenue manipulation to meet pecuniary motives; specifically there is a positive association between revenue manipulation and meeting a zero earnings benchmark. Our results also suggest that when revenue manipulation is accompanied by higher performance on social goals, upcoding is found in more than one DRG family. As opposed to this, when revenue manipulation is accompanied by higher performance on pecuniary goals, upcoding is restricted to the DRG family where there is highest financial benefit from upcoding. Finally, we rerun our analysis for the time period 1996-1998, in which hospitals did not have the opportunity to observe regulatory preferences. Consistent with expectation, we find that the significant relationship between upcoding and social performance either disappears or gets weaker. These results indicate that upcoding to meet social goals is a strategy that was employed by hospitals after their observance of regulators' conviction behavior and the regulatory preferences conveyed therein.

We contribute to the accounting literature in the following ways. Accounting researchers have expressed the need for studies that enhance our understanding of the complex social dynamics surrounding regulation (Bozanic et al. 2012; Canning and O’Dwyer 2013). Prior evidence suggests that regulators are subject to institutional pressures (Bealing et al. 1996). Further, the processes by which regulations are produced, the institutions where they are practiced, and the manner in which they are implemented can influence organizational responses (Cooper and Robson 2006). In this study, we focus on another dimension of regulation that influences the outcomes, i.e., regulator preferences. First, we show that regulators reduce their enforcement for firms that perform activities that increase societal welfare. Accounting research has not hitherto examined whether social preferences of the regulator drive enforcement efforts. Although sociology theory has long articulated the endogeneity between regulators and organizations (Edelman and Suchman 1997), the dominant assumption in archival

\footnotetext{
9 A DRG "family" is a group of DRGs that are associated with the same underlying body system. For example, Angina and Cardiac Arrhythmia belong to the same family, i.e., circulatory system disorders. Throughout the paper we use the terms DRG family and DRG group interchangeably.
} 
accounting research is that firms in the same industry are exposed to similar levels of enforcement, i.e., regulation is exogenous and uniformly imposed. Our study shows that this assumption is likely to be invalid in some industries. Second, prior literature generally treats all forms of revenue or profit manipulation to be driven by managerial self-interest to improve contractual outcomes such as incentive compensation (Healy and Wahlen 1999). We provide evidence that in nonprofit settings, revenue manipulation could be driven by a desire to cross-subsidize social goals. Finally, we identify upcoding as a novel method for revenue manipulation that increases revenues but not costs, does not have to reverse in the future, and is not easily detected. While the current study focuses on the healthcare industry, this type of manipulation tool is likely available in other industries as well. ${ }^{10}$

Our findings also have policy implications. First, our results suggest that regulators are likely to take the motives for financial manipulation into consideration while making decisions about which firms to pursue. Second, our results indicate that although upcoding is an important problem in the health care sector, leading to improper payments, it does not necessarily increase hospital rents because a portion (or all) of these rents are used to meet the hospital's uncompensated social goals. Finally, our results identify one potential reason for the high cost of health care in the US relative to other countries. To the extent hospitals are not able to obtain resources to meet their social goals, the cost of health care for insured patients will increase. ${ }^{11}$

Section 2 gives an overview of the coding procedures in the US health care system and introduces the concept of upcoding. Section 3 discusses how upcoding can be used as a revenue manipulation tool and develops the hypotheses. Section 4 presents the data and research method while Section 5 provides the empirical results and additional robustness checks. Section 6 concludes.

\subsection{Coding Procedures in US Hospitals}

The Federal Medicare Program is the largest payer for hospital services in the US, accounting for about one third of hospital revenues (Winter and Pettengill 2003). ${ }^{12}$ Under the Prospective Payment System (PPS), which became effective in 1984 as a means of controlling hospital costs (Preston 1992), Medicare pays hospitals a fixed price per patient depending on the patient's diagnosis related group (DRG). At the time of this study, the DRG system consists of approximately 550 different DRG codes, each

\footnotetext{
${ }^{10}$ For instance, professional service firms such as lawyers and consultancies could engage in overbilling practices that have similar features as upcoding.

11 As per the US Census Bureau, there were 49.9 million uninsured individuals in the US in 2010, which represents $16.3 \%$ of the population (HHS 2011).

${ }^{12}$ Medicare is an insurance program for individuals over 65 years and is administered by the US government and financed by payroll taxes.
} 
of which indicates a similar medical condition requiring a particular type of treatment protocol and corresponding expenditure of resources. Although PPS was first introduced for Medicare patients, soon DRG-based reimbursements were used by Medicaid as well as most major insurers (Reinhardt 2006).

The DRG to which a patient is assigned has important implications for the revenue received by a hospital for that patient. The manner in which the DRG assignment is made is as follows. When a patient is admitted to the hospital, the attending physician makes a report of the patient's condition and the recommended procedures and treatment. This report is then forwarded to the hospital's medical coders who assign the patient to a specific DRG at the time of the discharge of the patient from the hospital. ${ }^{13}$ Although this assignment is based on the diagnoses and procedures that are documented by the attending physician in the patient's medical record, there is latitude in assigning a patient to one DRG versus the other. For example, suppose a patient is admitted with respiratory infections and does not exhibit any complicating factors. This patient should be assigned to DRG 80, and the hospital will receive $\$ 4,377.50$ reimbursement from Medicare for this DRG. To "upcode" the patient to DRG 79, i.e., respiratory infections and inflammations with complications, the hospital has to add a complicating or comorbidity (cc) factor such as asthma to the patient's medical record. By such upcoding, the hospital will obtain a reimbursement of $\$ 8,188.50$, which is a revenue gain of $\$ 3,811$ without any corresponding additional cost. A bill listing the primary diagnoses, the occurrences of complications and comorbidities, the patient's age and discharge status, and the DRG is sent to Medicare or other relevant insurers (Steinbusch et al. 2007).

Since 1990, the General Accounting Office of the United States (GAO) has designated the Medicare program as a high-risk program that is vulnerable to improper payments (GAO 2000). One of the top five risks identified for Medicare fraud is DRG upcoding. ${ }^{14}$ DRG upcoding allows the hospital to use the information asymmetry between the hospital and Medicare and obtain a financial advantage. Hospital management can use several mechanisms to facilitate upcoding (Dafny 2005). First, because DRG assignment involves subjectivity and judgment, coders can be trained to err on the side of assignment to the DRG with higher reimbursement. Second, physicians can be persuaded to change their diagnoses to increase revenues. Third, the hospital may deliberately falsify patient records. Thus, upcoding is an improper shift of a patient's DRG to obtain higher reimbursement from Medicare and other relevant insurers (Dafny and Dranove 2009). Hospitals that upcode can be convicted under the

\footnotetext{
13 "Medical coder" is a professional qualification and thus requires obtaining certification based on educational achievement and successful completion of a qualifying examination.

${ }^{14}$ GAO reports several other sources of vulnerability such as payments for services not rendered, payments for services medically unnecessary, and services billed without documentation (GAO 2000).
} 
False Claims Act. ${ }^{15}$ If patient coding is deemed to be fraudulent, it "may be subject to fine, imprisonment, or civil penalty” (Blount and Gold 1999).

The Health Care Financing Administration (HCFA) uses a number of control and monitoring tools to reduce the risk of upcoding. ${ }^{16}$ Two such tools include The Hospital Payment Monitoring Program and The Comprehensive Error Rate Testing Program. These programs check medical records to estimate "whether the medical services paid for were allowable, medically necessary, accurately coded and sufficiently documented" (CMS 2004). Based on the results from this assessment, a composite error rate is estimated. An additional control instrument is the requirement for hospitals to use "grouper" software that can partially prevent upcoding through built-in checks. Other instruments to prevent upcoding include the code of ethics, which is the professional standard for the medical coder developed by the American Health Information Management Association (AHIMA) and the education provided by AHIMA, which emphasizes the undesirability of upcoding (Steinbusch et al. 2007).

Although substantial resources are allocated to investigate upcoding, the Office of the Inspector General (OIG) of the US Department of Health and Human Services (HHS) has stated that CMS' current efforts to prevent upcoding are not satisfactory (OIG 2005) ${ }^{17}$ Qui tam actions that are part of the False Claims Act are a powerful instrument against upcoding. ${ }^{18}$ In qui tam actions whistleblowers with direct knowledge of the fraud scheme initiate the litigation on behalf of the government. The Department of Justice (DOJ) in conjunction with other agencies then makes a judgment on whether to investigate the allegations and intervene. Only a fraction of the allegations are forwarded by the False Claims Act inspectors (typically, the State Attorney General's Office) to the DOJ for a formal intervention and only $25 \%$ of the forwarded cases undergo an intervention. In case of a conviction the whistleblowers are eligible to receive $15 \%$ to $25 \%$ of the recovery (DOJ 2012).

Upcoding has been investigated by researchers as well as by government agencies. One set of studies examines the magnitude of upcoding. The OIG of the HHS has conducted several studies to assess the magnitude of upcoding. In these studies, medical review personnel from HCFA compare claims from a random sample of beneficiaries to the beneficiaries' medical records (CMS 2008; GAO 2000; OIG 2001a). These studies

\footnotetext{
15 The False Claims Act (31 USC. §§ 3729 - 3733) is an US federal law that penalizes persons and companies who defraud governmental programs such as Medicare. The Act allows people to file actions on behalf of the government and provides them with a share of any recovered damages. After a lawsuit is filed the US Department of Justice assesses whether it will pursue the case (DOJ 2012).

${ }^{16}$ The HCFA is an operating division within the US Department of Health and Human Services (HHS) that is accountable for how it spends Medicare dollars and is responsible for safeguarding against improper payments (GAO 2000). In 2001 HCFA changed its name into Centers for Medicare and Medicaid Services (CMS).

17 In the year 2000, $\$ 78$ million of Medicare funding was allocated to detect upcoding, which was about $0.04 \%$ of the total Medicare budget (Becker et al. 2005).

${ }^{18}$ During the time of our study about $80 \%$ of health care fraud cases were qui tam actions (TAF 2007).
} 
conclude that improper payments ranged from \$23.2 billion in 1996 to $\$ 10.4$ billion in 2008 , or $14 \%$ to $3.6 \%$ of Medicare's payments. ${ }^{19}$ While the estimated amount of improper payments reduced over the last 15 years, the dollar magnitude is considerable. Furthermore, these estimates likely understate the extent of improper payments since the methodology used to assess the extent of improper payments assumes that medical records are accurate. That is, these estimates only consider whether the DRG classification is consistent with the medical documentation. Thus, improper payments supported by falsified documentation may go undetected (GAO 2000). Psaty et al. (1999) use detailed medical chart reviews as well as information collected from patient interviews and conclude that about one-third of all heart failure cases (DRG 127) are upcoded. Thus, upcoding of heart failure alone cost Medicare about \$933 million in 1993.

A second set of studies aims to identify observable characteristics of providers or claims associated with fraudulent or abusive behavior. HHS OIG (1998) compares audits of a sample of claims from 50 hospitals considered to be likely abusers with audits of claims from a random sample of 20 hospitals. It identifies 10 DRGs that have the highest rates of upcoding. Evidence suggests that for-profit hospitals engage in more upcoding than nonprofit hospitals; however, upcoding behavior of nonprofits more closely resembles that of for-profits in markets where for-profit hospitals have a high market share (Silverman and Skinner 2004). A study by Soderstrom (1993) provides evidence that hospitals in poor financial condition and/or with higher marginal costs engage in more upcoding. Dafny (2005) uses a policy reform as a natural experiment to show that hospitals upcode patients to DRGs with the largest price increases. Becker et al. (2005) investigate the influence of differences in state-level law enforcement activities on upcoding. They find that hospitals decrease their upcoding behavior as the level of enforcement increases. Dafny and Dranove (2009) show that management teams that fail to exploit the upcoding potential are vulnerable to replacement, suggesting that hospitals expect their managers to upcode. They also find that hospitals with new management teams upcode to a greater extent than hospitals whose management did not get replaced.

Thus, upcoding is an issue that has a large impact on the overall trend of rising health care costs. Because of its high potential to directly impact revenues without having to change the underlying operations and cost structures, upcoding provides hospitals with a potentially powerful tool for revenue manipulation. However, as upcoding bears a significant risk and therefore potential reputational and financial costs for hospitals, hospitals may have to carefully choose the contexts in which the benefits of upcoding outweigh its risks.

\footnotetext{
19 These amounts also include payments for services not rendered, payments for services medically unnecessary, and services billed without documentation.
} 


\subsection{Theory and Hypotheses}

The accounting literature generally uses the term "management” or "manipulation" if reported performance (such as revenues, costs, or profit) is different from actual economic performance. Information asymmetry between the firm and other parties reduces the likelihood of detection of manipulation behavior. Information asymmetries are likely to be substantially higher in industries where the service provided is relatively complex and the assessment of optimal service is relatively opaque (Arrow 1963). ${ }^{20}$ This type of situation exists in the health care industry. We exploit the unique features of the health care industry and argue that upcoding provides a tool for revenue manipulation in the hospital industry.

We expect upcoding to be a highly effective tool for revenue manipulation in hospitals for the following reasons. First, upcoding immediately and directly affects revenues without generating additional costs. Second, upcoding does not require a change to the underlying operating activities. Third, upcoding does not reverse in the future. In the following section we examine cross-sectional variations in regulatory oversight of revenue manipulation as a result of regulator preferences.

\subsubsection{Regulator preferences}

The general goal of regulation is to protect public interest and the objective of the regulators is to act as benevolent maximizers of social welfare (Laffont and Tirole 1991). Consistent with this, economists posit that regulators have objective functions that seek to maximize the weighted average of consumer surplus and producer surplus (Armstrong and Sappington 2007; Naughton 1989). ${ }^{21}$ Regulators can incorporate their preferences into the objective function; these preferences can include equity, or the regulators' interpretations of social welfare. Additionally, these preferences can vary across consumer groups as well as within consumer groups (Klein and Sweeney 1999; Peltzman 1976). The preference weights assigned to heterogeneous consumer groups and producers can therefore vary based on the goals of the regulator (Naughton 1989). Regulators could choose not to pursue a firm for regulatory violation if such violation benefits a desired consumer segment. The key point is that economic theory does not

\footnotetext{
${ }^{20}$ These criteria are also met in several other service industries. For instance, customers of car garages cannot assess whether all services billed have actually been provided at all or provided to the appropriate extent. Other examples are companies that hire lawyers or consultancies and agree on a fixed price per hour (e.g., analysts vs. partners). It is almost impossible for the firm to assess whether the partner has actually worked the hours billed.

21 Regulators could also use their power to pursue personal agendas, maximize their side payments from bribes, or collude with the regulated firm (Laffont and Martimort 1999). Demski and Sappington (1987) analytically model a self-interested regulator who has to be motivated to acquire valuable information about the firm.
} 
assume that regulators are passive machines that merely implement regulatory rules; it also recognizes that regulators exercise judgment, and may act in their own interest, the consumers' interest, or in the interest of the industries that they are supposed to regulate.

Another prominent theory of regulation is Stigler's (1971) theory of regulatory capture, which argues that regulators could be captured by the industry and operate for the benefit of the very industry that they are supposed to regulate. The goal of regulatory capture is to increase the firm's rent at the cost of the consumer. Additionally, politicians supply regulations, primarily driven by the selfish motive to augment their political power by providing favors to large corporations that capture regulations. This prominent view on regulation fueled considerable debate in economics, including the question of whether regulations are necessary for the market to function efficiently, and whether the loss of consumer surplus in the absence of regulation is sufficient to warrant the costs of regulatory capture and market failure. Although many critiques of regulatory capture theory have been offered (Samuelson and Nordhaus 2004; Wilson 1989), it remains popular.

In a recent study, Bozanic et al. (2012) combine institutional theory with regulatory capture theory in their study of SEC insider trading regulations. Using qualitative as well as quantitative analysis, they show that regulated firms exerted powerful influence on several aspects of the insider trading regulations. Their findings imply that, as suggested by institutional sociologists, accounting regulations exhibit endogeneity in the regulation setting process. Based on latent content analysis of insider trading cases, they conclude that (page 462): "federal circuit courts differentially applied what seemed at the time ambiguous standards to gauge insider trading, yielding inconsistent verdicts." In this study, we argue that inconsistencies in applying regulations may be a manifestation of regulator preferences, and a mechanism to signal their assessment of an organization's legitimacy.

Institutional theory, especially the work of Edelman, provides important insights regarding the role of regulation, mechanisms by which organizations comply to regulations, and regulator responses to cross-sectional and temporal variations in compliance. Edelman (1992) points out that many regulations not only contain broad and or vague language, but also have weak enforcement mechanisms. Organizations have to determine how best to comply with regulations such that their legitimacy is intact, while at the same time such compliance does not seriously undermine their competitiveness. As Edelman (1992) mentions (page 1532): “organizations test and collectively construct the form and boundaries of compliance in a way that meets legal demands yet preserves managerial interests.” Indeed, institutional sociologists recognize that regulation itself is socially constructed and that the very institutions that the regulation seeks to constrain, in turn not only influence the letter of the law but also how it is implemented (Edelman et al. 1999). This approach recognizes that regulators are not only susceptible to influence, but may willingly allow such influence based on their notion of socially desirable outcomes. We therefore argue that the complicit 
behavior of regulators that may suggest regulatory capture may instead be driven by regulatory preferences for a desired social goal such as improved access to health care for indigent patients or medical education.

Before the advent of fixed-price regulation, hospitals used cross subsidization, whereby the prices charged to some patient groups and some ailments were systematically higher than costs. The widespread prevalence of cross subsidization was tacitly approved by regulators and payers because it compensated for the distortions and inequities in health care coverage (Covaleski et al. 1993; Harris 1979; Sapolsky 1986). Hospitals are by law not allowed to turn away patients, but treating uninsured or underinsured patients is expensive and charging higher prices to fully insured patients allowed hospitals to cover the costs of servicing the uninsured and underinsured. After fixed-price regulation, cross subsidization was no longer possible; as a result, hospitals explored upcoding as a strategy that permitted implicit cross subsidization.

Upcoding increases the hospital's revenue, and consequently, hospital profit. The False Claims Act is aimed at preventing upcoding because it allows the hospital to extract a higher benefit than the value of the service rendered. A regulator who is simply a passive implementer of regulations will allocate scarce resources to investigate those hospitals that are most likely to upcode, and uniformly enforce and convict hospitals if it detects upcoding. However, if a regulator has preferences for social goals, it will assess the benefits provided by the hospital to a desired consumer group. To the extent that such assessment reveals that the hospital has a track record of providing benefits to a desired community of stakeholders (such as the uninsured), regulators are less likely to allocate scarce resources to investigate that hospital. That is, regulators confer legitimacy to socially responsible hospitals by reducing their enforcement efforts. This lower likelihood of investigation thus makes it less likely that hospitals with higher social performance get convicted under the False Claims Act, leading to the following hypothesis:

\section{Hypothesis 1: Hospitals with demonstrated social performance are less likely to be convicted under the False Claims Act.}

\subsubsection{Social motives for upcoding}

Extant accounting literature has examined financial motives for performance manipulation. We explore whether performance manipulation could also be motivated by the need to generate resources to meet social goals. Social goals are particularly salient in nonprofit hospitals, which seek to maximize a multi-dimensional objective function subject to a breakeven profit constraint (Newhouse 1970). The objective function of a nonprofit hospital includes providing access to health care for the indigent population, and in the case of teaching hospitals, providing high quality medical education. Indeed, two fundamental reasons for the emergence of the nonprofit form 
are, first to provide services in markets that are unattractive to for-profit firms, and second, to complement the role of the government (Weisbrod 1977, 1988). Because of the role that nonprofits have as alternative service providers to the government, they are supported by the government via subsidies as well as by the community via donations (Weisbrod 1977, 1988). As a consequence, to some extent, nonprofits receive governmental subsidies for the treatment of indigents and for medical education. ${ }^{22}$

However, governmental subsidies and private donations are scarce and nonprofits hospitals have to compete not only with other hospitals, but also with charitable and public organizations. In addition, nonprofits do not have access to some types of capital markets that for-profits can access (Hansmann 1980). Therefore, to a large extent nonprofit hospitals have to meet their social goals with their own resources. These social goals are expensive; for example, providing access via emergency rooms and trauma centers involves tremendous outlay of resources with limited or no cash inflows. For teaching hospitals, installation and operation of medical facilities and teaching staff consumes considerable resources with limited inflows. Revenue manipulation by upcoding is a powerful tool that allows hospitals to obtain some of the resources required to provide unprofitable services that are critical to fulfill the hospitals' social objectives.

While upcoding is an attractive mechanism to obtain higher revenues without incurring additional costs, there is regulatory scrutiny to ensure that upcoding does not occur. If upcoding is detected and penalized, the hospital may have high reputation costs as well as financial costs such as penalties and losses and potential loss of nonprofit tax-exempt status. Therefore, upcoding strategies have to be applied cautiously and hospitals must trade-off the costs and benefits. Specifically, the opportunity to upcode as well as the pecuniary benefit from upcoding varies across DRG groups. Certain DRG groups provide larger scope for revenue manipulation; thereby upcoding may be more frequent for these DRG groups (Dafny and Dranove 2009).

All hospitals can benefit by upcoding. However, hospitals that have higher performance on social goals have a greater need to upcode to obtain resources to continue to meet their social goals. Additionally, these hospitals, after having observed the enforcement process, are likely aware that regulators are less likely to convict them as predicted in H1. That is, high social performance hospitals recognize that they have a legitimacy advantage, signaled by the lower enforcement by regulators. Therefore, we

\footnotetext{
${ }^{22}$ Hospitals are partially reimbursed by Medicaid or state/county indigent programs for a proportion of their indigent patients. The primary source of financing for teaching hospitals is Medicare, which provides a higher reimbursement rate to teaching hospitals. The rate premium depends on the number of residents trained per inpatient bed (resident-to-bed ratio) leading to a per-case premium of 5.5 percent for approximately a 10 percent increase in the resident-to-bed ratio. In addition, nonprofits are exempted from property taxes and from the corporate income tax (Frank and Salkever 1994).
} 
argue that nonprofits that have higher performance on social goals such as charity care and medical education are more likely to use upcoding as a revenue manipulation tool to meet their resource needs. This leads to the following hypothesis:

\section{Hypothesis 2: There is a positive association between social performance and upcoding.}

\subsubsection{Extent of upcoding}

A hospital can pursue two upcoding strategies: upcode across all DRG families that have potential for financial gain, or upcode selectively based on the extent of financial gain obtained. DRGs in which upcoding confers higher financial gains are attractive targets. Because of the considerable effort that is involved in detection, upcoding at the margin where only one DRG family is upcoded is less likely to be detected as opposed to upcoding across all DRG families that are amenable to upcoding. To maximize the benefit from upcoding therefore, most hospital managers will choose the DRG family that provides the highest benefit relative to the regulatory and institutional risk imposed by upcoding. Upcoding behavior of hospitals with higher performance on social goals is likely to be different, however. They have a higher need for resources to meet their more ambitious social goals, as well as an awareness of their preferential treatment from regulators. That is, from their previous observance of the conviction frequency, high social performance hospitals are able to construct more generous boundaries around their compliance relative to organizations with lower social performance. This is consistent with Clune's (1983) notion of regulatory compliance, not as a static and pre-set legal fulfillment (bright line), but rather as a dynamic and emergent relationship between the regulator and the organization. This leads to H3.

\section{Hypothesis 3: Hospitals with higher social performance will upcode across a larger number of DRG families relative to hospitals with lower social performance.}

\subsubsection{Pecuniary motives for revenue manipulation}

We control for the pecuniary motives for performance management that have been identified in prior literature (Eldenburg et al. 2011; Hoerger 1991; Leone and Van Horn 2005). Nonprofit hospitals attempt to break even (zero earnings) to continue their operations (Newhouse 1970), but do not aim to report high income margins. Thus, financial variables are important in evaluating a nonprofit hospital manager's performance (Pizzini 2006). For instance, Brickley and Van Horn (2002) find that CEOs who are unable to meet the zero earnings benchmark have higher turnover relative to other CEOs. Meeting the zero earnings benchmark also helps hospitals raise 
funds. Consistently managing earnings towards zero reduces the variance of earnings and consequentially decreases the cost of debt (Trueman and Titman 1988). As a result, nonprofit CEOs have incentives to meet the zero earnings benchmark. We control for the likelihood that hospitals that just beat the zero earnings benchmark are more likely to have upcoded relative to other hospitals. An additional managerial motive for upcoding is incentive compensation. Prior research finds evidence that nonprofit hospitals use performance-based compensation contracts tied to profit performance of the hospital (Brickley and Van Horn 2002; Eldenburg and Krishnan 2003; Lambert and Larcker 1995). We control for the effect of pay-for-performance incentives on upcoding. We expect higher upcoding in hospitals that just meet the zero earnings benchmark, and hospitals that have performance based compensation.

Although we do not posit formal hypotheses, we expect that when hospitals upcode for pecuniary benefits such as meeting an income target or garnering incentive compensation, they will upcode only in DRG families that provide the maximum financial benefit. As argued in the previous section, if upcoding is detected and such upcoding is driven by pecuniary motives, there is a higher likelihood that the regulator will impose penalties. That is, hospitals will trade off the risk of regulatory sanctions with the financial return from upcoding. Therefore, when pecuniary motives drive upcoding, DRGs where the financial benefits from upcoding are low are unattractive targets relative to DRGs where the financial benefits from upcoding are high.

\subsection{Data and Research Method}

\subsubsection{Data}

For several reasons, we use data from nonprofit hospitals in California to test the hypotheses. First, California is one of the biggest hospital markets in the US with a large number of nonprofit hospitals. Second, focusing only on one state controls for inter-state variations in enforcement activities. Third, detailed data on hospitals' financials and patients are available for California hospitals. California hospitals are required to provide the state Office of Statewide Health Planning and Development (OSHPD) with financial statements that have to conform to US Generally Accepted Accounting Principles.

We collect financial and patient data from all nonprofit general acute care hospitals located in California from OSHPD for the time period 1996 (the first year when patient level data using DRGs are available) to 2007. We focus on general acute care hospitals and exclude specialty hospitals such as children's hospitals, substance abuse hospitals, and psychiatric hospitals since reimbursement rates, production functions, and patient mixes differ at these hospitals relative to general acute care hospitals (Eldenburg et al. 2011).

We test H1 using data from the False Claim Act settlement agreements of the US Department of Justice, which covers convictions during the 1999-2007 time period for 
upcoding that occurred between 1996 and 1999. As a result, our empirical test of H1 relates to the 1996-1999 time period. A 1998 report by the Department of Health and Human Services identified the DRG families that are prone to upcoding. Thus, from the calendar year 1999 onwards, hospitals were aware that regulators had knowledge of the upcoding potential occurring in these DRG families. The first set of convictions for upcoding occurred in 1999, which implies that hospitals would be able to infer the enforcement strategy of the regulator beginning in 1999. Therefore, our empirical test of H2 and H3 uses the 1999-2007 time period.

We examine upcoding for three distinct DRG families that have been identified by the US Department of Health and Human Services (1998) as being prone to upcoding, and have been used by prior research (Becker et al. 2005; Silverman and Skinner 2004). ${ }^{23}$ These DRG families are listed as high upcoding risk for two reasons. First, the individual DRGs belonging to each of these families are relatively similar from a medical point of view; therefore it is easier for the hospital to make a case that the DRG assignment was based on medical judgment rather than for financial benefit. Second, these DRG families offer financial incentives to upcode. These three DRG families include general respiratory ailments (DRG79), circulatory system disorders (DRG144), and diabetes and metabolic disorders (DRG296). ${ }^{24}$

Table 1 provides an overview of the high upcoding risk DRG families and the financial incentives that can be obtained from upcoding. These financial incentives are a function of the weight of each DRG. ${ }^{25}$ Based on the weight differences within a family and the resulting financial incentives, we classify DRG79 as the high incentive family, DRG144 as the medium incentive family, and DRG296 as the low incentive family. To calculate the specific upcoding incentive in dollars we apply the hospital's base rate for a DRG weight of 1 . This rate is adjusted for area specific wage differences and thus differs across hospitals. The average base rate for the year 2005 for a DRG weight of 1 is $\$ 5,150$ (CMS 2010; OIG 2001b) and we use this rate as the base for the dollar values reported in Table 1, Panel B. ${ }^{26}$ It can be seen from Table 1, Panel B that hospitals have substantial incentives to upcode depending on the DRG family.

\footnotetext{
${ }^{23}$ Use of these DRG families in the analysis provides us with a conservative measure of upcoding because we focus on DRGs that are known as being prone to upcoding for over a decade. Therefore, enforcement actions are likely to be high for these DRGs, reducing the extent of upcoding.

${ }^{24}$ The name indicates the DRG with the highest weight within the family. For a detailed description of DRG79 see Silverman and Skinner (2004).

25 CMS assigns a unique weight to each DRG. The weight reflects the average level of resources for an average Medicare patient belonging to the DRG, relative to the average level of resources for all Medicare patients. The weights are intended to account for cost variations between different types of treatments. More expensive conditions are assigned higher DRG weights (OIG 2001b).

${ }^{26}$ The rate of $\$ 5,150$ is relatively constant during the time of study. For a detailed example of how a specific payment per case is set up see HHS OIG (2001b).
} 


\section{Table 1: Overview of DRG monetary incentives}

Panel A: Description of DRG groups

\begin{tabular}{|c|c|c|c|c|}
\hline $\begin{array}{l}\text { Incentive } \\
\text { Classification of } \\
\text { DRG Family }^{\mathrm{a}}\end{array}$ & $\begin{array}{c}\text { DRG } \\
\text { Number } \\
\text { (based on } \\
\text { ICD-9- } \\
\text { CM) } \\
\end{array}$ & Description & $\begin{array}{c}\text { DRG } \\
\text { Weight }^{c}\end{array}$ & $\begin{array}{l}\text { Medicare } \\
\text { Revenue } \\
\text { Estimate } \\
\underset{(\$)^{d}}{ }\end{array}$ \\
\hline \multirow{4}{*}{$\begin{array}{l}\text { High Incentives } \\
\text { Family (General } \\
\text { Respiratory } \\
\text { Ailments) }\end{array}$} & 79 (TOP) & $\begin{array}{l}\text { Respiratory infections and inflammations } \\
\text { with complicating \& comorbidity factors } \\
\text { (cc) }\end{array}$ & 1.59 & $8,188.50$ \\
\hline & 80 & Respiratory infections without cc & 0.85 & $4,377.50$ \\
\hline & 89 & Pneumonia with (w) cc & 1.05 & $5,407.50$ \\
\hline & 90 & Pneumonia without (w/o) cc & 0.62 & $3,193.00$ \\
\hline \multirow{9}{*}{$\begin{array}{l}\text { Medium Incentives } \\
\text { Family (Circulatory } \\
\text { System Disorders) }\end{array}$} & 132 & Atherosclerosis w cc & 0.64 & $3,296.00$ \\
\hline & 133 & Atherosclerosis w/o cc & 0.54 & $2,781.00$ \\
\hline & 138 & $\begin{array}{l}\text { Cardiac arrhythmia and conduction } \\
\text { disorders w cc }\end{array}$ & 0.84 & $4,326.00$ \\
\hline & 139 & $\begin{array}{l}\text { Cardiac arrhythmia and conduction } \\
\text { disorders w/o cc }\end{array}$ & 0.52 & $2,678.00$ \\
\hline & 140 & Angina Pectoris & 0.53 & $2,729.50$ \\
\hline & 141 & Syncope and collapse w cc & 0.76 & $3,914.00$ \\
\hline & 142 & Syncope and collapse w/o cc & 0.59 & $3,038.50$ \\
\hline & 144 (TOP) & Other circulatory system diagnoses w cc & 1.25 & $6,437.50$ \\
\hline & 145 & Other circulatory system diagnoses w/o cc & 0.59 & $3,038.50$ \\
\hline \multirow{4}{*}{$\begin{array}{c}\text { Low Incentives } \\
\text { Family (Diabetes and } \\
\text { Nutritional/Metabolic } \\
\text { Disorders) }\end{array}$} & 182 & $\begin{array}{l}\text { Esophagitis, gastroent and miscellaneous } \\
\text { digest disorders age }>17 \mathrm{w} \mathrm{cc}\end{array}$ & 0.79 & $4,068.50$ \\
\hline & 294 & Diabetes age $>35$ & 0.78 & $4,017.00$ \\
\hline & 296 (ТOP) & $\begin{array}{l}\text { Nutritional and miscellaneous metabolic } \\
\text { disorders age }>17 \mathrm{w} \text { cc }\end{array}$ & 0.84 & $4,326.00$ \\
\hline & 297 & $\begin{array}{l}\text { Nutritional and miscellaneous metabolic } \\
\text { disorders age }>17 \text { w/o cc }\end{array}$ & 0.5 & $2,575.00$ \\
\hline
\end{tabular}

Notes to Table 1, Panel A:

${ }^{a}$ Based on the financial benefit from upcoding from one of the lower revenue DRG numbers to the highest revenue DRG number.

b “TOP” refers to the DRG that has the highest revenue in the DRG family. ICD-9-CM refers to the International Classification of Diseases, Ninth Revision, Clinical Modification. This classification is used to assign diagnostic and procedure codes associated with inpatient, outpatient, and physician office utilization in the United States.

${ }^{c}$ Refers to the weight assigned by CMS to each DRG. The weight reflects the average level of resources for an average Medicare patient belonging to the DRG, relative to the average level of resources for all Medicare patients. The weights are intended to account for cost variations between different types of treatments. More expensive conditions are assigned higher DRG weights.

${ }^{d}$ Refers to the revenue estimate per DRG in dollar calculated as the DRG weight times the average base rate for the year 2005 for a DRG weight of $1(\$ 5,150)$. 
Table 1 (Continued)

Panel B: Monetary incentives per DRG groups

\begin{tabular}{|c|c|c|c|c|c|c|}
\hline $\begin{array}{l}\text { Incentive } \\
\text { Classification of } \\
\text { DRG Family }\end{array}$ & $\begin{array}{l}\text { Difference } \\
\text { between } \\
\text { Top DRG } \\
\text { and Family } \\
\text { Average }^{\text {a }} \\
\end{array}$ & $\begin{array}{l}\text { Average } \\
\text { Payment } \\
\text { Incentive } \\
(\$)^{\mathbf{b}}\end{array}$ & $\begin{array}{l}\text { Max. } \\
\text { Difference }^{c}\end{array}$ & $\begin{array}{l}\text { Max. } \\
\text { Payment } \\
\text { Incentive } \\
(\$)^{\mathrm{d}}\end{array}$ & $\begin{array}{l}\text { Min. } \\
\text { Difference }^{\text {e }}\end{array}$ & $\begin{array}{l}\text { Min. } \\
\text { Payment } \\
\text { Incentive } \\
(\$)^{\mathrm{f}}\end{array}$ \\
\hline $\begin{array}{l}\text { High Incentives } \\
\text { (General } \\
\text { Respiratory } \\
\text { Ailments) } \\
\end{array}$ & 0.75 & $3,862.50$ & 0.97 & 4,995.50 & 0.54 & 2,781.00 \\
\hline $\begin{array}{c}\text { Medium Incentives } \\
\text { (Circulatory system } \\
\text { disorders) } \\
\end{array}$ & 0.62 & $3,212.31$ & 0.73 & $3,759.50$ & 0.41 & $2,111.50$ \\
\hline $\begin{array}{c}\text { Low Incentives } \\
\text { (Diabetes and } \\
\text { nutritional/metabolic } \\
\text { disorders) }\end{array}$ & 0.15 & 772.50 & 0.34 & $1,751.00$ & 0.06 & 309.00 \\
\hline \multicolumn{7}{|c|}{$\begin{array}{l}\text { Notes to Table 1, Panel B: } \\
\text { a Computed as the difference between the TOP DRG weight and the average DRG weight of the other DRGs } \\
\text { in the family. } \\
\text { b Computed as the average difference between TOP DRG weight and family average weight in dollars, i.e., } \\
\text { difference in weight times the average base rate for the year } 2005 \text { for a DRG weight of } 1(\$ 5,150) \text {. } \\
\text { c Computed as the difference between the TOP DRG weight and the lowest DRG weight per family. } \\
{ }^{d} \text { Computed as the maximum difference between TOP DRG weight and lowest DRG weight per family in } \\
\text { dollar, i.e., difference in weight times the average base rate for the year } 2005 \text { for a DRG weight of } 1(\$ 5,150) \text {. } \\
\text { e Computed as the difference between the TOP DRG weight and the second highest DRG weight per family. } \\
{ }^{\mathrm{f}} \text { Computed as the minimum difference between TOP DRG weight and second highest DRG weight per family } \\
\text { in dollar, i.e., difference in weight times the average base rate for the year } 2005 \text { for a DRG weight of } 1 \\
(\$ 5,150) \text {. }\end{array}$} \\
\hline
\end{tabular}

\subsubsection{Research method}

\subsubsection{Test of $\mathrm{H1}$}

$\mathrm{H} 1$ proposes that regulators are less likely to investigate, and therefore convict under the False Claims Act, those hospitals that have demonstrated performance on social goals, i.e., charity care and medical education. We examine the likelihood of being convicted for upcoding using the following logistic regression model where subscript $i$ represents the hospital and $t$ the year:

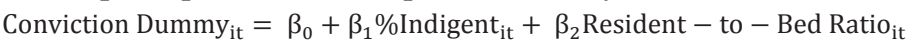

$$
\begin{aligned}
& +\beta_{3} \text { Zero Earnings Benchmark Dummy }{ }_{i t}+\beta_{4} \text { P4P Dummy }_{i}+\beta_{5} \mathrm{ROA}_{\mathrm{it}} \\
& +\beta_{6} \text { Zscore }_{i t}+\beta_{7} \% \text { Medicare }_{i t}+\beta_{8} \mathrm{CMI}_{\text {it }}+\beta_{9} \text { LogDischarges }_{\text {it }} \\
& +\beta_{10} \text { LogBoardsize }_{i t}+\beta_{11} \text { Church }_{i t}+\beta_{12} \text { System Dummy }_{i t}+\beta_{13} \text { Rural Dummy }_{\text {it }} \\
& +\beta_{14} \mathrm{HHI}_{\text {it }}+\beta_{15} \text { LogMedianHouseholdIncome }_{i t}+\delta_{16} \text { Year Dummies } \\
& +\mathrm{e}_{\mathrm{it}}
\end{aligned}
$$

The CONVICTION DUMMY is an indicator variable that is equal to one in the years a hospital has been convicted for upcoding under the False Claims Act, and zero otherwise. To identify convicted hospitals, we collected data from the False Claims Act settlement agreements published by the US Department of Justice. The published 
information allows us to identify the exact period in which the convicted hospitals engaged in upcoding.

We test $\mathrm{H} 1$ using two variables that measure social goals. These include indigent care and medical education. For the former, we construct a variable that captures the share of indigent patients (\%INDIGENT) as a percentage of the hospital's total patient population measured in patient days. We define indigent patients as those for which the hospital does not receive any or only a small amount of money. The higher this share, the more indigent patients a hospital receives relative to other patients. Thus, a hospital with a higher \%INDIGENT has a higher demand for additional resources to serve these patients. For medical education, we construct a variable that captures the share of residents trained per inpatient bed (RESIDENT-TO-BED RATIO). The larger this ratio, the higher is the magnitude of medical education provided by a specific hospital. Accordingly, hospitals with a larger resident-to-bed ratio have a higher demand for additional resources to provide medical education. H1 predicts a negative coefficient on $\beta_{1}$ and $\beta_{2}$, i.e., a higher percentage of indigent patients and higher residents ratio will be associated with lower likelihood of conviction.

We also test the influence of two important pecuniary motives to upcode on the likelihood of convictions. These motives include, to meet a zero earnings benchmark and to obtain higher incentive compensation. To identify hospitals that just meet the zero earnings benchmark, we group hospital-years into intervals based on net income divided by total assets at the beginning of the year. Following Degeorge et al. (1999), we determine our categories of scaled earnings based upon 2(IQR) $\mathrm{n}^{-1 / 3}$ leading to a bin width of $0.02 .^{27}$ Thus, hospitals whose net income divided by lagged total assets lies in the interval [0, 0.02] are identified as having just met the benchmark, and are coded as 1 in the ZERO EARNINGS BENCHMARK DUMMY.

To construct the incentive compensation variable, we conduct a hospital-level variable of pay for performance (P4P). We follow Eldenburg et al.'s (2011) version of Sloan's (1993) model and regress the change in log of managerial compensation on the change in return on asset $(R O A)$. Since our dataset does not include compensation details for individual managers or the CEO, we use the annual sum of direct salaries, bonuses, and benefits of the top hospital administrators including the CEO, Medical Director, Nursing Director, and their assistants as our measure of compensation (TOTAL COMPENSATION) (Eldenburg et al. 2011). We scale this variable by the number of full-time equivalent employees (FTEs) in the top administrative team to obtain an individual score. We also include the Herfindahl-Hirshman index (HHI) to control for the influence of competition on incentive compensation and the standard deviation of ROA over three years to control for earnings volatility (StdROA). We exploit the panel

\footnotetext{
${ }^{27}$ IQR is the sample interquartile range and $n$ is the number of observations.
} 
structure of our dataset and estimate the following model for the time period 1996 to 2007 using panel-specific random parameters:

$\Delta \log \left[\frac{\text { Total Compensation }_{i t}}{F T E_{i t}}\right]=n_{i 0}+n_{i 1} \Delta R O A_{i t}+n_{i 2} H H I_{i t}+n_{i 3} S_{T} d R O A_{i t}+e_{i t}$

where subscript $i$ relates to an individual hospital and $t$ to year. Based on the coefficient $n_{i 1}$, which is our hospital-specific measure of P4P, we create a dummy (P4P $D U M M Y$ ) that equals one for all hospitals that have a positive $n_{i 1}$.

We use several variables that control for the hospital's operations and its financial condition. First, we include a hospital's return on asset (ROA). A higher level of profitability could likely increase regulators' scrutiny towards a hospital's coding practices. We also include the Altman Z-score (Altman 1968) (ZSCORE) to capture the level of financial distress of a hospital. We adjust the original formula and replace the market value of equity with the book value of equity (Altman and Saunders 1997). To control for the hospital's patient mix, we include the percentage of Medicare patients (\%MEDICARE) treated by the hospital measured in patient days. ${ }^{28}$ Although the DRG classification system is used by Medicaid as well as most major insurers, Medicare is the only insurer that fully links reimbursement to the DRG classification system (Reinhardt 2006). However, hospitals are likely to apply a similar coding strategy across patients of different types of insurances to show a uniform coding behavior to regulators.

Next, we control for the hospital's case mix index (CMI). The CMI captures the average severity of illness of patients at the hospital. The CMI controls for the potential conflict that a hospital with higher performance on social goals (e.g., a teaching hospital) might automatically be confronted with more severely ill patients. We also control for hospital size by including the natural logarithm of the number of discharges (LOGDISCHARGES). Furthermore, we include the natural logarithm of the number of board members (LOGBOARDSIZE) to control for monitoring effectiveness. A larger board might lead to a lower monitoring effectiveness because of dysfunctional behavior, such as free-rider problems (Aggarwal et al. 2011; Yermack 1996), and thus enable more upcoding. We further address the possibility that a hospital is church-owned (CHURCH DUMMY). We include additional controls for hospital membership in a multi-hospital system (SYSTEM DUMMY), and location in a rural area (RURAL DUMMY). Finally, we include the Herfindahl-Hirshman index (HHI) to measure the level of competition within a local hospital market (Kwoka 1985). Consistent with prior research (Silverman and Skinner 2004; Wennberg and Cooper 1999) we use hospital service areas to determine local hospital markets. Higher competition might lead to more financial pressure and thus encourage more upcoding. Finally, we obtain data on

\footnotetext{
${ }^{28}$ As a robustness check, we also estimate the model using the percentage of Medicare patients treated by the hospital measured in patient discharges for the three specific DRG families (DRG79, DRG144, and DRG296). All results remain the same (untabulated).
} 
the median household income per hospital service area from the US Census Bureau and include the natural logarithm of that income (LOGMEDIANHOUSEHOLDINCOME) to control for differences in the economics across local hospital markets. On the one hand, hospitals that operate in poorer areas are likely to have a higher percentage of indigent patients and thus a larger incentive to upcode. On the other hand, regulator's scrutiny might depend on the economics of the local hospital market.

Our final sample for testing H1 consists of 207 nonprofit hospitals and 741 hospital-year observations. Table 2 provides an overview of hospital convictions by year. The number of convictions has a slightly increasing trend over the time period of our analysis, both in an absolute and relative sense.

Table 2: Overview of convicted hospitals per year ${ }^{\mathrm{a}}$

\begin{tabular}{cccc}
\hline Year & Number of Hospitals $^{\mathbf{b}}$ & Number of convicted Hospitals & \% of Sample \\
\hline 1996 & 178 & 18 & 10.1 \\
1997 & 177 & 20 & 11.3 \\
1998 & 180 & 24 & 13.3 \\
1999 & 176 & 26 & 14.8 \\
\hline
\end{tabular}

\section{Notes to Table 2:}

${ }^{a}$ Data from the False Claim Act settlement agreements of the US Department of Justice. The data relate to convictions during the 1999-2007 time period for upcoding that occurred between 1996 and 1999.

b Number of all California nonprofit general acute care hospitals per year. The data are obtained from the Office of Statewide Health Planning and Development (OSHPD).

Table 3 provides an overview and definitions of the variables that we use in this study. Descriptive statistics for the sample used to test $\mathrm{H} 1$ are summarized in Table 4. The mean (median) revenue for the sample is \$232 million (\$168 million). The mean (median) net income for the sample is $\$ 4.77$ million (\$1.91 million). Mean (median) total assets are $\$ 120$ million (\$78 million). The mean (median) return on assets is 3.1 percent (3.4 percent). The mean (median) number of discharges is $9,389(8,079)$. The skewness of these distributions suggests that the sample includes more small hospitals than large hospitals, which is consistent with prior studies (Eldenburg et al. 2011). The average hospital has about 40.9 percent Medicare patients, a case mix index of 1.08 and 15 board members. 13.9 percent of the hospitals are located in rural areas, 22.4 percent of the hospitals are church-owned, and almost half of the hospitals (49.7 percent) belong to a system. The mean (median) Herfindahl-Hirshman index is $0.20(0.12)$ and the mean median household income is $\$ 39,460$.

On average 11.4 percent of the hospitals just meet the zero earnings benchmark. About 43.6 percent of the hospitals in our sample have incentive compensation based on financial performance. About 1.24 percent of all patients treated are indigent. The mean resident-to-bed ratio is 4.5 percent. About 22.5 percent of hospitals in our sample provide medical education. 
Chapter 2

Table 3: Overview of variables

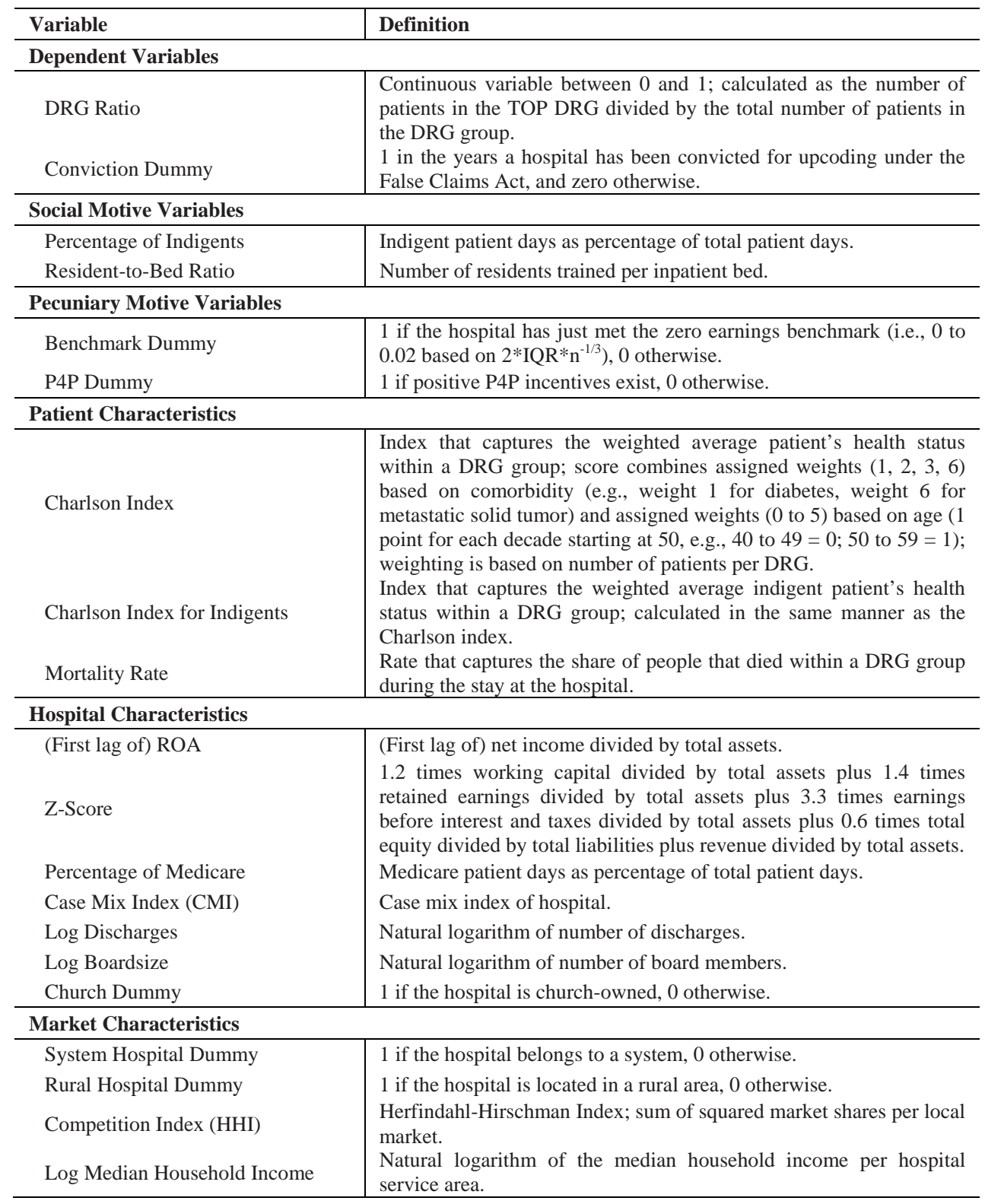


The Interplay between Regulator Preferences and Organizational Motives for Revenue Manipulation

Table 4: Descriptive statistics for years 1996 to $1999(\mathrm{~N}=741)^{\mathrm{a}}$

\begin{tabular}{|c|c|c|c|c|c|c|c|}
\hline Variable & Mean & $\begin{array}{l}\text { Std. } \\
\text { Dev. }\end{array}$ & Min. & Q1 & Median & Q3 & Max. \\
\hline \multicolumn{8}{|l|}{ Dependent Variables } \\
\hline DRG Ratio 79 & 0.268 & 0.117 & 0.023 & 0.186 & 0.256 & 0.337 & 0.631 \\
\hline DRG Ratio 144 & 0.122 & 0.065 & 0.007 & 0.076 & 0.114 & 0.158 & 0.359 \\
\hline DRG Ratio 296 & 0.357 & 0.076 & 0.146 & 0.309 & 0.353 & 0.405 & 0.548 \\
\hline \multicolumn{8}{|l|}{ Social Motive Variables } \\
\hline \%Indigents & 1.238 & 2.021 & 0 & 0 & 0.299 & 1.837 & 10.227 \\
\hline Resident-to-Bed Ratio & 0.045 & 0.124 & 0 & 0 & 0 & 0 & 0.901 \\
\hline \multicolumn{8}{|c|}{ Pecuniary Motive Variables } \\
\hline Benchmark Dummy & 0.114 & 0.318 & 0 & 0 & 0 & 0 & 1 \\
\hline P4P Dummy & 0.436 & 0.496 & 0 & 0 & 0 & 1 & 1 \\
\hline \multicolumn{8}{|l|}{ Patient Characteristics } \\
\hline Charlson Index 79 & 4.136 & 0.461 & 2.438 & 3.896 & 4.200 & 4.445 & 4.989 \\
\hline Charlson Index Ind. 79 & 0.490 & 0.975 & 0 & 0 & 0 & 0.667 & 5.000 \\
\hline Mortality Rate 79 & 0.067 & 0.024 & 0 & 0.052 & 0.066 & 0.081 & 0.132 \\
\hline Charlson Index 144 & 3.276 & 0.409 & 2.010 & 3.036 & 3.307 & 3.564 & 4.154 \\
\hline $\begin{array}{l}\text { Charlson Index Ind. } \\
144\end{array}$ & 0.682 & 1.110 & 0 & 0 & 0 & 0.481 & 4.333 \\
\hline Mortality Rate 144 & 0.015 & 0.010 & 0 & 0.008 & 0.014 & 0.020 & 0.052 \\
\hline Charlson Index 296 & 3.362 & 0.534 & 1.782 & 3.074 & 3.404 & 3.700 & 4.525 \\
\hline $\begin{array}{l}\text { Charlson Index Ind. } \\
296\end{array}$ & 0.394 & 0.845 & 0 & 0 & 0 & 0.481 & 5.000 \\
\hline Mortality Rate 296 & 0.016 & 0.012 & 0 & 0.007 & 0.014 & 0.023 & 0.062 \\
\hline \multicolumn{8}{|c|}{ Hospital Characteristics } \\
\hline Revenues in 000s & 231,995 & 221,713 & 8,853 & 79,873 & 168,142 & 312,675 & $1,254,061$ \\
\hline Net Income in 000s & 4,771 & 11,823 & $-16,861$ & -494 & 1,909 & 6,626 & 67,563 \\
\hline Total Assets in 000s & 120,112 & 129,190 & 2,159 & 33,523 & 78,352 & 166,459 & 718,047 \\
\hline $\mathrm{ROA}_{\mathrm{t}-1}$ & 0.031 & 0.092 & -0.290 & -0.002 & 0.034 & 0.070 & 0.341 \\
\hline Zscore & 3.301 & 1.946 & -0.649 & 2.303 & 2.946 & 3.653 & 14.386 \\
\hline \%Medicare & 40.943 & 13.816 & 7.849 & 31.405 & 41.008 & 51.680 & 71.963 \\
\hline CMI & 1.084 & 0.192 & 0.740 & 0.950 & 1.050 & 1.190 & 1.750 \\
\hline Teaching Dummy & 0.225 & 0.418 & 0 & 0 & 0 & 0 & 1 \\
\hline Discharges & 9,389 & 6,624 & 307 & 4,064 & 8,079 & 13,306 & 30,653 \\
\hline Log Discharges & 8.834 & 0.895 & 5.740 & 8.310 & 8.997 & 9.496 & 10.326 \\
\hline Boardsize & 14.71 & 5.19 & 2 & 12 & 15 & 18 & 29 \\
\hline Log Boardsize & 2.604 & 0.466 & 0.693 & 2.485 & 2.708 & 2.890 & 3.367 \\
\hline Church Dummy & 0.224 & 0.417 & 0 & 0 & 0 & 0 & 1 \\
\hline \multicolumn{8}{|c|}{ Hospital Market Characteristics } \\
\hline System Dummy & 0.497 & 0.500 & 0 & 0 & 0 & 1 & 1 \\
\hline Rural Dummy & 0.139 & 0.345 & 0 & 0 & 0 & 0 & 1 \\
\hline HHI & 0.195 & 0.235 & 0.015 & 0.040 & 0.117 & 0.273 & 1 \\
\hline $\begin{array}{l}\text { Median Household } \\
\text { Income in \$ }\end{array}$ & 39,460 & 7,826 & 27,885 & 33,828 & 37,655 & 44,998 & 61,257 \\
\hline $\begin{array}{l}\text { Log Median Household } \\
\text { Income }\end{array}$ & 10.565 & 0.190 & 10.236 & 10.429 & 10.536 & 10.714 & 11.023 \\
\hline
\end{tabular}

\section{Notes to Table 4:}

${ }^{\mathrm{a}}$ The data are obtained from the OSHPD and the US Census Bureau. See Table 3 for variable definitions. 


\subsubsection{Test of $\mathrm{H} 2$ and $\mathrm{H3}$}

$\mathrm{H} 2$ predicts a positive association between upcoding and performance on social goals and H3 predicts that - depending on the underlying motive - upcoding occurs across the board or only in the high incentive DRG family. To test H2 and H3 we use three different dependent variables in a system of three equations. We estimate the equation system using seemingly unrelated regressions (SUR) (Zellner 1962), which takes into consideration the correlation in the error terms across equations (Wooldridge 2002). This method is appropriate because upcoding strategies are likely to be associated across DRG families. That is, a hospital that upcodes in the DRG79 family either has a higher likelihood of upcoding in DRG144 and DRG296 families if it is an aggressive upcoder, or has a lower likelihood of upcoding in the latter two families if it balances the risk of detection and regulatory sanctions with the cost of upcoding. Therefore, our three equations are unlikely to be independent. To test our assumption, we conduct a Lagrange Multiplier (LM) test proposed by Breusch and Pagan (1980). The LM test statistic suggests that the residuals of our three equations are not independent $(p<0.001)$. Therefore, we use the following SUR model where subscript $i$ represents the hospital, $t$ the year:

$$
\begin{aligned}
& \text { DRG Ratio } X_{\text {it }}=\beta_{0}+\beta_{1} \% \text { Indigent }_{\text {it }}+\beta_{2} \text { Resident }- \text { to }- \text { Bed Ratio }_{\text {it }} \\
& +\beta_{3} \text { Zero Earnings Benchmark Dummy it }+\beta_{4} \text { P4P Dummy } y_{i}+\beta_{5} \text { DRG Ratio } X_{i t-1} \\
& +\beta_{6} \text { Charlson Index } X_{i t}+\beta_{7} \text { Charlson Index Indigents } X_{i t}+\beta_{8} \text { Mortality Rate } X_{i t} \\
& +\beta_{9} \text { ROA A }_{i t-1}+\beta_{10} \text { Zscore }_{i t}+\beta_{11} \text { \% Medicare }_{i t}+\beta_{12} \text { CMI }_{i t}+\beta_{13} \text { LogDischarges }_{\text {it }} \\
& +\beta_{14} \text { LogBoardsize }_{i t}+\beta_{15} \text { Church Dummy }_{i t}+\beta_{16} \text { System Dummy }_{\text {it }} \\
& +\beta_{17} \text { Rural Dummy it }+\beta_{18} \mathrm{HHI}_{\mathrm{it}}+\beta_{19} \text { LogMedianHouseholdIncome }_{\text {it }} \\
& +\delta_{\mathrm{t}-1} \text { Year Dummies }+\mathrm{e}_{\mathrm{it}}
\end{aligned}
$$

In the above specification, $X$ is either 79,144 , or 296 . There are three equations, one for each DRG family. Our three dependent variables (DRG RATIO 79, DRG RATIO 144, and DRG RATIO 296) are calculated as the ratio of the number of patients coded into the Top DRG divided by the sum of patients discharged from all DRGs within a family. $^{29}$

To control for other factors that may drive the proportion of patients in each DRG within a family, we include the first lag of the DRG ratio (DRG RATIO $X_{t-1}$ ), the Charlson index (CHARLSON INDEX X), and the mortality rate (MORTALITY RATE X) within the DRG. The Charlson index captures the weighted average of a patient's health status within the specific DRG family (Charlson et al. 1987). The index assigns weights

\footnotetext{
29 Although the False Claims Act only applies to Medicare patients, we include all patients discharged in each of the three DRG families because it is unlikely that hospitals will use different upcoding strategies for Medicare versus other insured patients. Differences in upcoding strategies across payer groups are much more likely to be detected relative to upcoding across the board.
} 
$(1,2,3,6)$ based on comorbidity (e.g., weight 1 for diabetes, weight 6 for metastatic solid tumor) and age ( 0 to 5 ; where 1 point is assigned for each decade starting at 50 , e.g., 40 to $49=0$; 50 to $59=1$ ). The weighting is based on the number of patients per DRG within a family. In addition, we include a separate Charlson index calculated for the indigent patient population within the specific DRG family only (CHARLSON INDEX INDIGENTS $X$ ) to control for the possibility that indigents are more severely ill when they demand medical services (Hsia and Shen 2011). The underlying idea of the Charlson index is that the more severely ill the patients (i.e., the higher the index) the more likely it is to have patients in the Top DRG of the respective DRG family. However, if the documentation of comorbidities is adjusted by hospitals to justify their coding choice to Medicare (CMS 2004; Silverman and Skinner 2004), then including the Charlson index as a control leads to an understatement of the real upcoding behavior. Thus, our measure of upcoding is conservative. The mortality rate reflects the proportion of patients that died within a specific DRG while staying at the hospital. This rate also captures the health status of the patient population. Other control variables are included as explained in the test of $\mathrm{H} 1$.

Our final sample for testing $\mathrm{H} 2$ and $\mathrm{H} 3$ consists of 187 nonprofit hospitals and 1,447 hospital-year observations. Descriptive statistics are summarized in Table 5. The mean (median) revenue for the sample is $\$ 529$ million (\$335 million). The mean (median) net income for the sample is $\$ 9.08$ million (\$3.07 million). Mean (median) total assets are $\$ 182$ million ( $\$ 105$ million). The mean (median) return on assets is 2.7 percent (3.3 percent). The mean (median) number of discharges is 10,721 $(9,392)$. The average hospital has about 46.7 percent Medicare patients, a case mix index of 1.12 and 15 board members. 16.1 percent of the hospitals are located in rural areas, 14.6 percent of the hospitals are church-owned, and more than half of the hospitals (54 percent) belong to a system. The mean (median) Herfindahl-Hirshman index is $0.23(0.16)$ and the mean median household income is $\$ 47,586$.

An average of 22.8 percent of patients is coded into the Top DRG for family DRG79, 14.6 percent for family DRG144 and 33.7 percent for family DRG296. The Charlson index and the mortality rate for family DRG79 (4.28 and 6.1 percent) is higher on average than for the other two groups (3.44 and 3.45 Charlson index and 1.5 and 1.6 percent mortality rate respectively). Thus, patients belonging to DRG79 have on average a lower health status. The maximum values of the Charlson indices for indigent patients (4 for DRG79, 3.25 for DRG144, and 3 for DRG296) are lower than the mean of the overall Charlson index indicating that the few indigent patients treated in these DRG families, on average are not more severely ill than other patient populations. On average 10.9 percent of the hospitals just meet the zero earnings benchmark. About half (50.3 percent) of the hospitals in our sample have incentive compensation based on financial performance. About 1.39 percent of all patients treated are indigent. The mean resident-to-bed ratio is 4.7 percent. About 24.4 percent of hospitals in our sample provide medical education. 
Table 5: Descriptive statistics for years 1999 to $2007(\mathrm{~N}=1,447)^{\mathrm{a}}$

\begin{tabular}{|c|c|c|c|c|c|c|c|}
\hline Variable & Mean & $\begin{array}{l}\text { Std. } \\
\text { Dev. }\end{array}$ & Min. & Q1 & Median & Q3 & Max. \\
\hline \multicolumn{8}{|l|}{ Dependent Variables } \\
\hline DRG Ratio 79 & 0.228 & 0.093 & 0.022 & 0.167 & 0.216 & 0.282 & 0.541 \\
\hline DRG Ratio 144 & 0.146 & 0.078 & 0 & 0.094 & 0.134 & 0.182 & 0.423 \\
\hline DRG Ratio 296 & 0.337 & 0.069 & 0.167 & 0.292 & 0.337 & 0.379 & 0.547 \\
\hline \multicolumn{8}{|l|}{ Social Motive Variables } \\
\hline \%Indigents & 1.392 & 1.902 & 0 & 0 & 0.381 & 2.271 & 7.142 \\
\hline Resident-to-Bed Ratio & 0.047 & 0.132 & 0 & 0 & 0 & 0 & 0.680 \\
\hline \multicolumn{8}{|c|}{ Pecuniary Motive Variables } \\
\hline Benchmark Dummy & 0.109 & 0.312 & 0 & 0 & 0 & 0 & 1 \\
\hline P4P Dummy & 0.503 & 0.500 & 0 & 0 & 1 & 1 & 1 \\
\hline \multicolumn{8}{|l|}{ Patient Characteristics } \\
\hline Charlson Index 79 & 4.282 & 0.453 & 2.739 & 4.025 & 4.322 & 4.601 & 5.221 \\
\hline Charlson Index Ind. 79 & 0.232 & 0.715 & 0 & 0 & 0 & 0 & 4.000 \\
\hline Mortality Rate 79 & 0.061 & 0.025 & 0 & 0.043 & 0.059 & 0.076 & 0.134 \\
\hline Charlson Index 144 & 3.444 & 0.400 & 2.315 & 3.196 & 3.476 & 3.700 & 4.363 \\
\hline Charlson Index Ind. 144 & 0.233 & 0.667 & 0 & 0 & 0 & 0 & 3.250 \\
\hline Mortality Rate 144 & 0.015 & 0.011 & 0 & 0.008 & 0.014 & 0.020 & 0.060 \\
\hline Charlson Index 296 & 3.452 & 0.476 & 2.086 & 3.165 & 3.476 & 3.750 & 4.595 \\
\hline Charlson Index Ind. 296 & 0.184 & 0.551 & 0 & 0 & 0 & 0 & 3.000 \\
\hline Mortality Rate 296 & 0.016 & 0.010 & 0 & 0.008 & 0.014 & 0.022 & 0.048 \\
\hline \multicolumn{8}{|l|}{ Hospital Characteristics } \\
\hline Revenues in 000s & 529,218 & 562,417 & 9,149 & 145,342 & 334,718 & 716,537 & $3,081,531$ \\
\hline Net Income in 000s & 9,075 & 20,605 & $-30,071$ & -520 & 3,070 & 11,179 & 94,391 \\
\hline Total Assets in 000s & 181,822 & 234,249 & 3,123 & 43,097 & 104,975 & 211,894 & $1,374,073$ \\
\hline $\mathrm{ROA}_{\mathrm{t}-1}$ & 0.027 & 0.105 & -0.363 & -0.011 & 0.033 & 0.078 & 0.314 \\
\hline Zscore & 4.555 & 2.051 & 0.620 & 3.052 & 4.164 & 5.693 & 11.057 \\
\hline \%Medicare & 46.688 & 14.065 & 12.051 & 38.276 & 47.506 & 56.929 & 77.984 \\
\hline CMI & 1.117 & 0.213 & 0.740 & 0.970 & 1.080 & 1.230 & 1.807 \\
\hline Teaching Dummy & 0.244 & 0.430 & 0 & 0 & 0 & 0 & 1 \\
\hline Discharges & 10,721 & 7,722 & 310 & 4,170 & 9,392 & 15,612 & 31,598 \\
\hline Log Discharges & 8.930 & 0.970 & 5.737 & 8.336 & 9.148 & 9.656 & 10.351 \\
\hline Boardsize & 15.22 & 5.28 & 2 & 12 & 15 & 18 & 30 \\
\hline Log Boardsize & 2.645 & 0.440 & 0.693 & 2.485 & 2.708 & 2.890 & 3.401 \\
\hline Church Dummy & 0.146 & 0.353 & 0 & 0 & 0 & 0 & 1 \\
\hline \multicolumn{8}{|c|}{ Hospital Market Characteristics } \\
\hline System Dummy & 0.540 & 0.499 & 0 & 0 & 1 & 1 & 1 \\
\hline Rural Dummy & 0.161 & 0.368 & 0 & 0 & 0 & 0 & 1 \\
\hline HHI & 0.230 & 0.245 & 0.015 & 0.053 & 0.157 & 0.358 & 1 \\
\hline $\begin{array}{l}\text { Median Household } \\
\text { Income in \$ }\end{array}$ & 47,586 & 10,346 & 30,915 & 40,007 & 44,360 & 53,564 & 74,557 \\
\hline $\begin{array}{l}\text { Log Median Household } \\
\text { Income }\end{array}$ & 10.748 & 0.212 & 10.339 & 10.597 & 10.700 & 10.889 & 11.219 \\
\hline
\end{tabular}

Notes to Table 5:

a The data are obtained from the OSHPD and the US Census Bureau. See Table 3 for variable definitions. 


\subsection{Results}

\subsubsection{Test of $\mathrm{H1}$}

Table 6 shows the results of estimating equation 1, which examines the likelihood of being convicted for upcoding. The negative and significant coefficient on the share of indigents $\left(\beta_{1}\right)$ and the resident-to-bed ratio $\left(\beta_{2}\right)$ indicates that hospitals that have a higher percentage of indigent patients and have a higher proportion of residents are less likely to be convicted for upcoding. Furthermore, the coefficient on the benchmark dummy is significant ( $p=0.096$, two-tailed) providing evidence that hospitals that have just met the zero earnings benchmark are more likely to be convicted for upcoding. These results are consistent with $\mathrm{H} 1$; regulators are less likely to convict hospitals that have higher performance on social goals. In addition, regulators are also more likely to convict hospitals that just meet the zero earnings benchmark. These results provide evidence that regulators have social preferences.

The control variables indicate that hospitals with higher ROA are more likely to be convicted for upcoding, indicating that regulators are less tolerant of hospitals with high financial performance that upcode. Hospitals that are members of a hospital system are more likely to be convicted, as are Church hospitals and hospitals that are located in less competitive areas. These hospitals have more market power in the community; therefore regulators likely scrutinize them to a greater extent to ensure that they do not misuse their market power to extract monopoly rent by upcoding. A higher case mix index also increases the likelihood of convictions. Higher case mix indicates a sicker patient pool and correspondingly higher information asymmetry, which increases the ability to upcode. These results indicate that regulators do scrutinize hospitals that have a higher potential to upcode. In sum, the results indicate that regulators not only are less likely to convict hospitals with higher performance on social goals, but also more likely to convict hospitals that have higher likelihood of upcoding for pecuniary benefits. 
Chapter 2

Table 6: Logistic regression estimation of the probability of being convicted for upcoding $^{\mathrm{a}}$

\begin{tabular}{|c|c|c|}
\hline Variables & Pred. & Conviction Dummy \\
\hline \multicolumn{3}{|l|}{ Social Motive Variables } \\
\hline \%Indigents & - & $-37.033^{* *}(0.020)$ \\
\hline Resident-to-Bed Ratio & - & $-4.895 * *(0.026)$ \\
\hline \multicolumn{3}{|l|}{ Pecuniary Motive Variables } \\
\hline Benchmark Dummy & + & $0.747 *(0.096)$ \\
\hline P4P Dummy & + & $0.410(0.386)$ \\
\hline \multicolumn{3}{|c|}{ Control Variables for Hospital Characteristics } \\
\hline ROA & & $6.165 *(0.097)$ \\
\hline Zscore & & $-0.131(0.442)$ \\
\hline \%Medicare & & $-0.253(0.901)$ \\
\hline CMI & & $3.116^{* *}(0.011)$ \\
\hline Log Discharges & & $-0.086(0.850)$ \\
\hline Log Boardsize & & $1.311(0.116)$ \\
\hline Church Dummy & & $1.854 * * *(<0.001)$ \\
\hline \multicolumn{3}{|c|}{ Control Variables for Hospital Market Characteristics } \\
\hline System Dummy & & $2.715^{* * *}(<0.001)$ \\
\hline Rural Dummy & & $-1.337(0.131)$ \\
\hline HHI & & $2.450 *(0.069)$ \\
\hline Log Median Household Income & & $0.135(0.927)$ \\
\hline Constant & & $-12.197(0.397)$ \\
\hline Year Dummies & & Yes \\
\hline Clustered by & & Hospital \\
\hline Observations & & 741 \\
\hline R-squared & & 0.373 \\
\hline
\end{tabular}

\section{Notes to Table 6:}

${ }^{a} p$-values in parentheses, $* * * p<0.01, * * p<0.05, * p<0.1$ (two-tailed), year dummies included but not reported, standard errors clustered by hospital, variables are winsorized at $1 \%$ and $99 \%$ levels. See Table 3 for variable definitions.

\subsubsection{Test of $\mathrm{H} 2$ and $\mathrm{H3}$}

Table 7 presents the results of estimating the system of three equations using SUR. Recall that $\mathrm{H} 2$ states that social goals are associated with upcoding and H3 states that depending on the underlying motive - upcoding occurs across the board or only in the high incentive DRG family. The results indicate a positive and significant coefficient on \%INDIGENTS $\left(\beta_{1}\right)$ for both the high and the medium incentive groups. These results indicate that hospitals use upcoding as a mechanism to cross-subsidize the cost of meeting their social goal of charity care. The coefficient on the resident-to-bed ratio $\left(\beta_{2}\right)$ is positive and significant for all three DRG families. These results are similar to the high charity care hospitals and indicate that teaching hospitals exhibit across the board upcoding. These results are consistent with $\mathrm{H} 2$ and indicate that there is a positive association between performance on social goals and revenue manipulation via upcoding. 
The results for the control variables related to pecuniary motives for upcoding show that the coefficient on the benchmark dummy is positive and significant $\left(\beta_{3}=0.008\right)$ for the high incentive DRG family (DRG79). Therefore, hospitals that have just met the zero income benchmark are more likely to have upcoded in the high incentive DRG family. However, hospitals that just met the earnings benchmark do not exhibit significant upcoding in the medium and low incentive DRGs. Thus, while these hospitals upcode to facilitate the achievement of their earnings targets, they apply a cautious strategy by upcoding selectively only in those DRGs where there is a large financial incentive from upcoding. They do not upcode across the board, likely due to the fear that regulators will detect such upcoding. Upcoding occurs across the board for hospitals with higher performance on social goals, whereas when the motive is to meet the zero earnings benchmark, upcoding occurs only in the high incentive DRG. These results are consistent with $\mathrm{H} 3$.

The incentive compensation variable ( $P 4 P D U M M Y)$ is not significantly different from zero. This result indicates that incentive compensation is not associated with higher upcoding. The results in Table 7 also indicate that hospitals located in more competitive markets upcode to a greater extent in the high incentive DRG group, which suggests that competition increases financial pressure and results in higher upcoding. Consistent with this finding our results also show that hospitals with a higher Z-score and thus a higher level of financial health engage in less upcoding in the high incentive DRG group. Higher CMI is associated with a higher upcoding ratio, consistent with these hospitals having a sicker patient pool and correspondingly higher information asymmetry, which increases the ability to upcode. Furthermore, we find evidence that hospital membership in a multi-hospital system is associated with a higher upcoding ratio in the high and low incentive DRG group. 
Table 7: Seemingly unrelated regression estimation of upcoding as a function of social goals for the time period 1999 to $2007^{\mathrm{a}}$

\begin{tabular}{|c|c|c|c|c|}
\hline Variables & Pred. & $\begin{array}{c}\text { DRG Ratio79 (High } \\
\text { Incentives) }\end{array}$ & $\begin{array}{l}\text { DRG Ratio144 } \\
\text { (Medium Incentives) }\end{array}$ & $\begin{array}{l}\text { DRG Ratio296 (Low } \\
\text { Incentives) }\end{array}$ \\
\hline \multicolumn{5}{|c|}{ Social Motive Variables } \\
\hline \%Indigents & + & $0.263 * * *(0.002)$ & $0.138 * *(0.038)$ & $0.032(0.707)$ \\
\hline $\begin{array}{l}\text { Resident-to-Bed } \\
\text { Ratio }\end{array}$ & + & $0.026 *(0.064)$ & $0.065 * * *(<0.001)$ & $0.024 *(0.085)$ \\
\hline \multicolumn{5}{|c|}{ Pecuniary Motive Variables } \\
\hline $\begin{array}{l}\text { Benchmark } \\
\text { Dummy }\end{array}$ & + & $0.008^{*}(0.080)$ & $-0.003(0.345)$ & $0.003(0.433)$ \\
\hline P4P Dummy & + & $-0.001(0.651)$ & $-0.002(0.270)$ & $-0.002(0.563)$ \\
\hline \multicolumn{5}{|c|}{ Control Variables for Patient Characteristics } \\
\hline DRG Ratio $\mathrm{X}_{\mathrm{t}-1}$ & & $0.726 * * *(<0.001)$ & $0.695 * * *(<0.001)$ & $0.500 * * *(<0.001)$ \\
\hline Charlson Index X & & $0.022 * * *(<0.001)$ & $0.004(0.239)$ & $0.033^{* * *}(<0.001)$ \\
\hline $\begin{array}{l}\text { Charlson Index } \\
\text { Indigents X }\end{array}$ & & $0.002(0.310)$ & $0.002(0.235)$ & $-0.001(0.970)$ \\
\hline Mortality Rate X & & $0.313^{* * *}(<0.001)$ & $0.461 * * *(<0.001)$ & $0.513^{* * *}(<0.001)$ \\
\hline \multicolumn{5}{|c|}{ Control Variables for Hospital Characteristics } \\
\hline $\mathrm{ROA}_{\mathrm{t}-1}$ & & $0.011(0.407)$ & $-0.007(0.505)$ & $-0.003(0.836)$ \\
\hline Zscore & & $-0.002 * *(0.022)$ & $-0.001(0.718)$ & $0.001(0.593)$ \\
\hline \%Medicare & & $0.013(0.256)$ & $-0.017 *(0.054)$ & $0.001(0.936)$ \\
\hline CMI & & $0.013 *(0.095)$ & $0.023 * * *(<0.001)$ & $0.010(0.232)$ \\
\hline Log Discharges & & $-0.002(0.328)$ & $0.004 * *(0.015)$ & $-0.009 * * *(<0.001)$ \\
\hline Log Boardsize & & $-0.001(0.893)$ & $0.004(0.103)$ & $0.001(0.954)$ \\
\hline Church Dummy & & $-0.005(0.211)$ & $-0.001(0.859)$ & $0.002(0.553)$ \\
\hline \multicolumn{5}{|c|}{ Control Variables for Hospital Market Characteristics } \\
\hline System Dummy & & $0.006 * *(0.046)$ & $0.002(0.339)$ & $0.010 * * *(<0.001)$ \\
\hline Rural Dummy & & $-0.004(0.456)$ & $-0.007 *(0.058)$ & $-0.007(0.183)$ \\
\hline HHI & & $-0.026 * * *(0.001)$ & $-0.001(0.848)$ & $0.007(0.364)$ \\
\hline $\begin{array}{l}\text { Log Median } \\
\text { Household } \\
\text { Income }\end{array}$ & & $0.0130 *(0.099)$ & $-0.006(0.347)$ & $-0.003(0.703)$ \\
\hline Constant & & $-0.208 * *(0.015)$ & $-0.043^{* *}(0.011)$ & $0.139(0.112)$ \\
\hline Year Dummies & & Yes & Yes & Yes \\
\hline Clustered by & & Hospital & Hospital & Hospital \\
\hline Observations & & 1,447 & 1,447 & 1,447 \\
\hline R-squared & & 0.704 & 0.744 & 0.455 \\
\hline
\end{tabular}

Notes to Table 7:

${ }^{a} p$-values in parentheses, $* * * p<0.01, * * p<0.05, * p<0.1$ (two-tailed), year dummies included but not reported, standard errors clustered by hospital, variables are winsorized at $1 \%$ and $99 \%$ levels. See Table 3 for variable definitions.

\subsubsection{Robustness tests}

To examine the robustness of our results, we re-estimate our model employing alternative measures for our independent variables. First, although the SUR estimation takes into consideration the possibility that the upcoding behaviors in the three DRG families are jointly determined, we also consider two-stage least squares (2SLS) as an 
alternate econometric specification (Wooldridge 2002). Specifically, the coding behavior for one DRG family (DRG RATIO X, where X could be DRG Ratio 79, DRG Ratio 144, or DRG Ratio 296) and the two other DRG families (DRG RATIO $Y$ and DRG RATIO Z, where Y and $\mathrm{Z}$ are the two other DRG families) might be jointly determined, leading to a potential simultaneous-equation bias. Hence, we also include the potentially endogenous dependent variables as control variables (DRG RATIO Y and $D R G$ RATIO Z) in our model.

To use 2SLS, we require instrumental variables (IVs) that are correlated with our potentially endogenous variables, i.e., DRG RATIO Y and DRG RATIO Z, but not with the error term (Wooldridge 2002). Thus, the instruments have to be relevant and exogenous. In our setting the Charlson index and the mortality rate are likely to meet the requirements for IVs. It seems reasonable that the average health status of DRG families $\mathrm{Y}$ and $\mathrm{Z}$, measured by the mortality rate and the Charlson index, are correlated with the coding outcome in these families (relevance) and, furthermore, not related to the coding outcome of DRG family X (exogeneity). Tests of the relevance and exogeneity of the instruments confirm that our instruments are valid. A Hausman (1978) test indicates no evidence of a simultaneity bias.

Next, we adjust our benchmark dummy and define hospitals whose net income divided by lagged total assets lies in the intervals [0, 0.01] and [0, 0.03], respectively, as having just met the benchmark. Applying these different intervals leads to qualitatively similar results. We also construct the P4P dummy by using change in net income and the standard deviation of net income over three years instead of ROA. Our results remain unchanged.

Furthermore, we apply two alternative measures to capture a hospital's provision of charity care in our model for H2 and H3. First, we limit our measure of share of indigent patients to those patients for which the hospital does not receive any money. Due to data limitations we can only apply this measure in the 1999-2007 period. Second, we use charity care as a percentage of total assets. Charity care includes all amounts which stem from the difference between established charges for services rendered and the amount paid by or on behalf of the patient, if any. The higher this share, the more costs the hospital faces from treating patients that cannot - or only partly - pay their bills. Applying these two alternative measures does not affect our results.

We also measure the extent of medical provision with a teaching dummy variable instead of the resident-to-bed ratio in our model for $\mathrm{H} 2$ and H3. Using the teaching dummy leads to qualitatively similar results.

We re-estimate the model using the percentage of Medicare patients treated by the hospital for each of the three specific DRG families (DRG79, DRG144, and DRG296) instead of the hospital-level percentage of Medicare patients. Using the percentage of Medicare patients for these specific DRG families ensures that our results are not driven 
by a family specific composition of patients insured by Medicare. Again, our results are unaffected by this alternative measure.

Finally, we re-estimate our system of three equations for the time period 19961998. As stated earlier, the report issued by the Department of Health and Human Services in 1998 revealed that regulators were aware of the upcoding strategies used by hospitals. However, during the time period 1996-1998, there was no reliable, public information about the information set of the regulators. Consequently, we expect the following. First, the overall level of upcoding is likely to be higher since the enforcement activities for the three high upcoding risk DRGs was not revealed to the hospitals. Second, there are unlikely to be differences across hospitals based on their performance on social goals because hospitals did not have information regarding the differential regulatory enforcement across hospital groups.

Perusal of the means in Tables 4 and 5 indicates that there was likely higher upcoding in the DRG79 and DRG296 families during 1996-1999 compared to 19992007 since the coding ratios are significantly higher in the 1996-1999 period ( $t$ values of difference are 8.089 and 6.007 respectively, $p<0.01$ ) and the Charlson index is significantly lower in the 1996-1999 period ( $t$ values of difference are 7.052 and 3.868 respectively, $p<0.01)$. For the DRG144 family the result is not that clear as both the coding ratio ( $t$ value of difference $=7.625, p<0.01)$ and the Charlson index ( $t$ value of difference $=9.161, p<0.01$ ) are significantly higher during 1999-2007 relative to 19961999. Second, a comparison of the estimation results in Table 7 and 8 indicates that the coefficients on the share of indigent patients are not significant in 1996-1998 and are individually and jointly significantly lower $(p<0.001)$ during 1996-1998 compared to 1999-2007, indicating that from 1996-1998 hospitals with a higher share of indigent patients were not more likely to upcode relative to the other hospitals. The coefficient on the benchmark dummy is also not significant for the high incentive DRG group, even though the coefficient does not differ significantly across time periods. Although the coefficients on the resident-to-bed ratio are larger during 1999-2007 compared to 19961998 (except for the coefficient in DRG family 79) the differences are not statistically significant. The significantly higher coding levels for the high and low incentive DRG groups $(p<0.001)$ in combination with a more healthy patient population, i.e., significantly lower Charlson indices $(p<0.001)$, in the time period 1996-1999 in comparison to the period 1999-2007 indicates that the overall upcoding level was likely higher in the time period 1996-1999. Overall, the results of our robustness test indicate that during the time period 1996-1998, there were no cross-sectional differences in upcoding behavior based on the underlying motives. 
The Interplay between Regulator Preferences and Organizational Motives for Revenue Manipulation

Table 8: Seemingly unrelated regression estimation of upcoding as a function of social goals for the time period 1996 to $1998^{\mathrm{a}}$

\begin{tabular}{|c|c|c|c|c|}
\hline Variables & Pred. & $\begin{array}{l}\text { DRG Ratio79 (High } \\
\text { Incentives) }\end{array}$ & $\begin{array}{l}\text { DRG Ratio144 } \\
\text { (Medium Incentives) }\end{array}$ & $\begin{array}{l}\text { DRG Ratio296 (Low } \\
\text { Incentives) }\end{array}$ \\
\hline \multicolumn{5}{|c|}{ Social Motive Variables } \\
\hline \%Indigents & + & $-0.030(0.869)$ & $-0.084(0.385)$ & $0.038(0.807)$ \\
\hline $\begin{array}{l}\text { Resident-to-Bed } \\
\text { Ratio }\end{array}$ & + & $0.053 *(0.054)$ & $0.033 * *(0.045)$ & $0.003(0.895)$ \\
\hline \multicolumn{5}{|c|}{ Pecuniary Motive Variables } \\
\hline $\begin{array}{l}\text { Benchmark } \\
\text { Dummy }\end{array}$ & + & $0.002(0.848)$ & $-0.007(0.172)$ & $-0.004(0.626)$ \\
\hline P4P Dummy & + & $-0.005(0.393)$ & $-0.001(0.824)$ & $-0.004(0.495)$ \\
\hline \multicolumn{5}{|c|}{ Control Variables for Patient Characteristics } \\
\hline DRG Ratio $\mathrm{X}_{\mathrm{t}-1}$ & & $0.705 * * *(<0.001)$ & $0.586 * * *(<0.001)$ & $0.468 * * *(<0.001)$ \\
\hline Charlson Index X & & $0.016 * *(0.035)$ & $-0.007(0.150)$ & $0.031 * * *(<0.001)$ \\
\hline $\begin{array}{l}\text { Charlson Index } \\
\text { Indigent X }\end{array}$ & & $0.003(0.180)$ & $0.002(0.389)$ & $0.004 *(0.069)$ \\
\hline Mortality Rate X & & $0.381^{* * *}(0.002)$ & $0.637 * * *(<0.001)$ & $0.290(0.171)$ \\
\hline \multicolumn{5}{|c|}{ Control Variables for Hospital Characteristics } \\
\hline $\mathrm{ROA}_{\mathrm{t}-1}$ & & $0.004(0.910)$ & $0.018(0.387)$ & $-0.026(0.413)$ \\
\hline Zscore & & $0.001(0.600)$ & $0.002 * *(0.029)$ & $0.001(0.503)$ \\
\hline \%Medicare & & $0.027(0.282)$ & $-0.018(0.193)$ & $0.022(0.319)$ \\
\hline CMI & & $0.023(0.224)$ & $0.036 * * *(0.001)$ & $0.039 * *(0.021)$ \\
\hline Log Discharges & & $-0.001(0.916)$ & $0.013 * * *(<0.001)$ & $-0.009 * *(0.032)$ \\
\hline Log Boardsize & & $-0.004(0.585)$ & $-0.005(0.235)$ & $-0.001(0.922)$ \\
\hline Church Dummy & & $0.012 *(0.096)$ & $0.006(0.127)$ & $0.014 * *(0.025)$ \\
\hline \multicolumn{5}{|c|}{ Control Variables for Hospital Market Characteristics } \\
\hline System Dummy & & $0.001(0.895)$ & $0.001(0.969)$ & $0.003(0.532)$ \\
\hline Rural Dummy & & $-0.013(0.255)$ & $0.005(0.408)$ & $0.001(0.929)$ \\
\hline HHI & & $-0.023(0.147)$ & $0.003(0.719)$ & $0.001(0.921)$ \\
\hline $\begin{array}{l}\text { Log Median } \\
\text { Household Income }\end{array}$ & & $-0.011(0.509)$ & $-0.002(0.804)$ & $0.004(0.777)$ \\
\hline Constant & & $0.093(0.616)$ & $-0.059(0.573)$ & $0.048(0.770)$ \\
\hline Year Dummies & & Yes & Yes & Yes \\
\hline Clustered by & & Hospital & Hospital & Hospital \\
\hline Observations & & 522 & 522 & 522 \\
\hline R-squared & & 0.697 & 0.674 & 0.444 \\
\hline
\end{tabular}

Notes to Table 8:

${ }^{a} p$-values in parentheses, $* * * p<0.01, * * p<0.05, * p<0.1$ (two-tailed), year dummies included but not reported, standard errors clustered by hospital, variables are winsorized at $1 \%$ and $99 \%$ levels. See Table 3 for variable definitions.

\subsection{Conclusions}

The nonprofit literature acknowledges that in addition to financial objectives, nonprofit hospitals also pursue social objectives such as charity care and medical education, even though such objectives are not financially beneficial. Although donations and subsidies may cover some of the cost of social objectives, there is often a resource gap. We investigate whether nonprofits use revenue manipulation as a 
mechanism to generate resources to meet their social objectives and whether this behavior is tacitly supported by regulators. The revenue manipulation we explore, i.e., "upcoding", involves classifying an ailment as more severe than it actually is to earn higher revenues.

Economic theory acknowledges that regulators have preferences, which can vary across and within consumer groups. However, typically these preferences have been studied from the perspective either of regulatory capture whereby the regulator starts operating for the benefit of the organization it is supposed to regulate, or from the perspective of the political economy of the supply of regulation to serve politicians' ambitions. Archival accounting research has used a much narrower perspective and has treated regulations as exogenously imposed and consistently applied to all organizations. Sociologists on the other hand have long recognized and documented the endogeneity between regulations and organizations, and the fact that there is a complicated and dynamic process by which organizations influence the regulation as well as draw boundaries regarding appropriate compliance - boundaries that can vary within and across industries. In this study, we explore such differentiated boundaries in the context of the hospital industry.

The health care industry has substantial distortions in the access to health care, which regulators likely perceive. However, fixed-price regulation prevents regulators from using the price mechanism to correct such distortions to access. We explore whether regulators' social preferences manifest in the form of lower convictions of hospitals that have higher performance on social goals. Our results indicate that hospitals with higher performance on social goals are less likely to be convicted for upcoding under the False Claims Act. This is consistent with sociology theory; through differential application of the False Claims Act, regulators provide hospitals with varying degrees of latitude in complying with the Act. We next empirically examine whether hospitals engage in revenue manipulation to meet two important social goals charity care and medical education. We find that the share of indigent patients and the provision of medical education is positively associated with upcoding. The leniency of regulators in convicting higher social performance hospitals coupled with the higher upcoding exhibited by these hospitals results in an implicit two-part pricing mechanism. That is, the regulatory process permits hospitals with high social performance to obtain higher prices for the same treatment basket in order to partially cross-subsidize the cost of social goals.

Our study has several limitations. First, we focus only on three DRG families. Including more DRG families in the analysis will indeed provide more complete results, but will greatly increase the complexity of the analysis because we need to account for interactions between these DRG families. We believe that the use of only three DRG families provides a conservative analysis because these DRG families are known for being prone to upcoding for over a decade. Second, although we include two measures to control for the patient health status, i.e., Charlson index and mortality rate, we cannot 
conclusively state that every case where there is a higher proportion of DRGs in the top of the DRG family is indeed upcoding. Finally, our analysis focuses only on California. However, our results should be generalizable to other nonprofit hospitals not only in the United States but also in countries that use DRG-type reimbursement systems such as Australia, Germany, The Netherlands, and the United Kingdom.

Our results indicate that regulators are likely to provide greater latitude to hospitals which exhibit higher performance on social goals. Indeed, the weaker regulatory enforcement likely serves as a signal of the greater legitimacy enjoyed by such hospitals. It would be fruitful to explore this issue in other industries. For example, research could explore whether firms that signal the importance of non-monetary goals such as environmental sustainability or employee learning (e.g., firms that communicate the importance of the triple bottom line), obtain some leniency from financial regulators such as the Securities and Exchange Commission (SEC).

It is possible that from a social welfare perspective, upcoding is a preferable method to meet the cost of providing indigent people with health care or providing medical education. The price elasticity of demand for insured patients is likely to be fairly low. Moreover, insured individuals may perceive the upcoding as a "tax", which helps in meeting important social needs. Alternatively, the government could also directly provide hospitals with additional subsidies (which would directly or indirectly lead to higher taxes). However, subsidies would not guarantee that the hospitals actually provide more indigent care, would not prevent upcoding, and would require additional monitoring costs for the government.

Our study contributes to the accounting literature by providing evidence that in nonprofit settings, revenue manipulation is used to generate resources to cross-subsidize the cost of pursuing objectives that are valuable for society. Furthermore, we find evidence that regulators also have social preferences and are less likely to convict hospitals that have demonstrated performance on social goals. Future research could explore reasons for variations in regulatory oversight in greater detail. 



\title{
Chapter 3
}

\section{The Role of Revenue Manipulation in the Trade-Off Decision between Performance Management Strategies}

\begin{abstract}
In this paper, I investigate the role of revenue manipulation (RM) in firms' performance management activities. In particular, I study how managers make trade-off decisions between revenue manipulation and two traditional manipulation strategies, i.e., accrual-based earnings management (AEM) and real activities manipulation (RAM). Revenue manipulation is a powerful tool since it (a) generates additional revenues, (b) does not increase costs, and (c) does not have to reverse in future years. I use a sample of for-profit hospitals and examine revenue manipulation via "upcoding”, i.e., classifying an ailment as more severe than it actually is to earn higher revenues without incurring commensurate costs. I find that managers incorporate revenue manipulation in their pool of manipulation strategies and trade off between these three strategies depending on the costs associated with each strategy. More precisely, I document that revenue manipulation is preferred over AEM (RAM) when RAM (AEM) is costly and that hospitals use AEM and RAM when RM is costly. Overall, my findings suggest that organizations with access to RM make different trade-off decisions than organizations that are limited to RAM and AEM.
\end{abstract}




\subsection{Introduction}

Accounting literature has extensively investigated firms' motives for managing their reported financial performance via accrual-based earnings management (AEM) and real activities manipulation (RAM) (Graham et al. 2005; Healy and Wahlen 1999; Roychowdhury 2006; Schipper 1989). Recently, accounting researchers have started to examine how firms make choices between these two strategies depending on the costs associated with each strategy (Badertscher 2011; Cohen et al. 2008; Cohen and Zarowin 2010; Zang 2012). Fraud scandals, however, indicate that firms' performance manipulation tools are not limited to AEM and RAM. In particular, many firms operating in various industries engage in overbilling practices as a form of revenue manipulation (RM) to boost their performance. For instance, companies such as Lend Lease, a US construction company (Rashbaum 2012), Holland \& Knight LLP, a US law firm (Koppel 2006), and Origin Energy, Australia’s largest power company (Thomas 2011), all overbilled clients.

In this study, I argue that, next to AEM and RAM, firms engage in revenue manipulation to manipulate their performance. Using a sample of for-profit hospitals, I hypothesize that hospital managers make trade-off decisions between these three different types of manipulation techniques based on the costs associated with each strategy.

Revenue manipulation has significant advantages over traditional manipulation techniques as - through revenue manipulation - firms can increase revenues without (1) altering operations, (2) affecting costs directly or (3) facing the need to reverse in the future (Heese et al. 2014). In contrast, RAM requires changing the firm's underlying operating activities such as the timing or structuring of an operation, investment, or financing transaction in an effort to alter current-period earnings (Gunny 2010; Roychowdhury 2006; Zang 2012). Unlike RAM, AEM involves judgment in the application and selection of reporting methods to manage earnings using accruals after fiscal year-end without changing the underlying operating activities of the firm and without generating a direct cash flow effect (Healy and Wahlen 1999; Schipper 1989). In addition, the application of RAM and AEM is very costly and constrained by many operational and financial circumstances such as the level of competition, a firm's financial health (Zang 2012), regulatory changes such as the Sarbanes-Oxley Act (SOX) (Cohen et al. 2008), and firms' accounting choices in prior periods (Baber et al. 2011; Barton and Simko 2002). Even though revenue manipulation can be applied in the longer term without increasing costs or changing operations and has a direct cash flow effect, it carries a considerable risk as its detection can lead to high reputational and financial costs including possible lawsuits. Thus, it is likely that managers will trade off between these three different strategies depending on the specific constraints they are facing.

The health care industry provides an attractive setting to investigate revenue manipulation and, consequently, hospital managers' trade-off decisions between these 
strategies for three reasons. First, hospitals have the possibility to manage their revenues by using discretion in coding their patients into diagnostic related groups or DRGs. ${ }^{30} \mathrm{By}$ “upcoding” a patient into a DRG that yields higher reimbursement from the Medicare system and other insurance companies, the hospital generates greater revenues. ${ }^{31}$ Since upcoding does not involve changing the treatment protocol that the patient receives but purely the patient's classification into a specific DRG, no additional costs incur. The factor that makes such behavior feasible and therefore difficult to detect is the information asymmetry between the provider (i.e., the hospital) and the payers (i.e., the insurance companies) as well as the patients. ${ }^{32}$ Second, due to the high scrutiny from various stakeholders such as patients, governmental agencies, hospital owners and donors in this highly regulated industry, hospitals are likely to pursue multiple objectives varying from economic viability to clinical quality (Eldenburg et al. 2004). Thus, hospitals are more likely to manipulate their performance on several dimensions and not just earnings. ${ }^{33}$ These multiple objectives generate a variety of incentives for managers to engage in performance manipulation making it likely to observe the application of these three tools in the cross-section. Finally, in contrast to most other industries data are available which allows the investigation of this performance manipulation tool.

In order to assess how managers make choices between the three performance management strategies, I examine the simultaneous use of these three tools for performance management. I hypothesize that managers apply revenue manipulation as an alternative manipulation tool when the costs for RAM and AEM are relatively high. Thus, I argue that throughout the year hospitals apply RM as a substitute to real activities manipulation, meaning that the benefits of RAM decrease with the use of RM (and vice versa), while at year-end the realized level of RM negatively affects the level of AEM conducted at fiscal year-end.

I empirically examine the hypotheses using 809 hospital-year observations from California for-profit hospitals for the period 1997 to 2007. Following prior studies, I investigate AEM using discretionary accruals (Jones 1991), RAM through cutting discretionary expenses in non-revenue generating and non-operating activities

\footnotetext{
30 DRGs identify patients with similar conditions and processes of care and requiring similar resources for treatment. Each DRG has a relative weight that compares its costliness to the average for all DRGs. These weights are used for reimbursement by various programs including Medicare and other public and private insurance programs (Folland et al. 1997).

${ }^{31}$ Upcoding is essentially a form of overbilling. Medicare is an insurance program for individuals over 65 years, is administered by the US government and financed by payroll taxes.

32 Most medical treatments involve considerable judgment on the part of the hospital and its staff regarding the optimal treatment protocol.

33 Thus, throughout the study I use the term "performance manipulation/management" instead of “earnings management" to address that hospitals manipulate their performance on several dimensions and not just earnings.
} 
(Eldenburg et al. 2011) and RM through the upcoding level of one DRG family that has been identified by the US Department of Health and Human Services (1998) as being prone to upcoding and as providing high financial incentives to upcode (Becker et al. 2005; Heese et al. 2014; Silverman and Skinner 2004). ${ }^{34}$

My results confirm that managers trade off between these three activities. More precisely, I show that throughout the year RM and RAM are direct substitutes and that at the end of the fiscal year, hospital managers engage in less AEM the more RM has been applied throughout the year. Thus, the results indicate that the use of RM as an alternative manipulation tool directly decreases the hospital's need to apply RAM and AEM. On the other hand, I document that the level of RAM at fiscal year-end is positively associated with the level of AEM applied at fiscal-year end, indicating that if a hospital resorts to RAM it is likely to also engage in more AEM.

Furthermore, I show that the trade-off decisions are driven by the operational constraints the hospital is facing. In particular, when hospitals face high competition or financial distress, which are considered constraints for RAM, hospitals increase RM, but not AEM. This finding indicates that RM is preferred over AEM in situations that potentially threaten an organization's survival. When AEM is constrained by prior accounting choices and regulatory changes such as the passage of SOX, I find that hospital managers resort to using more RM instead of RAM. On the other hand, hospitals that are constrained in applying $\mathrm{RM}$, as they have been convicted for upcoding, apply RAM and AEM instead of RM in the year of conviction, demonstrating the direct substitution between these strategies and the concurrent application of RAM and AEM. When RM via upcoding is constrained by a hospital's patient mix, managers replace RM with RAM indicating that hospitals need sufficient "room to upcode" to obtain larger financial gains and to conceal upcoding more thoroughly. Overall, my results suggest that organizations that have the opportunity to engage in revenue manipulation are likely to make different trade-off decisions in their performance manipulation than organizations that have only RAM and AEM at their disposal.

I contribute to the accounting literature in the following ways. First, I provide a more complete picture of the types of performance management tools that firms use to manipulate their performance by including revenue manipulation in the portfolio of manipulation strategies and showing that firms trade off between these strategies. Prior studies have either focused on real activities manipulation versus accrual-based earnings management (Cohen et al. 2008; Cohen and Zarowin 2010; Zang 2012) or have examined revenue manipulation in isolation without assessing its power and applicability in comparison to AEM and RAM (Dafny and Dranove 2009; Heese et al.

\footnotetext{
34 A DRG "family" is a group of DRGs that are associated with the same underlying body system. For example, Angina and Cardiac Arrhythmia belong to the same family, i.e., circulatory system disorders. Throughout the paper I use the terms DRG family and DRG group interchangeably.
} 
2014; Silverman and Skinner 2004; Soderstrom 1993). However, to get to definitive conclusions about the application and effect of the various performance management strategies, it is important to consider these strategies together (Fields et al. 2001). Second, I provide additional insights on the costs that determine managers' decisions to choose one of the three performance manipulation tools over the other (Zang 2012). Thus, my findings help to further understand which manipulation strategy firms choose depending on their operational environment. Finally, by documenting that the trade-off decisions of firms that have access to RM differ to firms' trade-off decisions that cannot engage in RM, I provide further evidence for the effectiveness and flexibility of revenue manipulation in comparison to AEM and RAM and emphasize the importance of considering firms' access to additional powerful tools to manage their performance.

The findings of this study also have important implications for regulators, auditors and investors by indicating the significant role of upcoding as an alternative, powerful instrument to manipulate financial performance, which can hardly be detected from financial reporting numbers. With respect to the health care industry, for auditors of hospitals' financial statements it might be important to incorporate the potential performance manipulation stemming from upcoding into their auditing processes in order to conduct a more thorough analysis of hospitals' reported figures. This study also provides a set of conditions that auditors of medical claims should incorporate in their assessment of which hospitals to investigate and a potential method to identify hospitals with abnormal billing behavior.

Section II explains revenue manipulation and reviews relevant prior studies on all three types of manipulation activities. Section III develops the hypotheses. Section IV presents the data and methodology while Section $\mathrm{V}$ provides the empirical results and additional robustness checks. Section VI concludes.

\subsection{Revenue Manipulation and Prior Earnings Management Literature}

In this study, revenue manipulation is defined as a performance manipulation tool to increase revenues without changing the firm's underlying operations, without affecting the firm's cost structure and without having to reverse in the future (Heese et al. 2014). ${ }^{35}$ However, significant information asymmetries between the firm and other parties have to exist in order for such revenue manipulation to go undetected.

\footnotetext{
35 The definition of revenue manipulation differs from the definition by Stubben (2010) who also uses the term revenue manipulation or revenue management. In Stubben's (2010) and related studies (Caylor 2010; Marquardt and Wiedman 2004; Plummer et al. 2001) revenue manipulation is either a specific form of accrual-based earnings management (e.g., revenues recognized using an aggressive or incorrect application of Generally Accepted Accounting Principles, fictitious revenues, and revenue deferrals) or a specific form of real activities manipulation (e.g., sales discounts, relaxed credit requirements, channel stuffing, and bill and hold sale).
} 
Information asymmetries are likely to be substantially higher in industries where the service provided is relatively complex and the assessment of optimal service is relatively opaque. This type of situation exists in the health care industry where hospitals can conduct revenue manipulation via upcoding.

Hospitals in the US receive about one third of their revenues from Medicare (Winter and Pettengill 2003). Under the Prospective Payment System (PPS) Medicare pays hospitals a fixed amount per patient treated depending on the patient's diagnosis related group or DRG. ${ }^{36}$ A hospital has to use judgment in assigning a patient to a DRG and even though this assignment is based on diagnoses and procedures, there is latitude in assigning a patient to one DRG versus the other. For example, suppose a patient is admitted with respiratory infections and does not exhibit any complicating factors. This patient should be assigned to DRG 80, and the hospital will on average receive $\$ 4,377.50$ reimbursement from Medicare for this DRG. To "upcode" the patient to DRG 79 , i.e., respiratory infections and inflammations with complications, the hospital has to add a complicating or comorbidity (cc) factor such as diabetes, high blood pressure, or asthma to the patient's medical record. By such upcoding, the hospital will obtain a reimbursement of $\$ 8,188.50$, which is a revenue gain of $\$ 3,811$ without any corresponding additional cost (CMS 2010; OIG 2001b). Thus, upcoding is an improper shift of a patient's DRG to obtain higher reimbursement from the Medicare system (Dafny and Dranove 2009; Silverman and Skinner 2004).

Revenue manipulation via upcoding also carries considerable risk. If such behavior is detected, the hospital may face high reputational as well as financial costs such as penalties and losses (Blount and Gold 1999). ${ }^{37}$ For instance, in 2000 HCA - The Healthcare Company, a US hospital chain, was convicted for unlawful billing practices and was sentenced to pay a fine of more than $\$ 840$ million (Crennen 2013). Therefore, hospital managers are likely to apply upcoding cautiously and trade off the costs and benefits each instance that it is applied. Accordingly, Becker et al. (2005) who investigate whether differences in the level of governmental enforcement activities across US states affect upcoding find that hospitals engage in less upcoding in states with higher levels of law enforcement.

Next to studies that examine the magnitude of upcoding (OIG 2001a; Psaty et al. 1999), another set of studies has tried to identify hospitals' motives to engage in upcoding. ${ }^{38}$ For instance, an early study by Soderstrom (1993) provides limited evidence that hospitals in poor financial condition and/or with higher marginal costs engage in more upcoding. Dafny and Dranove (2009) show that management teams that

\footnotetext{
${ }^{36}$ Although PPS was first developed for Medicare patients, soon DRG-based reimbursements were used by Medicaid as well as most major insurance companies (Reinhardt 2006).

37 Becker et al. (2005), Steinbusch et al. (2007) and Heese et al. (2014) provide more details on the (up)coding process in US hospitals, the extent of upcoding and Medicare's efforts to reduce upcoding.

${ }^{38}$ Heese et al. (2014) provide more details on studies that investigate the magnitude of upcoding.
} 
fail to exploit the upcoding potential are vulnerable to replacement. They also find that hospitals with new management teams upcode more than a sample of similar hospitals whose management did not get replaced. In a recent study, Heese et al. (2014) find that nonprofit hospitals apply upcoding to generate additional resources which are used to pursue non-monetary objectives such as the provision of charity care and medical education. Furthermore, they show that regulators are less likely to convict nonprofit hospitals that engage in these socially desirable objectives for upcoding.

While revenue manipulation via upcoding is an issue that is generally established in the health care sector, it has rarely been studied in the accounting literature or linked to other manipulation activities. In contrast, there is a huge literature in accounting on earnings management via accruals (Healy and Wahlen 1999; Schipper 1989) and a fast growing research stream on earnings management via real activities (Graham et al. 2005; Gunny 2010; Roychowdhury 2006). This literature has identified pressures resulting from capital markets such as meeting analysts' forecasts (Abarbanell and Lehavy 2003; Burgstahler and Eames 2006), avoiding losses (Burgstahler and Dichev 1997; Degeorge et al. 1999) or smoothing earnings (Barth et al. 1999; Degeorge et al. 1999) as some of the main drivers to engage in earnings management. Other motives to engage in earnings management are bonus payments (Healy 1985), reputation with stakeholders (Burgstahler and Dichev 1997) or managers' career concerns (Farrell and Whidbee 2003; Graham et al. 2005).

Studies in this field of research have found several factors that make the application of these strategies costly. AEM is limited by the quality of auditing since high-quality auditors more likely restrict managers' aggressive accounting estimates (Eldenburg et al. 2011; Zang 2012). Related to that, also the passage of SOX, which heightened scrutiny of firms' accounting practices from both auditors and regulators, further limit AEM (Zang 2012; Cohen et al. 2008). Next, accruals have to reverse in the future and thus prior accounting choices restrict the applicability of AEM in the current period (Baber et al. 2011; Barton and Simko 2002; Healy 1985). In addition, AEM is risky because if detected, it can reduce firm value (Healy and Wahlen 1999). However, AEM is not always effective since investors are not necessarily fooled by that strategy (Healy and Wahlen 1999). RAM, on the other hand, can be costly as well as timeconsuming since the underlying operational activities have to be adjusted leading to a deviation from optimal operations (Graham et al. 2005). For instance, adjusting expenses in the short-run might have negative long-run consequences with respect to quality or reputation (Leone and Van Horn 2005) and is especially costly in situations of high competition and poor financial health (Zang 2012). Furthermore, changes in the operating activities have to be implementable in the short term and must have an immediate impact on accounting performance (Eldenburg et al. 2011), limiting the potential set of RAM measures to a few specific ones.

Most previous research on AEM and RAM only examines one of these earnings management tools in settings where earnings management is likely to occur (Eldenburg 
et al. 2011; Gunny 2010; Healy 1985). Recent research streams, however, have started to acknowledge that, given the portfolio of earnings management strategies, managers use multiple techniques (at the same time) and trade off between these instruments depending on the costliness of the respective strategy. For instance, Graham et al. (2005), who surveyed more than 400 executives, document that managers rather apply RAM than AEM to manage earnings. In a recent survey, Dichev et al. (2012) confirm these findings. Their survey of CFOs shows that earnings are often managed using real actions and engaging in these actions is value-decreasing. Also several studies focusing on specific manipulation motives provide evidence consistent with these results. Cohen et al. (2008) find that following the passage of SOX accrual-based earnings management declined, while real activities manipulation increased. These results suggest that firms switched to managing earnings using RAM, possibly because this strategy, while more costly, is likely more difficult to be detected (Cohen et al. 2008). Studying overvaluation as an incentive for earnings management, Badertscher (2011) finds that managers engage in within-GAAP accrual-based earnings management in the early stages of overvaluation before moving to real activities manipulation, in order to sustain their overvalued equity. He also finds that the longer a firm is overvalued, the more likely it is to engage in non-GAAP earnings management. Furthermore, Cohen and Zarowin (2010) show that firms' choices of RAM versus AEM around SEOs vary as a function of the firm's ability to use AEM and the costs of doing so. Finally, Zang (2012) provides systematic evidence on the trade-off decision between RAM and AEM based on the relative costs of these strategies and the sequential nature.

With respect to the hospital industry, which includes for-profit, nonprofit and government-owned hospitals, prior research has shown that a hospital's objective is likely to be a function of various factors. ${ }^{39}$ For instance, nonprofit and for-profit hospitals care about economic viability but also about clinical quality and patient satisfaction (Eldenburg et al. 2004). Accordingly, also nonprofit hospitals incorporate accounting measures of performance in their CEO compensation contracts (Eldenburg et al. 2012) and managers of these hospitals engage in accrual-based earnings management and real activities manipulation to beat the zero earnings benchmark and to increase their performance-based bonus (Eldenburg et al. 2011; Leone and Van Horn 2005). Nonprofit hospitals often also focus on additional costly objectives such as the provision of care for indigents and medical education (Frank and Salkever 1994) and engage in revenue manipulation to generate resources to pursue these objectives (Heese et al. 2014). However, Norton and Staiger (1994) find that for-profit and nonprofit hospitals serve an equivalent number of uninsured patients when they are located in the

\footnotetext{
39 I focus my discussion on for-profit and nonprofit hospitals since government-owned hospitals, in contrast to their nonprofit and for-profit counterparts, receive funding from the government to assure their survival (Eldenburg et al. 2004).
} 
same area, indicating that these additional motives might also be present in for-profit hospitals.

\subsection{Hypotheses Development}

As explained in the previous section, recent accounting research has begun to acknowledge that managers have a portfolio of tools to manipulate their financial performance. These studies, however, have limited the examination of performance management tools to the use of accounting and real operating measures. Following the findings of earlier studies on multiple earnings management strategies, I predict that managers use revenue manipulation as a substitute for real activities manipulation and accrual-based earnings management. With respect to the three performance management strategies, I argue that throughout the year hospitals apply RM as a substitute to real activities manipulation, while at year-end the realized level of RM negatively affects the level of AEM conducted after fiscal year-end. Furthermore, I claim that the trade-off decision to apply revenue manipulation instead of real activities manipulation or accrual-based earnings management is based on the relative costliness of the three methods. This relative costliness is a function of (1) the hospital's incentives for performance manipulation, and (2) the hospital's constraints for applying a specific strategy. ${ }^{40}$

Before analyzing the costliness of each manipulation strategy based on their specific constraints, it is important to consider two fundamental differences between these three strategies, i.e., the strategies' timing difference and cash flow effect. While revenue manipulation and real activities manipulation have to be conducted throughout the fiscal year, accrual-based earnings management is conducted after fiscal year-end. Therefore, managers simultaneously decide whether to apply RAM or RM, whereas the decision to apply AEM is dependent on the effectiveness of applying RAM or RM. With respect to the cash flow effect both RAM and RM have a direct cash flow effect in the sense that revenue manipulation increases revenues and holds costs constant while real activities manipulation decreases costs and holds revenues constant (at least in the short term). In contrast, accrual-based earnings management does not lead to a direct cash flow effect, making it possibly more constrained for some performance management purposes. These two fundamental differences shape to a large extent the applicability of these three strategies when hospitals face the specific incentives and constraints.

\footnotetext{
40 The literature on potential motives for performance manipulation has been discussed in the prior section. Since the focus of this study is on the hospital's constraints for applying any of these three manipulation strategies, I control for all of these motives rather than formulating hypotheses. However, it is important to keep in mind that hospitals are likely to manipulate their performance on various dimensions and not just earnings.
} 


\subsubsection{Constraints for performance management strategies}

With respect to the constraints, I first investigate whether managers apply RM instead of RAM and AEM in situations where the constraints for these latter two strategies are present. Prior literature has shown that the competitive environment as well as the financial condition of an organization constrain the applicability of RAM (Zang 2012), while the use of AEM has been found to be constrained by prior accounting choices and the passage of SOX (Barton and Simko 2002; Cohen et al. 2008). Second, I identify hospitals that have been convicted for revenue manipulation via upcoding under the False Claims Act and a hospital's patient or customer mix as constraints for RM and examine how these constraints shape the application of the three strategies. $^{41}$

\subsubsection{Constraints associated with real activities manipulation}

The application of real activities manipulation has generally been shown to be constrained by the level of competition (Zang 2012). Higher levels of competition are likely to reduce the bargaining power with suppliers and customers, the attention from investors, and the influence on competitors (Woo 1983). Thus, competition decreases equilibrium profit levels (Raith 2003; Tinaikar and Xue 2009) and can ultimately lead to a higher takeover (Kole and Lehn 1997) and liquidation risk (Schmidt 1997; Shleifer 2004). In the health care industry, for instance, over 45 percent of all US hospitals have been involved in mergers and acquisitions since 1990 (Jaspen 1998). The application of RAM requires changing the operating activities, which potentially leads to a deviation from optimal operations (Graham et al. 2005). This deviation becomes more costly when facing higher levels of competition. Consistently, Zang (2012) finds that benchmark beating firms are more likely to apply AEM instead of RAM in situations of intense competition.

However, Zang ignores that also AEM might be constrained by intense competition. For instance, Marciukaityte and Park (2009) argue that in a competitive environment firms are less likely to engage in AEM since firms are more harshly punished by the stock market when the market learns about the earnings manipulation. ${ }^{42}$ Hospitals might also be punished by other stakeholders. For instance, Yetman and

\footnotetext{
${ }^{41}$ The False Claims Act (31 U.S.C. §§ 3729 - 3733) is an US federal law that imposes liability on persons and companies who defraud governmental programs such as Medicare. The Act allows people to file actions on behalf of the government and provides them with a share of any recovered damages. After a lawsuit is filed the US Department of Justice assesses whether it will pursue the case (DOJ 2012).

42 I acknowledge that other studies, e.g., by Tinaikar and Xue (2009), state that conducting AEM might be particularly rewarding in more competitive markets since the boost in market value of reporting higher earnings might be especially important. Markarian and Santalo (2009) find that either of the latter two effects can dominate depending on the shareholders' information on real firm output.
} 
Yetman (2013) find that the average donor reduces donations to hospitals with low quality accounting information.

Revenue manipulation is not directly constrained in the above mentioned respects, making it potentially the least costly instrument of performance manipulation in situations of high competition. In contrast to RAM, revenue manipulation allows the hospital to manage its performance without deviating from optimal business conduct since operations remain unchanged. In comparison to AEM, revenue manipulation provides the hospital with additional resources which can be used to reduce the impact of the various pressures and risks stemming from intense competition. Therefore, I argue that managers of hospitals operating in highly competitive markets perceive revenue manipulation as the least costly tool. Hence, I hypothesize the following:

\section{Hypothesis 1a: Hospitals with a lower market share have a higher level of revenue manipulation.}

In comparison to intense competition, financial distress can pose an even more severe constraint for certain manipulation strategies since distress directly threatens the organization's survival, while competition might lead to a situation that threatens survival. In line with this argumentation, the survey by Graham et al. (2005) shows that managers of firms in poor financial health focus especially on surviving. For firms that are in such a "negative tailspin" (Graham et al. 2005), the marginal cost of deviating from optimal business operations is likely to be especially high. Thus, managers might perceive real activities manipulation as too costly and therefore choose to conduct accrual-based earnings management instead (Zang 2012). However, conducting AEM might also be constrained by financial distress since auditors of financially distressed firms are likely to prefer conservative accounting choices to protect themselves against future litigation (DeFond and Subramanyam 1998). In much the same manner as for higher levels of competition, revenue manipulation via upcoding provides the hospital with actual additional resources which can be used to reduce the impact of financial distress (Soderstrom 1993). Thus, I argue that, in situations of financial distress, managers perceive revenue manipulation as the least costly tool. This reasoning leads to the following subsidiary hypothesis to $\mathrm{H} 1$ :

\section{Hypothesis 1b: Hospitals with poor financial health have a higher level of revenue manipulation.}

\subsubsection{Constraints associated with accrual-based earnings management}

Prior research has extensively shown that accrual-based earnings management is constrained by the available accounting flexibility (Baber et al. 2011; Barton and Simko 
2002) and auditors' scrutiny (Cohen et al. 2008). More precisely, prior years' accounting choices limit the firm's flexibility to apply AEM due to the need of accruals to reverse and the related increased risk of detection. In addition, with the passage of the Sarbanes-Oxley Act regulators have heightened the scrutiny towards firms' accounting choices, limiting the applicability of AEM (Cohen et al. 2008; Zang 2012). Consistent with this argument, prior studies have shown that these constraints lead managers to apply more RAM (Cohen et al. 2008; Zang 2012). ${ }^{43}$

However, RAM requires the hospital to change its operations, while RM does not. Therefore, managers may prefer applying more RM via upcoding instead of RAM. Especially after the passage of SOX, which permanently heightened scrutiny towards firms' accounting choices, RM is likely to be less costly than constantly applying RAM. In contrast, prior years' accounting choices only limit AEM in the short-term. Given that revenue manipulation bears a lot of risks if detected, RAM is potentially less costly if it is only applied in the short-term. Thus, I predict that managers switch to RAM when facing short-term AEM constraints such as prior years' accounting choices but apply RM after a permanent regulatory change such as SOX. Hence, I state the following hypotheses:

\section{Hypothesis 1c: Hospitals facing greater scrutiny from regulators have a higher level of revenue manipulation.}

\section{Hypothesis 1d: Hospitals with lower accounting flexibility have a higher level of real activities manipulation.}

\subsubsection{Constraints associated with revenue manipulation}

Even though upcoding can potentially provide the hospital with a very powerful instrument for revenue manipulation, hospitals also face several constraints for applying this strategy. First, RM carries the highest legal costs of all three manipulation strategies since its application mainly requires abusive or fraudulent behavior in the form of "wrong" coding of patients. If upcoding is detected, hospitals are confronted with significant fines (Crennen 2013). On the other hand, while AEM includes activities that are within-GAAP and are thus non-fraudulent, it also encompasses activities that are non-GAAP conform and thus have a fraudulent character. RAM, on the contrary, does not require adjusting or violating any rules since the manager merely reports how he has changed the operations. Therefore, hospitals that are constrained by regulatory scrutiny

\footnotetext{
43 Although SOX applies to listed corporations it has affected the corporate governance mechanism of hospitals as well (Alexander and Lee 2006).
} 
to apply upcoding are more likely to resort to RAM as it is the only non-fraudulent instrument for financial manipulation. Furthermore, unlike AEM, RAM offers a direct cash flow effect by decreasing costs and holding revenues constant, making it a more attractive substitute for RM. Thus, I argue that hospitals that have been convicted for upcoding will refrain from using this strategy (at least in the short term) since regulators and other stakeholders will pay special attention to the coding behavior of these hospitals. Instead they will apply RAM to a larger extent, leading to the following hypothesis:

\section{Hypothesis 1e: Hospitals that have been convicted for upcoding have a higher level of real activities manipulation.}

In addition to the aforementioned legal constraint, revenue manipulation via upcoding is constrained by a hospital's patient mix. More precisely, to conduct upcoding the health insurance company has to reimburse the hospital based on the DRG system. Since only inpatient reimbursement is linked to this classification system only inpatients can be upcoded (Steinbusch et al. 2007). Next to affecting the potential financial gains from upcoding, the composition of the customer mix also impacts the hospital's detection risk as a larger inpatient population decreases this risk. Therefore, hospitals may be limited to using AEM or RAM instead. However, similar to RM, only RAM has the potential to generate direct cash flows. Therefore, I expect hospitals to use RAM instead of RM. In particular, I argue that the smaller the hospital's inpatient population is, the less it has "room" to upcode, leading to higher levels of real activities manipulation. This discussion is summarized in the following hypothesis:

\section{Hypothesis 1f: Hospitals with a smaller share of inpatients have a higher level of real activities manipulation.}

\subsubsection{The direct trade-off decision between different performance management strategies}

Following the above argumentation, I predict that the trade-off decision between these strategies depends on their relative costliness, which is driven by the respective incentives and constraints. It also implies that RM has a wider applicability and lower costs in comparison to the other two manipulation strategies. Therefore, I argue that in 
the presence of the above mentioned incentives and constraints, the more the hospital can benefit from revenue manipulation, the less it uses RAM or AEM. More precisely, I predict that conditional on the incentives and constraints managers apply RM and RAM as substitutes. Substitution means that the benefits of applying one strategy decrease with the use of another (and vice versa) (Grabner and Moers 2013). It also implies that the choice of one strategy depends on the use of the other one as well as the incentives and constraints (Grabner and Moers 2013).

Consequently, I argue that, while RAM and RM are used as substitutes, managers further incorporate the effectiveness of RAM and RM in their AEM decision at the end of the financial year, and thus predict a unidirectional relationship between RM or RAM and AEM. This unidirectional relationship would imply that the realized levels of RM and RAM at fiscal year-end impact the level of AEM. Therefore, I hypothesize the following:

\section{Hypothesis 2a: Real activities manipulation and revenue manipulation are substitutes.}

\section{Hypothesis 2b: The level of accrual-based earnings management is negatively related to the amount of realized real activities manipulation and revenue manipulation.}

\subsection{Data and Methodology}

\subsubsection{Data}

I use data from for-profit hospitals in California to test the hypotheses. California was chosen for several reasons. First, California is one of the biggest hospital markets in the US with a large number of for-profit hospitals. Second, focusing only on one state controls for inter-state variations in enforcement activities. Third, detailed data on hospitals' financials and patients are available for California hospitals, allowing me to study all three types of manipulation strategies. ${ }^{44}$

I collect financial and patient data from all general acute care for-profit hospitals located in California from the Office of Statewide Health Planning and Development for the time period 1997 to 2007. I focus on general acute care hospitals and exclude specialty hospitals such as children's hospitals, substance abuse hospitals, and psychiatric hospitals since reimbursement rates, production functions, and patient mixes

\footnotetext{
${ }^{44}$ California hospitals are required to provide the state Office of Statewide Health Planning and Development (OSHPD) with financial statements that have to conform to US Generally Accepted Accounting Principles.
} 
differ at these hospitals relative to general acute care hospitals (Eldenburg et al. 2011). I study for-profit hospitals due to three reasons. First, prior research has shown that forprofits apply all three types of performance management strategies (Healy and Wahlen 1999; Roychowdhury 2006; Silverman and Skinner 2004; Zang 2012). Second, studying for-profit hospitals makes my results more comparable to prior research that investigates earnings management of for-profit firms in other industries. Third, in contrast to nonprofit and government-owned hospitals (Hoerger 1991; Leone and Van Horn 2005), for-profit hospitals aim to maximize earnings making it easier to predict for-profits' trade-off behavior across the three types of manipulation strategies. I choose the 1997-2007 time period due to limitations in the availability of patient level data before 1997 and due to the introduction of new Medicare Severity DRGs (MS-DRGs) after 2007 (CMS 2010). Since these new MS-DRGs differ significantly from the old DRGs, it would be difficult to compare the coding behavior across these two systems.

Following prior research (Becker et al. 2005; Heese et al. 2014; Silverman and Skinner 2004), I examine upcoding for one DRG family, i.e., general respiratory ailments (DRG79), that is prone to upcoding (OIG 1998). ${ }^{45}$ The upcoding potential of this DRG family stems from three reasons. First, the individual DRGs belonging to this family are relatively similar from a medical point of view; therefore it is easier for the hospital to make a case that the DRG assignment was based on medical judgment rather than for financial benefit. Second, this DRG family provides strong financial incentives to upcode (see Table 1, Panel B). Third, general respiratory ailments or pneumonia are a very common illness. Thus, hospitals treat on average a large number of patients with this illness; making it easier to hide upcoding. On the other hand, using this DRG family in my analyses likely provides me with a conservative measure of upcoding because I focus on a DRG family that is known as being prone to upcoding for over a decade. Therefore, enforcement actions are likely to be high for this DRG family, reducing the extent of upcoding.

Table 1 provides an overview of DRG79 and the implied financial incentives that can be obtained from upcoding. ${ }^{46}$ These financial incentives are a function of the weight of each DRG. ${ }^{47}$ To calculate the specific upcoding incentive in dollars I apply the hospital's base rate for a DRG weight of 1 . This rate is adjusted for area specific wage differences and thus differs across hospitals. The average base rate for the year 2005 for

\footnotetext{
45 The name DRG79 indicates the DRG with the highest weight within the family. For a detailed description of DRG79 see Silverman and Skinner (2004). The US Department of Health and Human Services (1998) used blinded case reviews by coding experts and found that 35\% of DRG79 claims were upcoded in 1996.

46 This table has been adopted from Heese et al. (2014).

47 CMS assigns a unique weight to each DRG. The weight reflects the average level of resources for an average Medicare patient belonging to the DRG, relative to the average level of resources for all Medicare patients. The weights are intended to account for cost variations between different types of treatments. More expensive conditions are assigned higher DRG weights (OIG 2001b).
} 
Chapter 3

a DRG weight of 1 is $\$ 5,150$ and is relatively constant during the time of my study (CMS 2010; OIG 2001b). ${ }^{48}$ I use this rate as the base for the dollar values reported in Table 1, Panel B. As can be seen from Table 1, Panel B hospitals can generate up to about $\$ 5,000$ by upcoding patients within DRG79.

${ }^{48}$ For a detailed example how a specific payment per case is set up see OIG (2001b). 
Table 1: Overview of DRG monetary incentives

Panel A: Description of DRG group 79

\begin{tabular}{|c|c|c|c|c|}
\hline $\begin{array}{c}\text { Incentive } \\
\text { Classification of } \\
\text { DRG Family }^{\mathrm{a}}\end{array}$ & $\begin{array}{c}\text { DRG Number } \\
\text { (based on ICD-9- } \\
\text { CM) }\end{array}$ & Description & $\begin{array}{l}\text { DRG } \\
\text { Weight }^{c}\end{array}$ & $\begin{array}{c}\text { Medicare } \\
\text { Revenue } \\
\text { Estimated } \\
{(\$ \$)^{d}}^{d}\end{array}$ \\
\hline \multirow{4}{*}{$\begin{array}{c}\text { High Incentives } \\
\text { Family (General } \\
\text { Respiratory } \\
\text { Ailments) }\end{array}$} & 79 (TOP) & $\begin{array}{c}\text { Respiratory infections and } \\
\text { inflammations with complications }\end{array}$ & 1.59 & $8,188.50$ \\
\hline & 80 & $\begin{array}{l}\text { Respiratory infections without } \\
\text { complications }\end{array}$ & 0.85 & $4,377.50$ \\
\hline & 89 & Pneumonia with complications & 1.05 & $5,407.50$ \\
\hline & 90 & Pneumonia without complications & 0.62 & $3,193.00$ \\
\hline
\end{tabular}

\section{Panel B: Monetary incentives for DRG group 79}

\begin{tabular}{|c|c|c|c|c|c|c|}
\hline DRG Family & $\begin{array}{c}\text { Difference } \\
\text { between Top } \\
\text { DRG and } \\
\text { Family } \\
\text { Average }^{\text {e }} \\
\end{array}$ & $\begin{array}{c}\text { Average } \\
\text { Payment } \\
\text { Incentive } \\
(\$)^{f}\end{array}$ & $\begin{array}{c}\text { Max. } \\
\text { Difference }^{\mathrm{g}}\end{array}$ & $\begin{array}{c}\text { Max. } \\
\text { Payment } \\
\text { Incentive } \\
(\$)^{\mathbf{h}}\end{array}$ & $\begin{array}{c}\text { Min. } \\
\text { Difference }^{\mathrm{i}}\end{array}$ & $\begin{array}{c}\text { Min. } \\
\text { Payment } \\
\text { Incentive } \\
(\$)^{\mathrm{j}}\end{array}$ \\
\hline $\begin{array}{c}\text { General } \\
\text { Respiratory } \\
\text { Ailments }\end{array}$ & 0.75 & $3,862.50$ & 0.97 & $4,995.50$ & 0.54 & $2,781.00$ \\
\hline
\end{tabular}

\section{Notes to Table 1:}

${ }^{a}$ Based on the financial benefit from upcoding from one of the lower revenue DRG numbers to the highest revenue DRG number.

b "TOP" refers to the DRG that generates the highest revenue in the DRG family. ICD-9-CM refers to the International Classification of Diseases, Ninth Revision, Clinical Modification. This classification is used to assign diagnostic and procedure codes associated with inpatient, outpatient, and physician office utilization in the United States.

${ }^{c}$ Refers to the weight assigned by CMS to each DRG. The weight reflects the average level of resources for an average Medicare patient belonging to the DRG, relative to the average level of resources for all Medicare patients. The weights are intended to account for cost variations between different types of treatments. More expensive conditions are assigned higher DRG weights.

${ }^{\mathrm{d}}$ Refers to the revenue estimate per DRG in dollar calculated as the DRG weight times the average base rate for the year 2005 for a DRG weight of $1(\$ 5,150)$.

e Computed as the difference between the TOP DRG weight and the average DRG weight of the other DRGs in the family.

${ }^{\mathrm{f}}$ Computed as the average difference between TOP DRG weight and family average weight in dollars, i.e., difference in weight times the average base rate for the year 2005 for a DRG weight of $1(\$ 5,150)$.

${ }^{g}$ Computed as the difference between the TOP DRG weight and the lowest DRG weight per family.

${ }^{\mathrm{h}}$ Computed as the maximum difference between TOP DRG weight and lowest DRG weight per family in dollar, i.e., difference in weight times the average base rate for the year 2005 for a DRG weight of $1(\$ 5,150)$.

${ }^{\mathrm{i}}$ Computed as the difference between the TOP DRG weight and the second highest DRG weight per family.

${ }^{j}$ Computed as the minimum difference between TOP DRG weight and second highest DRG weight per family in dollar, i.e., difference in weight times the average base rate for the year 2005 for a DRG weight of 1 $(\$ 5,150)$. 


\subsubsection{Methodology}

\subsubsection{Measurement of revenue manipulation}

To investigate upcoding behavior I follow the methodology applied in the AEM and RAM literature. I express a hospital's appropriate coding behavior as a linear function of the health status of patients treated within DRG79 in the current period. The patients' health status is operationalized by the Charlson index and the mortality rate. To estimate the model, I run the following cross-sectional regression for every year $t$ :

DRG Ratio 79 $=\beta_{0}+\beta_{1}$ Charlson Index ${ }_{t}+\beta_{2}$ Mortality Rate $_{t}+e_{t}$

where DRG RATIO $79_{t}$ is calculated as the ratio of the number of patients coded into the Top DRG divided by the sum of patients discharged from all DRGs within the family. The Charlson index (CHARLSON INDEX $)$ captures the weighted average of a patient's health status within the DRG family (Charlson et al. 1987). The index assigns weights $(1,2,3,6)$ based on comorbidity (e.g., weight 1 for diabetes, weight 6 for metastatic solid tumor) and age ( 0 to 5 ; where 1 point is assigned for each decade starting at 50, e.g., 40 to $49=0 ; 50$ to $59=1$ ). The weighting is based on the number of patients per DRG within the family. The underlying idea of the Charlson index is that the more severely ill the patients (i.e., the higher the index) the more likely it is to have patients in the Top DRG of the DRG family. ${ }^{49}$ If the documentation of comorbidities is adjusted by hospitals to justify their coding choice to Medicare and other insurance companies (CMS 2004; Silverman and Skinner 2004), then including the Charlson index as a control leads to an understatement of the real upcoding behavior. Thus, my measure of upcoding is conservative. In addition, physicians might have incentives to engage in upcoding to increase their personal income. However, physicians can only influence the coding process by adjusting the patient documentation. Thus, including the Charlson index also controls for that behavior.

The mortality rate (MORTALITY RATE $)_{t}$ reflects the proportion of patients that died within a specific DRG while staying at the hospital. This rate also captures the health status of the patient population and also controls for the appropriateness of the coding scheme. The residuals from model 1 represent an estimate of the extent of revenue manipulation via upcoding as they contain the abnormal level of coding behavior (denoted as RM).

\footnotetext{
49 The Top DRG represents the most severe illness and is assigned the highest weight.
} 


\subsubsection{Measurement of real activities manipulation}

Following Eldenburg et al. (2011), I examine manipulation of real activities in two types of activities: increasing earnings by reducing costs of (1) non-revenue generating activities such as advertising expenditures, general services or public relations and (2) non-operating activities such as curtailing spending to maintain or refurbish office space rented to physicians. Eldenburg et al. (2011) find that hospitals especially focus on these activities to manipulate their earnings since these activities do not directly affect the core activities of the hospital. I follow Roychowdhury (2006) and estimate the normal level of non-revenue generating activities and non-operating activities using the following equations for every year $t$ :

$\operatorname{EXP}_{t}=\beta_{0}+\beta_{1}\left(1 / A_{t-1}\right)+\beta_{2}\left(S_{t-1} / A_{t-1}\right)+e_{t}$

$\mathrm{NOCC}_{t}=\beta_{0}+\beta_{1}\left(1 / A_{t-1}\right)+\beta_{2}\left(S_{t-1} / A_{t-1}\right)+e_{t}$

where $E X P_{t}$ are the expenditures on non-revenue generating activities (i.e., the sum of total research expenditures, total administrative services, total general services, and total education expenditures) in year $t ; N O C C_{t}$ are the expenditures on non-operating activities (i.e., the sum of total maintenance expenditures, physicians' offices and other rentals expenditures, total office building expenditures, child care services expenditures, family housing expenditures, retail operations expenditures, and other non-operating expenditures) in year $t$; $A_{t-1}$ is total assets in year $t-1$; and $S_{t-1}$ is net sales or revenues in year $t-1$.

The abnormal level of these expenditures is measured as the estimated residuals from these regressions. I multiply the residuals by -1 such that higher values indicate greater cuts in non-revenue generating or non-operating activities to increase earnings. As a next step, I take the sum of these two residuals to create one proxy for real activities manipulation (denoted as RAM).

\subsubsection{Measurement of accrual-based earnings management}

Following prior literature, I use discretionary accruals to proxy for AEM. Discretionary accruals are the difference between firms' actual accruals and the normal level of accruals. Similar to Leone and Van Horn (2005), who study AEM in hospitals, I estimate the latter using the following Jones (1991) model for every year $t$ :

ACCRUALS $/ A_{t-1}=\beta_{0}+\beta_{1}\left(1 / A_{t-1}\right)+\beta_{2} \frac{\Delta S_{t}}{A_{t-1}}+\beta_{3} \frac{P^{2 P E} t}{A_{t-1}}+e_{t}$

where ACCRUALS $S_{t}$ equals noncash working capital accruals as in Allen et al. (2013) and Richardson et al. (2005) in year $t ; \Delta S_{t}$ is change in net patient revenue; and 
$P P E_{t}$ is the gross property, plant, and equipment. ${ }^{50}$ The estimated residuals (AEM) are my proxy for AEM.

\subsubsection{The trade-off between revenue manipulation, real activities manipulation and accrual-based earnings management}

Following Zang (2012), I estimate the following equations to investigate how managers trade off these three strategies:

$$
\begin{aligned}
& \mathrm{RM}_{\mathrm{t}}=\beta_{0}+\sum_{\mathrm{k}} \beta_{1, \mathrm{k}} \text { Cost of } \mathrm{RM}_{\mathrm{k}, \mathrm{t}}+\sum_{\mathrm{l}} \beta_{2, \mathrm{l}} \text { Cost of } \mathrm{RAM}_{\mathrm{l}, \mathrm{t}}+\sum_{\mathrm{m}} \beta_{3, \mathrm{~m}} \text { Cost of } \mathrm{AEM}_{\mathrm{m}, \mathrm{t}} \\
& +\sum_{\mathrm{n}} \beta_{4, \mathrm{n}} \operatorname{Control}_{\mathrm{n}, \mathrm{t}}+\mathrm{u}_{\mathrm{t}} \\
& \mathrm{RAM}_{\mathrm{t}}=\gamma_{0}+\sum_{\mathrm{k}}^{\gamma} \gamma_{1, \mathrm{k}} \text { Cost of } \mathrm{RAM}_{\mathrm{k}, \mathrm{t}}+\sum_{\mathrm{l}}^{\gamma} \gamma_{2, \mathrm{l}} \operatorname{Cost} \text { of } \mathrm{RM}_{\mathrm{l}, \mathrm{t}}+\sum_{\mathrm{m}}^{\gamma} \gamma_{3, \mathrm{~m}} \text { Cost of } \mathrm{AEM}_{\mathrm{m}, \mathrm{t}} \\
& +\sum_{\mathrm{n}}^{\gamma}{ }_{4, \mathrm{n}} \text { Control }_{\mathrm{n}, \mathrm{t}}+\mathrm{v}_{\mathrm{t}} \\
& \mathrm{AEM}_{\mathrm{t}}=\delta_{0}+\sum_{\mathrm{k}} \delta \text { Cost of } \mathrm{AEM}_{\mathrm{k}, \mathrm{t}}+\sum_{\mathrm{l}} \delta_{2, \mathrm{l}} \text { Cost of } \mathrm{RAM}_{\mathrm{l}, \mathrm{t}}+\sum_{\mathrm{m}} \delta \text { Cost of } \mathrm{RM}_{\mathrm{m}, \mathrm{t}}+\delta_{4} \mathrm{RM}_{\mathrm{t}} \\
& +\delta_{5} \operatorname{RAM}_{\mathrm{t}}+\sum_{\mathrm{n}} \delta \text { Control }_{\mathrm{n}, \mathrm{t}}+\mathrm{w}_{\mathrm{t}}
\end{aligned}
$$

$\mathrm{H} 1$ and its subsidiary hypotheses predict that the trade-off decision between the performance management strategies depends on their relative costliness. Therefore, if the costs associated with one strategy are high, I predict that hospitals use at least one of the other two strategies more, and vice versa. Thus, depending on the specific subsidiary hypothesis, I expect $\beta_{2}, \gamma_{2}$ and $\delta_{2}$ or $\beta_{3}, \gamma_{3}$ and $\delta_{3}$ to be positive.

In order to investigate the possible substitution effect of RM and RAM with respect to hypothesis 2a, I estimate a conditional correlation, i.e., correlation of $u_{t}$ and $v_{t}$ (Arora 1996; Arora and Gambardella 1990; Athey and Stern 1998; Grabner and Moers 2013), and expect that correlation to be negative. In order to test H2b, which predicts that managers adjust the level of accrual-based earnings management based on the realized levels of RM and RAM, I examine whether $\delta_{4}$ and $\delta_{5}$ are both negative. All regressions are estimated using OLS estimation technique.

\subsubsection{Costs associated with real activities manipulation}

To capture the level of a hospital's financial distress I include the Altman Z-score (Altman 1968) at the beginning of the year $\left(Z S C O R E_{t-1}\right)$ (Zang 2012). I adjust the original formula and replace the market value of equity with the book value of equity (Altman and Saunders 1997). I use a hospital's market share at the beginning of the year

\footnotetext{
${ }^{50} T A_{t}=\left(\Delta C A_{t}-\Delta C L_{t}-\Delta C a s h_{t}+\Delta S T D_{t}\right) / A_{t-1}$ where $\Delta C A_{t}$ is change in current assets; $\Delta C L_{t}$ is change in current liabilities; $\Delta \operatorname{Cash}_{t}$ is change in cash and cash equivalents; $\Delta S T D_{t}$ is change in debt included in current liabilities; and $A_{t-1}$ is total assets in year $t-1$.
} 
(MARKET SHARE $E_{t-1}$ ) to measure the competitive pressures a hospital is confronted with within a local hospital market (Zang 2012). I define counties as local hospital markets and calculate the market share using discharges.

\subsubsection{Costs associated with accrual-based earnings management}

To proxy for the higher scrutiny of auditors and regulators stemming from the passage of SOX, I include a dummy (SOX) that equals one for all years from 2003 onwards (Badertscher 2011). According to Barton and Simko (2002), I use net operating assets (i.e., equity less cash and marketable securities plus total debt) at the beginning of the year divided by lagged revenues $\left(N O A_{t-1}\right)$ to proxy for a hospital's accounting flexibility. The rationale for that measure is that, because of the articulation between the income statement and the balance sheet, abnormal accruals reflected in past earnings are also reflected in net assets; hence the latter are overstated when firms engage in accrual manipulation in previous periods (Zang 2012).

\subsubsection{Costs associated with revenue manipulation}

In order to indicate whether the hospital has been convicted for upcoding, I create an indicator variable (CONVICTION DUMMY) that is equal to one in the year a hospital has been convicted for upcoding under the False Claims Act, and zero otherwise. To identify convicted hospitals, I collected data from the False Claims Act settlement agreements published by the US Department of Justice. I include the percentage of inpatients that the hospital treats (\%INPATIENTS) to capture the patient mix factor that constrains upcoding.

\subsubsection{Control variables}

I include several control variables. First, I acknowledge that hospitals have multiple motives to manage their performance. Thus, I control for these motives instead of restricting my sample to hospitals that likely face one specific motive such as meeting the zero earnings benchmark. Using such a sample also provides me with a conservative test of my hypotheses since it likely decreases the power of my tests (Zang 2012). I include four motives that prior literature has identified as triggering performance management behavior in the hospital sector, i.e., beating the zero earnings benchmark, presence of pay for performance bonuses, provision of charity care and medical education.

To identify hospitals that just meet the zero earnings benchmark, I group hospitalyears into intervals based on net income divided by total assets at the beginning of the 
year. Following Degeorge et al. (1999), I determine my categories of scaled earnings based upon 2(IQR) $n^{-1 / 3}$ leading to a bin width of $0.04 .^{51}$ Thus, hospitals whose net income divided by lagged total assets lies in the interval [0, 0.04] are identified as having just met the benchmark, and are coded as 1 in the ZERO EARNINGS BENCHMARK DUMMY, otherwise zero.

Managers who have compensation tied to performance may have an incentive to manage earnings. To construct the incentive compensation variable, I construct a hospital-level variable of the presence of pay for performance (P4P DUMMY). I follow Eldenburg's et al. (2011) version of Sloan's (1993) model and regress the change in log of managerial compensation as a function of the change in return on asset (ROA). Since my dataset does not include compensation details for individual managers or the CEO, I use the annual sum of direct salaries, bonuses, and benefits of the top hospital administrators including the CEO, Medical Director, Nursing Director, and their assistants as my measure of compensation (Eldenburg et al. 2011). I scale this variable by the number of full-time equivalent employees (FTEs) in the top administrative team to obtain an individual score. ${ }^{52} \mathrm{I}$ also include the Herfindahl-Hirshman index (HHI) to control for the influence of competition on incentive compensation and the standard deviation of ROA over three years to control for earnings volatility (STDROA). Thus, I estimate the following model at the hospital level for the time period 1997 to 2007, where all variables are panel-specific random parameters:

$\Delta \log \left[\frac{\text { Total Compensation }_{\mathrm{t}}}{\mathrm{FTE}_{\mathrm{t}}}\right]=\mathrm{n}_{0}+\mathrm{n}_{1} \Delta \mathrm{ROA}_{\mathrm{t}}+\mathrm{n}_{2} \mathrm{HHI}_{\mathrm{t}}+\mathrm{n}_{3} \mathrm{StdROA}_{\mathrm{t}}+\mathrm{e}_{\mathrm{t}}$

Based on the coefficient $n_{1}$, which is my firm-specific measure of pay for performance, I create the P4P DUMMY that equals one for all hospitals that have a positive $n_{1}$, otherwise zero.

To control for the two remaining motives, i.e., provision of charity care and medical education (Heese et al. 2014), I use two variables. For the former, I construct a variable that captures the share of charity care (\%CHARITY CARE) as a percentage of lagged total assets. Charity care includes all amounts which stem from the difference between established charges for services rendered and the amount paid by or on behalf of the patient, if any. The higher this share, the more costs the hospital faces from treating patients that cannot - or only partly - pay their bills. Thus, a hospital with a higher \%CHARITY CARE has a higher demand for additional resources to serve these patients. For the provision of medical education, I create a variable that captures the

\footnotetext{
${ }^{51} I Q R$ is the sample interquartile range and $n$ is the number of observations.

52 Examining the incentive compensation of the entire top management team is appropriate because these individuals work together to determine hospital operations.
} 
share of residents trained per inpatient bed (RESIDENT-TO-BED RATIO). ${ }^{53}$ The larger this ratio, the higher is the magnitude of medical education provided by a specific hospital. Accordingly, hospitals with a larger resident-to-bed ratio have a higher demand for additional resources to provide medical education (Heese et al. 2014).

I also include ROA ( $R O A$ ) to control for hospital performance and occupancy rate (OCCUPANCY RATE) to control for hospital efficiency (Eldenburg and Krishnan 2008; Zuckerman et al. 1994). OCCUPANCY RATE is defined as the number of patient days scaled by staffed beds times 365 (Eldenburg and Krishnan 2008). I also include the percentage of Medicare patients (\%MEDICARE) treated by the hospital measured in patient days to control for a hospital's patient mix. Further, I control for hospital size by including the natural logarithm of total assets (LOGTOTALASSETS). To control for monitoring effectiveness, I include the natural logarithm of the number of board members (LOGBOARDSIZE). A larger board might lead to a lower monitoring effectiveness because of dysfunctional behavior, such as free-rider problems (Aggarwal et al. 2011; Yermack 1996), and thus enable more performance management. I also include additional controls for hospital membership in a multi-hospital system (SYSTEM DUMMY), and location in a rural area (RURAL DUMMY). Table 2 provides an overview of my variables.

\footnotetext{
53 This ratio is also used by Medicare to provide a higher reimbursement rate to teaching hospitals. The higher rate depends on the number of residents trained per inpatient bed (resident-to-bed ratio) leading to a per-case premium of 5.5 percent for approximately a 10 percent increase in the resident-to-bed ratio.
} 


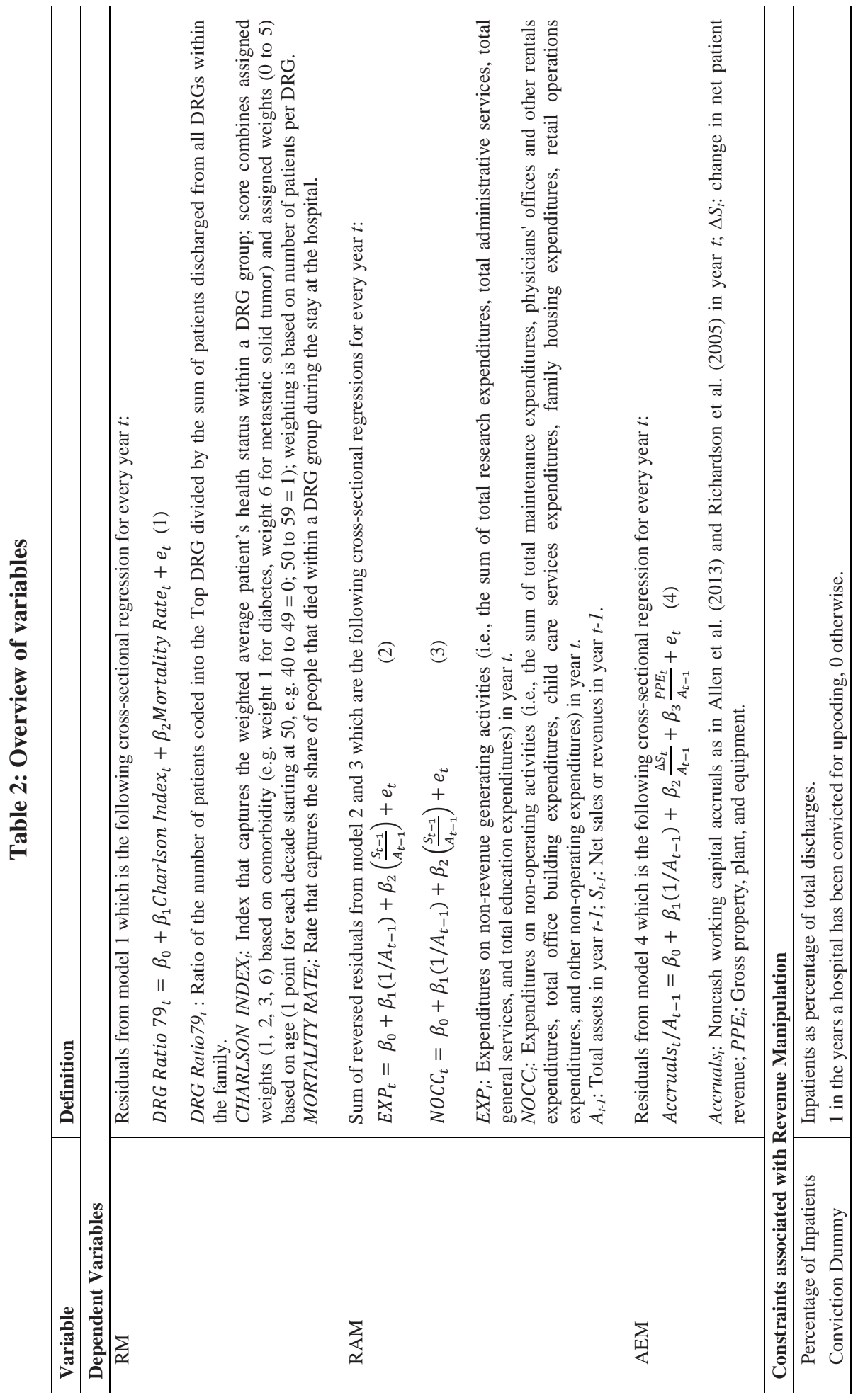


The Role of Revenue Manipulation in the Trade-Off Decision between Performance Management Strategies

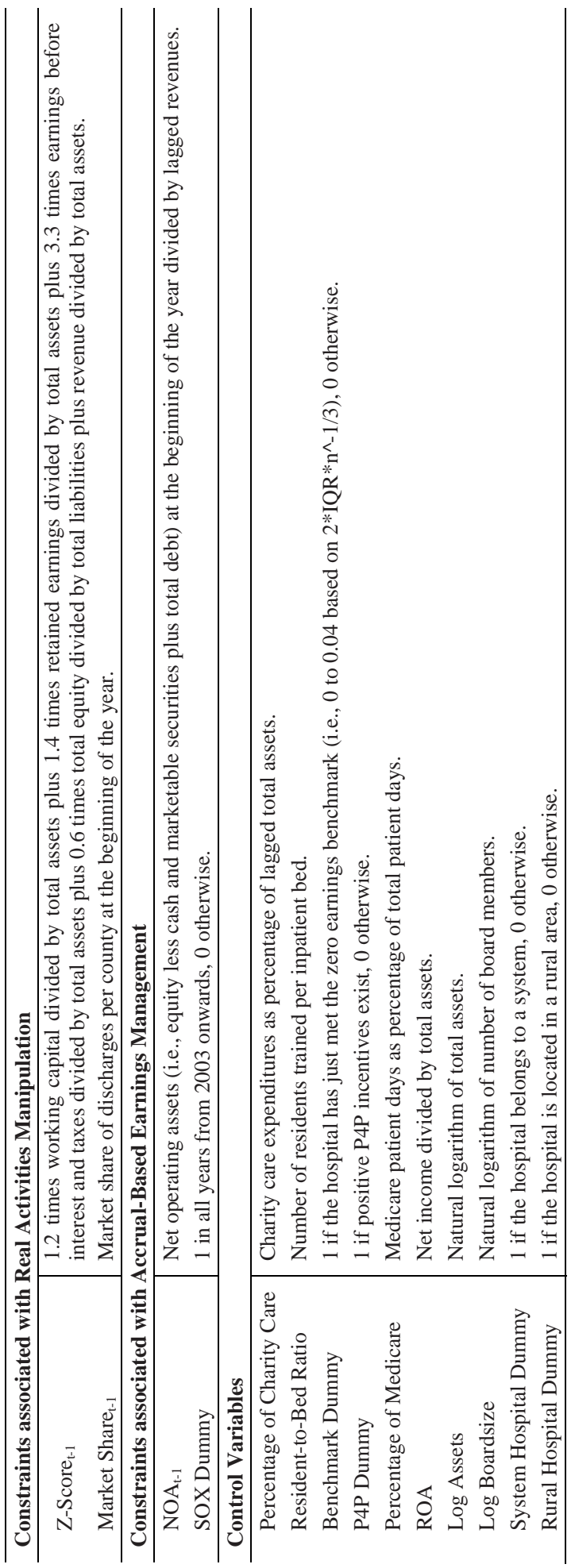


My final sample consists of 107 hospitals and 809 hospital-year observations. I start by estimating the normal levels of coding, non-revenue generating and nonoperating activities, and working capital accruals (i.e., Equations (1) to (4)) to determine the abnormal levels of coding, real activities and accruals (see Table 3, Panel A). Equations (1) to (4) are estimated cross-sectionally for each year. On average, each yearly regression contains more than 75 observations.

The results for estimating the normal levels of coding are consistent with prior research (Heese et al. 2014), i.e., the mean coefficients on the Charlson index, mortality rate and intercept are positive and significant. The mean adjusted $\mathrm{R}^{2}$ of 13.8 percent indicates that the model has reasonable explanatory power. Similar to AEM and RAM estimation models I cannot ensure that each case of abnormal coding is actually strategic up- or downcoding. For instance, within the DRG system only the principal diagnosis determines the appropriate DRG. Thus, it might be that cases of downcoding represent non-optimal coding decisions by the hospital but not strategic downcoding. However, this limitation in my measurement of abnormal coding is likely to work against me finding results consistent with my hypotheses.

The results for Equations (2) to (4), i.e., the estimations of the normal levels of non-revenue generating and non-operating activities, and working capital accruals, are largely consistent with prior research (Roychowdhury 2006; Zang 2012). The mean adjusted $\mathrm{R}^{2}$ ranges from 5.5\% for Equation (3), over 12.1 percent for Equation (4) to 73.6 percent for Equation (2) indicating that all models except for Equation (3) have reasonable to high explanatory power.

The estimated residuals from the estimation models measure the abnormal levels of coding, non-revenue generating and non-operating activities, and working capital accruals. Higher values of abnormal coding (RM) and discretionary working capital accruals (AEM) indicate more revenue manipulation through upcoding and accrualbased earnings management, respectively. I multiply the residuals from the estimation models (2) and (3) by -1 and take the sum of those residuals (RAM), such that higher values indicate a greater extent of real activities manipulation by cutting expenses in non-revenue generating and non-operating activities. The summary statistics for my proxies of RM, RAM and AEM are included in Table 3, Panel B. RM ranges from -0.25 to 0.36 , RAM from -0.52 to 0.33 , and AEM from -0.66 to 0.69 . All proxies have a mean close to zero. I also report the Pearson and Spearman correlations among the variables in Table 1, Panel C. For both Pearson and Spearman correlations there is a positive correlation between RAM and AEM, and a negative between RM and RAM and RM and AEM, respectively. These correlations provide some preliminary evidence that firms apply RAM and AEM as complements but apply RM as a substitute to the other two strategies. 
Table 3: Measurement of revenue manipulation, real activities manipulation and accrual-based earnings management

Panel A: Estimation of the normal levels of accruals, discretionary expenditures and coding ${ }^{\mathrm{a}}$

\begin{tabular}{|c|c|c|c|c|}
\hline Variables & DRG Ratio79, & $\mathbf{E X P}_{\mathrm{t}} / \mathbf{A}_{\mathrm{t}-1}$ & NOCC $_{t} / \mathbf{A}_{\mathrm{t}-1}$ & $\operatorname{ACCRUALS}_{\mathrm{t}} / \mathbf{A}_{\mathrm{t}-1}$ \\
\hline Intercept & $0.126^{* * *}(<0.001)$ & $0.038 * *(0.046)$ & $0.005^{* *}(0.028)$ & $0.001(0.967)$ \\
\hline Charlson Index $_{t}$ & $0.020 * *(0.015)$ & & & \\
\hline Mortality Rate $_{t}$ & $0.975^{* * *}(<0.001)$ & & & \\
\hline $1 / \mathrm{A}_{\mathrm{t}-1}$ & & $0.465 *(0.084)$ & $-0.013^{* *}(0.017)$ & $-0.164(0.392)$ \\
\hline $\mathrm{S}_{\mathrm{t}-1} / \mathrm{A}_{\mathrm{t}-1}$ & & $0.271^{* * *}(<0.001)$ & $0.006^{* * *}(0.004)$ & \\
\hline$\Delta \mathrm{S}_{\mathrm{t}} / \mathrm{A}_{\mathrm{t}-1}$ & & & & $0.093 *(0.051)$ \\
\hline$P P E_{t} / A_{t-1}$ & & & & $-0.200 * *(0.027)$ \\
\hline $\begin{array}{l}\text { Mean adjusted R- } \\
\text { squared }\end{array}$ & 0.138 & 0.736 & 0.055 & 0.121 \\
\hline $\begin{array}{l}\text { Mean Number of } \\
\text { Observations }\end{array}$ & 83.67 & 76.08 & 76.08 & 82.17 \\
\hline
\end{tabular}

Panel B: Summary statistics for revenue manipulation, real activities manipulation and accrual-based earnings management ${ }^{b}$

\begin{tabular}{lccccccc}
\hline Variable & Mean & Std. Dev. & Min. & 1st Quartile & Median & 3rd Quartile & Max. \\
\hline RM & 0.0000 & 0.119 & -0.245 & -0.080 & -0.018 & 0.059 & 0.355 \\
RAM & -0.0005 & 0.129 & -0.523 & -0.046 & 0.021 & 0.070 & 0.326 \\
AEM & -0.0002 & 0.228 & -0.663 & -0.095 & 0.011 & 0.101 & 0.688 \\
\hline
\end{tabular}

Panel C: Pearson (upper triangle) and Spearman (lower triangle) correlations

\begin{tabular}{llll}
\hline & RM & RAM & AEM \\
\hline RM & & $-0.15^{* * *}$ & $-0.05^{*}$ \\
RAM & $-0.14^{* * *}$ & & $0.13^{* * *}$ \\
AEM & $-0.05^{*}$ & $0.11^{* * *}$ & \\
\hline
\end{tabular}

Notes to Table 3:

${ }^{a} p$-values in parentheses, $* * * p<0.01, * * p<0.05, * p<0.1$ (two-tailed), variables are winsorized at $1 \%$ and $99 \%$ levels, regressions are estimated cross-sectionally for the period 1997-2007, reported coefficients are the mean values of the coefficients across years, adjusted R-squared is the mean adjusted R-squared across years. See Table 2 for variable definitions.

${ }^{\mathrm{b}} \mathrm{RM}$ and AEM are estimated residuals from Equations (1) and (4), respectively. RAM is the sum of the estimated residuals from Equations (2) and (3) multiplied by -1 .

Descriptive statistics of my sample and the variables used in my main test are summarized in Table 4. The mean (median) revenue and net income for the sample is \$272 million (\$143 million) and \$3.33 million (\$0.52 million), respectively. Mean (median) total assets are $\$ 62$ million (\$35 million) and the mean (median) number of discharges is 5,662 (4,795). The skewness of these distributions suggests that my 
sample includes proportionately more small hospitals than large hospitals. The mean (median) ROA is -0.1 percent (2.1 percent) indicating that for-profit hospitals are on average not profitable.

The percentage of inpatients ranges from a minimum of 2.1 percent, over an average of 13.8 percent to a maximum of 48.9 percent showing that all hospitals in my sample can engage in upcoding. The descriptive statistics also suggest that a fairly large number of hospitals have been convicted for upcoding as about 4 percent of all hospitalyear observations represent convicted hospitals. The mean (median) market share is 0.05 (0.15) revealing that the average hospital faces a high level of competition. On average the hospitals in my sample are financially healthy as the mean Z-score of 7.2 suggests. Hospitals in my sample have on average net operating assets of 0.29 and 42 percent of all observations are from the post-SOX period.

The average level of charity care is 7.5 percent and the mean resident-to-bed ratio is 1.1 percent. However, only a minority (15.6 percent) of hospitals in my sample provides medical education. On average 10 percent of the hospitals just meet the zero earnings benchmark and about 30.8 percent of the hospitals in my sample have incentive compensation based on financial performance. The mean occupancy rate is 64.5 percent and the percentage of Medicare patients ranges from 2.6 percent to 80.6 percent with an average of 43.7 percent. On average hospitals have 10.5 board members, 6.5 percent of the hospitals are located in rural areas, and about half of the hospitals (50.6 percent) belong to a system.

Table 4, Panel B presents the Pearson and Spearman correlations of the variables included in my main test. I find a high, positive and significant correlation between LOGTOTALASSETS and MARKET SHARE $E_{t-1}$ (Pearson correlation of 0.43), indicating that larger hospitals are likely to enjoy larger market shares in their local markets (Zang 2012). My proxy for hospital size (LOGTOTALASSETS) is also positively correlated with LOGBOARDSIZE (Pearson correlation of 0.43) and SYSTEM DUMMY (Pearson correlation of 0.48 ), suggesting that larger hospitals have larger boards and are more likely to belong to a system of hospitals. 


\section{Table 4: Descriptive statistics $(n=809)^{a}$}

Panel A: Summary statistics

\begin{tabular}{|c|c|c|c|c|c|c|c|}
\hline Variable & Mean & $\begin{array}{l}\text { Std. } \\
\text { Dev. }\end{array}$ & Min. & $\begin{array}{c}\text { 1st } \\
\text { Quartile } \\
\end{array}$ & Median & $\begin{array}{c}\text { 3rd } \\
\text { Quartile }\end{array}$ & Max. \\
\hline \multicolumn{8}{|c|}{ Constraints associated with Revenue Manipulation } \\
\hline \%Inpatients & 13.76 & 8.70 & 2.08 & 7.82 & 11.83 & 16.79 & 48.92 \\
\hline $\begin{array}{l}\text { Conviction } \\
\text { Dummy }\end{array}$ & 0.039 & 0.194 & 0 & 0 & 0 & 0 & 1 \\
\hline \multicolumn{8}{|c|}{ Constraints associated with Real Activities Manipulation } \\
\hline Market Share $_{\mathrm{t}-1}$ & 0.050 & 0.086 & 0.0002 & 0.006 & 0.015 & 0.045 & 0.415 \\
\hline Zscore $_{\mathrm{t}-1}$ & 7.191 & 4.652 & -0.914 & 3.583 & 6.357 & 10.551 & 18.384 \\
\hline \multicolumn{8}{|c|}{ Constraints associated with Accrual-Based Earnings Management } \\
\hline $\mathrm{NOA}_{\mathrm{t}-1}$ & 0.292 & 0.205 & 0.041 & 0.166 & 0.241 & 0.357 & 1.204 \\
\hline SOX & 0.419 & 0.494 & 0 & 0 & 0 & 1 & 1 \\
\hline \multicolumn{8}{|l|}{ Control Variables } \\
\hline \%Charity Care & 7.51 & 14.51 & 0 & 0 & 1.40 & 7.43 & 83.21 \\
\hline $\begin{array}{l}\text { Resident-to-Bed } \\
\text { Ratio }\end{array}$ & 0.011 & 0.039 & 0 & 0 & 0 & 0 & 0.246 \\
\hline $\begin{array}{l}\text { Benchmark } \\
\text { Dummy }\end{array}$ & 0.100 & 0.300 & 0 & 0 & 0 & 0 & 1 \\
\hline P4P Dummy & 0.308 & 0.462 & 0 & 0 & 0 & 1 & 1 \\
\hline Revenues in 000s & 271,542 & 348,841 & 2,956 & 63,597 & 142,713 & 343,612 & $1,545,023$ \\
\hline Net Income in 000s & 3,328 & 13,075 & $-23,721$ & $-1,897$ & 517 & 5,323 & 51,384 \\
\hline ROA & -0.001 & 0.191 & -0.562 & -0.079 & 0.021 & 0.116 & 0.454 \\
\hline Occupancy Rate & 0.645 & 0.254 & 0.128 & 0.456 & 0.614 & 0.929 & 1 \\
\hline \%Medicare & 43.72 & 17.30 & 2.57 & 32.44 & 44.04 & 54.81 & 80.60 \\
\hline $\begin{array}{l}\text { Total Assets in } \\
000 \mathrm{~s}\end{array}$ & 62,053 & 83,806 & 1,371 & 15,387 & 34,674 & 74,369 & 410,445 \\
\hline Teaching Dummy & 0.156 & 0.363 & 0 & 0 & 0 & 0 & 1 \\
\hline Discharges & 5,662 & 4,289 & 172 & 2,657 & 4,795 & 7,450 & 18,921 \\
\hline Board Size & 10.50 & 4.93 & 1 & 7 & 11 & 14 & 23 \\
\hline System Dummy & 0.506 & 0.500 & 0 & 0 & 1 & 1 & 1 \\
\hline Rural Dummy & 0.065 & 0.247 & 0 & 0 & 0 & 0 & 1 \\
\hline
\end{tabular}




\section{Chapter 3}

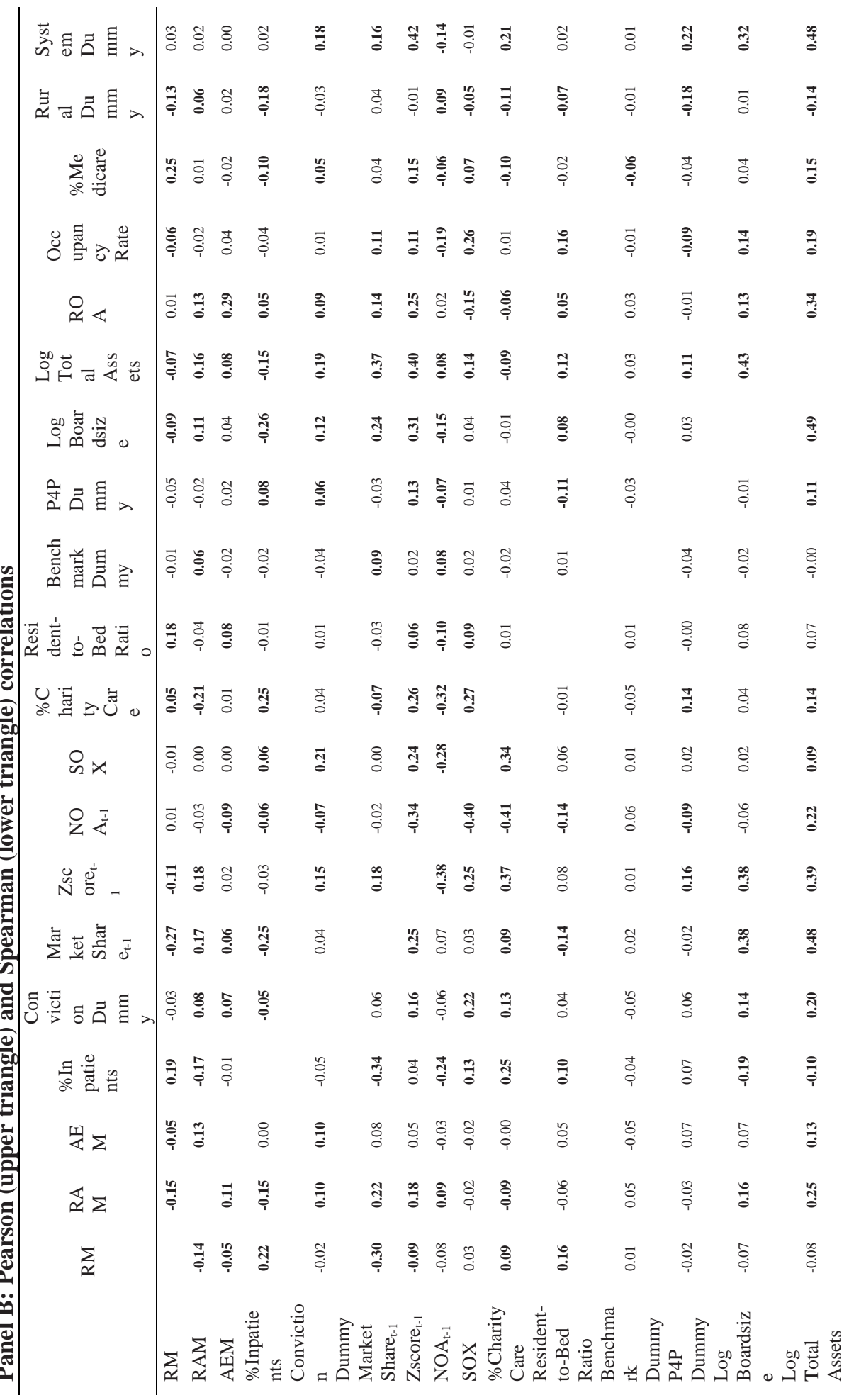


The Role of Revenue Manipulation in the Trade-Off Decision between Performance Management Strategies

\begin{tabular}{|c|c|c|c|c|c|}
\hline$\stackrel{7}{0}$ & ज़: & $\stackrel{\hat{\theta}}{0}$ & $\stackrel{\infty}{\underset{1}{1}}$ & & \\
\hline$\ddot{0}$ & $\ddot{\circ}$ & $\stackrel{\tilde{O}}{0}$ & & ঙ़̣ & \\
\hline$\stackrel{\text { ọ }}{0}$ & $\stackrel{\Delta}{\circ}$ & & $\stackrel{\Delta}{0}$ & $\begin{array}{l}\text { ô. } \\
\text { o. }\end{array}$ & \\
\hline$\stackrel{9}{\circ}$ & & đ̊ & ָ̊̊ & $\stackrel{9}{9}$ & \\
\hline & $\hat{\circ}$ & $\begin{array}{l}ت \overrightarrow{0} \\
\dot{i}\end{array}$ & $\stackrel{\leftrightarrow}{\circ}$ & $\stackrel{10}{0}$ & \\
\hline ભூఝ & $\frac{9}{3}$ & $\stackrel{\infty}{\circ}$ & $\stackrel{\mathbb{T}}{\stackrel{9}{i}}$ & ปี & \\
\hline$\stackrel{0}{0}$ & $\stackrel{\infty}{0}$ & $\stackrel{\infty}{\circ}$ & $\begin{array}{l}\text { L्: } \\
\stackrel{+}{9}\end{array}$ & ల్ & \\
\hline$\stackrel{-1}{\circ}$ & $\begin{array}{l}\infty \\
\stackrel{0}{i}\end{array}$ & $\begin{array}{l}\mathscr{0} \\
\stackrel{0}{1}\end{array}$ & $\stackrel{\infty}{\dddot{1}}$ & ָึ & \\
\hline $\begin{array}{l}\text { ö } \\
\stackrel{\leftrightarrow}{0}\end{array}$ & $\stackrel{\substack{0 \\
i}}{0}$ & ồ & $\begin{array}{l}\overrightarrow{0} \\
\stackrel{i}{i}\end{array}$ & $\ddot{0}$ & \\
\hline$\stackrel{\square}{\circ}$ & $\stackrel{8}{0}$ & $\begin{array}{l}8 \\
0 \\
\end{array}$ & $\stackrel{7}{\stackrel{1}{i}}$ & $\stackrel{0}{!}$ & \\
\hline$\ddot{\circ}$ & $\stackrel{7}{0}$ & $\begin{array}{l}\text { go } \\
1\end{array}$ & $\underset{i}{\stackrel{T}{i}}$ & $\bar{m}$ & \\
\hline $\begin{array}{l}0 \\
\stackrel{1}{1}\end{array}$ & సึ̆ & $\stackrel{8}{\circ}$ & $\begin{array}{l}\mathscr{0} \\
\stackrel{1}{1}\end{array}$ & $\stackrel{\text { L }}{\circ}$ & \\
\hline$\stackrel{\circ}{\circ}$ & $\frac{1}{0}$ & $\begin{array}{l}0 \\
\stackrel{0}{0}\end{array}$ & $\stackrel{20}{0}$ & $\stackrel{\infty}{\circ}$ & 寻 \\
\hline$\overline{\ddot{\theta}}$ & $\stackrel{8}{\circ}$ & $\stackrel{8}{\circ}$ & $\begin{array}{l}\overrightarrow{0} \\
\stackrel{i}{i}\end{array}$ & Эี & $\frac{\ddot{\theta}}{.0}$ \\
\hline$\stackrel{ \pm}{\stackrel{7}{0}}$ & $\stackrel{9}{0}$ & $\begin{array}{l}\text { Oै. } \\
\text { î. }\end{array}$ & $\stackrel{m}{0}$ & $\stackrel{\varphi}{0}$ & อี \\
\hline$\stackrel{1}{0}$ & $\ddot{\sigma}$ & $\stackrel{\text { 눙 }}{\circ}$ & $\begin{array}{l}\text { ț } \\
\stackrel{1}{0}\end{array}$ & $\stackrel{9}{0}$ & \\
\hline ชี & \% & $\Xi$ & $\tilde{\boldsymbol{\tau}}$ & \% & $\dot{0}$ \\
\hline 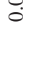 & $0^{\circ}$ & i & i & i & \\
\hline$\stackrel{\oplus}{0}$ & $\stackrel{8}{0}$ & $\begin{array}{l}\text { 눙 } \\
\stackrel{0}{1}\end{array}$ & $\stackrel{\wp}{0}$ & o̊ & $\Xi$ \\
\hline$\stackrel{0}{\circ}$ & ت্ & ö & $\begin{array}{l}\infty \\
\stackrel{0}{0}\end{array}$ & $\stackrel{0}{0}$ & \\
\hline$\stackrel{0}{\circ}$ & $\begin{array}{l}\infty \\
\stackrel{0}{0} \\
\end{array}$ & స్ิ & $\stackrel{\infty}{\stackrel{\infty}{0}}$ & $\stackrel{8}{0}$ & \\
\hline \multicolumn{5}{|c|}{ 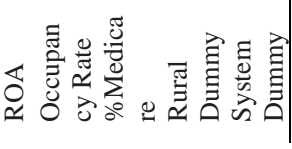 } & 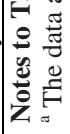 \\
\hline
\end{tabular}




\subsection{Results}

Table 5 presents the results of estimating models (5), (6) and (7) to test hypothesis 1(a-f). Recall that this hypothesis argues that the trade-off decision to apply any of the three strategies instead of the other two is based on the specific constraints associated with each of the three methods. The dependent variables in these equations are my proxies for RM, RAM and AEM as described in Table 3.

Although not directly hypothesized, all manipulation strategies are expected to be negatively associated with their own cost determinants. Except for the coefficient on SOX DUMMY the results are consistent with this expectation.

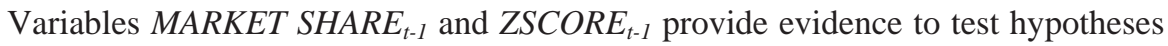
$1 \mathrm{a}$ and $1 \mathrm{~b}$ regarding the constraints associated with RAM. In the RAM equation, the coefficients on MARKET SHARE $E_{t-1}$ and $Z_{S C O R E}$ are positive and significant, indicating that hospitals indeed engage in less RAM if they face more competition or are financially less healthy. Instead hospitals engage in more revenue manipulation as the results in the RM equation show. In particular, the coefficients on MARKET $S H A R E_{t-1}$ and $Z S C O R E_{t-1}$ are negative and significant at the 0.01 level. In addition, for the AEM equation, the results show that hospitals engage in higher levels of AEM when they are financially less healthy. These findings are consistent with hypotheses $1 \mathrm{a}$ and $1 \mathrm{~b}$, as they indicate that managers apply RM when facing greater constraints for real activities manipulation. The results also indicate that when facing financial distress managers engage in both RM and AEM. Thus, in a situation that potentially threatens a hospital's survival, managers do not limit their manipulation behavior to one tool only but use both RM and AEM.

Recall that hypotheses 1c and 1d deal with the constraints associated with AEM. The coefficient on $N O A_{t-1}$ - but not on SOX DUMMY - is negative and significant in model (6) that explains accrual-based earnings management. These findings suggest that AEM is constrained by a hospital's accounting flexibility (Barton and Simko 2002) but does not significantly decrease in the post-SOX period. The effect of SOX on AEM in my setting might not be as pronounced as in other studies such as Cohen et al. (2008) and Zang (2012) due to the following reasons. First, I investigate managers trade-off decisions in the full sample of general acute care for-profit hospitals and do not study a subset of benchmark beating hospitals (Zang 2012). Given that AEM seems to be especially useful to meet these benchmarks I might not be able to observe the effect of SOX in my full sample. Second, even though prior research finds that SOX has an effect on hospitals (Alexander and Lee 2006) it might be that SOX does not constrain AEM in hospitals since the individual hospitals in my sample are not publicly listed. I find, however, support for hypothesis 1c. In particular, after the passage of SOX hospital managers conduct more RM indicating that the passage of SOX potentially stimulated managers to apply more upcoding. This finding provides some evidence that SOX indeed constrains AEM in hospitals. 
Contrary to hypothesis $1 \mathrm{~d}$, the negative and significant coefficient on $N O A_{t-1}$ in the RAM equation shows that hospitals engage in less real activities manipulation if their accounting flexibility is constrained. Instead, hospitals apply more upcoding in situations of low accounting flexibility, as evidenced by the positive and significant coefficient on $N O A_{t-1}$ in the RM equation. Thus, the results show that, if hospitals are constrained in applying AEM, they prefer upcoding over real activities manipulation.

My results confirm hypotheses 1e-1f which state that hospitals facing constraints for revenue manipulation switch to real activities manipulation. More precisely, in the RM equation, the coefficients on \%INPATIENTS and CONVICTION DUMMY are positive and negative, respectively, and significant at the 0.10 level indicating that a hospital's customer mix and the event of a conviction for upcoding indeed constrain upcoding. In the RAM equation, the results show that the coefficients for the two constraints associated with RM are significant with the predicted signs. These findings indicate that hospitals facing an unfavorable customer mix or those that have been convicted for upcoding use RAM instead of upcoding. I also find that in the extreme situation of a conviction for upcoding hospitals also use more AEM next to RAM, indicating that convicted hospitals do not necessarily reduce their performance management level but apply other manipulation techniques. 
Chapter 3

Table 5: Ordinary least squares model of trade-off between revenue manipulation, real activities manipulation and accrual-based earnings management

Panel A: Constraints associated with revenue manipulation, real activities manipulation and accrual-based earnings management ${ }^{a}$

\begin{tabular}{|c|c|c|c|c|c|c|}
\hline \multirow[t]{2}{*}{ Variables } & \multicolumn{2}{|c|}{ RM Equation (n=809) } & \multicolumn{2}{|c|}{ RAM Equation (n=809) } & \multicolumn{2}{|c|}{ AEM Equation $(n=809)$} \\
\hline & $\begin{array}{l}\text { Pred. } \\
\text { Sign }\end{array}$ & Coefficient & $\begin{array}{l}\text { Pred. } \\
\text { Sign }\end{array}$ & Coefficient & $\begin{array}{l}\text { Pred. } \\
\text { Sign }\end{array}$ & Coefficient \\
\hline \multicolumn{7}{|c|}{ Constraints associated with Revenue Manipulation } \\
\hline \%Inpatients & + & $0.158 *(0.055)$ & - & $-0.145 *(0.079)$ & & $-0.011(0.903)$ \\
\hline $\begin{array}{l}\text { Conviction } \\
\text { Dummy }\end{array}$ & - & $-0.021 *(0.099)$ & + & $0.040 * *(0.027)$ & & $0.082 * *(0.018)$ \\
\hline \multicolumn{7}{|c|}{ Constraints associated with Real Activities Manipulation } \\
\hline Market Share $_{\mathrm{t}-1}$ & - & $\begin{array}{l}-0.258^{* * *} \\
(<0.001)\end{array}$ & + & $0.104 *(0.094)$ & & $0.023(0.731)$ \\
\hline Zscore $_{\mathrm{t}-1}$ & - & $-0.004 * * *(0.009)$ & + & $0.005^{* * *}(0.006)$ & & $-0.010 * * *(<0.001)$ \\
\hline \multicolumn{7}{|c|}{ Constraints associated with Accrual-Based Earnings Management } \\
\hline $\mathrm{NOA}_{\mathrm{t}-1}$ & & $0.018 *(0.057)$ & + & $-0.080 * * *(0.008)$ & - & $-0.136^{* *}(0.016)$ \\
\hline SOX & + & $0.020 *(0.084)$ & & $0.001(0.972)$ & - & $0.011(0.715)$ \\
\hline \multicolumn{7}{|l|}{ Control Variables } \\
\hline \%Charity Care & & $0.051 *(0.079)$ & & $\begin{array}{l}-0.195^{* * *} \\
(<0.001)\end{array}$ & & $0.133^{*}(0.056)$ \\
\hline $\begin{array}{l}\text { Resident-to-Bed } \\
\text { Ratio }\end{array}$ & & $0.542 * *(0.010)$ & & $-0.181(0.414)$ & & $0.531 * *(0.014)$ \\
\hline $\begin{array}{l}\text { Benchmark } \\
\text { Dummy }\end{array}$ & & $0.022 * *(0.044)$ & & $0.018 *(0.096)$ & & $-0.014(0.370)$ \\
\hline P4P Dummy & & $-0.011(0.440)$ & & $-0.013(0.269)$ & & $0.026 *(0.050)$ \\
\hline Log Boardsize & & $0.015(0.220)$ & & $-0.005(0.562)$ & & $0.008(0.577)$ \\
\hline Log Total Assets & & $-0.005(0.639)$ & & $0.013(0.101)$ & & $0.014(0.210)$ \\
\hline ROA & & $0.016(0.599)$ & & $0.050(0.436)$ & & $0.413^{* * *}(<0.001)$ \\
\hline Occupancy Rate & & $-0.011(0.619)$ & & $-0.057 * *(0.035)$ & & $-0.020(0.482)$ \\
\hline \%Medicare & & $0.183^{* * *}(0.001)$ & & $-0.016(0.711)$ & & $0.039(0.368)$ \\
\hline Rural Dummy & & $-0.051^{* *}(0.016)$ & & $0.044(0.240)$ & & $0.030(0.277)$ \\
\hline System Dummy & & $0.022(0.160)$ & & $-0.020(0.259)$ & & $-0.010(0.538)$ \\
\hline Intercept & & $0.123(0.470)$ & & $-0.286^{* *}(0.046)$ & & $-0.194(0.282)$ \\
\hline Year Indicators & & Yes & & Yes & & Yes \\
\hline Clustered by & & Hospital & & Hospital & & Hospital \\
\hline R-squared & & 0.255 & & 0.164 & & 0.161 \\
\hline
\end{tabular}


Table 5: (Continued)

Panel B: Impact of realized revenue manipulation and real activities manipulation on accrual-based earnings management

\begin{tabular}{ccc}
\hline Variables & & AEM Equation $(\mathbf{n}=\mathbf{8 0 9})$ \\
\hline & Pred. & Coefficient \\
\hline Sign & - & $-0.154^{*}(0.062)$ \\
RAM & - & $0.183^{* *}(0.028)$ \\
\hline
\end{tabular}

Notes to Table 5:

${ }^{a} p$-values in parentheses, $* * * p<0.01, * * p<0.05, * p<0.1$ (two-tailed), standard errors clustered by hospital, variables are winsorized at $1 \%$ and $99 \%$ levels. See Table 2 for variable definitions.

The next analysis investigates whether, in the presence of the above identified constraints, hospitals apply revenue manipulation and real activities manipulation as direct substitutes. This can be observed if the conditional correlation of the error terms of the RM and the RAM equation is negative and significant. Consistent with hypothesis $2 \mathrm{a}$, this correlation is negative and significant $(-0.079, p<0.05)$ as reported in Table 6 . Thus, conditional on the constraints and incentives hospitals face managers use these two strategies as direct substitutes. This implies that throughout the year managers determine whether to apply RAM or RM given the specific incentives and constraints managers face. The results in Panel B of Table 5 also present partly support for H2b, which predicts that the realized levels of RM and RAM at fiscal year-end impact the level of AEM. In particular, the coefficient on RM is negative and significant indicating that the realized level of RM negatively affects the level of AEM. That is, managers determine the level of RM based on the constraints observable before the fiscal yearend, and adjust the level of AEM after the fiscal year-end based on the realized level of revenue manipulation. The fact that the coefficient on RAM is positive and significant indicates that hospital managers apply more AEM if they apply RAM. Overall, these findings suggest that hospital managers use upcoding as a substitute for both AEM and RAM, while AEM and RAM are applied as complements. These findings emphasize the power of RM as a manipulation tool.

Table 6: Conditional correlation of trade-off between revenue manipulation and real activities manipulation

\begin{tabular}{ccc}
\hline Variable & & Variable \\
\hline & Pred. Sign & RAM \\
RM & - & $-0.0794 * *(0.018)$ \\
\hline
\end{tabular}

The results also show that RM is positively and significantly associated with the provision of charity care and medical education and meeting the zero earnings benchmark (Heese et al. 2014). In the RAM equation, the coefficient on \%CHARITY 
CARE is negative and significant, indicating that pursuing this resource intensive objective via RAM is especially costly since RAM requires a deviation from optimal business conduct. In the AEM equation, the coefficients on \%CHARITY CARE and RESIDENT-TO-BED RATIO are both positive and significant, suggesting that AEM is potentially useful to pursue these objectives. ${ }^{54}$ In the RAM equation, the coefficient on the ZERO EARNINGS BENCHMARK DUMMY is positive and significant whereas the coefficient on the P4P DUMMY is only positive and significant in the AEM equation. Overall, these results provide additional evidence for the described relation between the manipulation strategies. While upcoding is positively associated with all (except for P4P DUMMY) potential manipulation incentives, AEM and RAM are positively associated with subsets of these four manipulation incentives. These findings provide further evidence for a substitutive relation between RM and RAM or AEM and a complementary one between AEM and RAM since upcoding alone is powerful enough to achieve most manipulation goals whereas AEM and RAM have to be applied both to manipulate performance on those goals.

I also find that rural hospitals and hospitals with a smaller Medicare population upcode less. Hospitals with a higher occupancy rate use less RAM and more profitable hospitals engage in AEM to a greater extent.

\subsubsection{Robustness tests}

To examine the robustness of my results, I use an alternative measure of discretionary accruals. I repeat my tests by using performance-matched discretionary accruals developed by Kothari et al. (2005). Following Kothari et al. (2005) I calculate performance-matched discretionary accruals as the difference between a hospital's discretionary accruals and the discretionary accruals of the hospital with the closest return on assets in the same year. My results using these alternative measures of accruals are consistent with those reported in the paper.

\subsection{Conclusions}

Prior accounting research has mainly focused on investigating firms' application of traditional earnings management methods such as accrual-based earnings management (AEM) and real activities manipulation (RAM) and how firms make choices between these strategies. In this study, I investigate whether firms apply revenue manipulation (RM) as an additional tool to manipulate their performance and

\footnotetext{
54 An alternative explanation for this finding might be that regulators scrutinize the accounting decisions of for-profit hospitals that show a strong performance on socially valuable goals to a lesser extent allowing these hospitals to engage in more AEM.
} 
how hospital managers make choices between these three manipulation strategies based on their associated constraints.

My results confirm that managers trade off between these three activities. In particular, I find that throughout the year RM and RAM are direct substitutes and that at the end of the fiscal year, hospital managers engage in less AEM the more RM has been applied throughout the year. Thus, the results indicate that RM is an important alternative manipulation strategy that is directly traded off against RAM and AEM. Moreover, I show that RAM is positively associated with the level of AEM at year end, suggesting a complementary relation between RAM and AEM.

I also document that hospitals' trade-off decisions are driven by the operational constraints they are facing. In particular, I find that RM is considered least costly when hospitals face high competition or financial distress. When AEM is constrained by prior accounting choices and the passage of SOX, hospitals resort to RM instead of RAM. The results also indicate that RM is constrained by a hospital's patient mix and enforcement actions against upcoding resulting in lower levels of RM and higher levels of RAM or RAM and AEM, respectively. Overall, my results suggest that organizations that have the opportunity to engage in revenue manipulation are likely to make different trade-off decisions in their performance manipulation than organizations that have only RAM and AEM at their disposal.

My study is subject to several limitations. First, I acknowledge that the possibility to manipulate revenues as described in this study might not be a feasible manipulation strategy for all types of firms. However, fraud scandals in various industries suggest that many firms have the possibility to manipulate revenues via overbilling, which is a similar mechanism as upcoding (Koppel 2006; Rashbaum 2012; Thomas 2011). Second, I focus only on upcoding as an alternative manipulation strategy of hospitals and ignore additional potential manipulation mechanism such as kickbacks or overtreatment of patients (GAO 2000). To measure upcoding I use only one DRG family. Including additional manipulation strategies and more DRG families in the analysis would provide more complete results, but would greatly increase the complexity of the analysis because the interactions between these strategies and DRG families would have to be accounted for. Future research could investigate the role of hospitals' additional potential manipulation tools. Third, my analysis focuses on hospitals whose operations and related manipulation incentives might differ to firms in other industries. However, prior research indicates that for-profit hospitals face similar manipulation incentives than firms in other industries. An interesting future research would be to investigate whether my findings are generalizable to other industries in which the possibility to manage revenues exists.

My findings have several implications for both researchers and regulators. For researchers, the findings suggest that focusing on accrual-based earnings management and real activities manipulation exclusively does not fully explain performance management activities. Thus, researchers should also consider alternative, powerful 
Chapter 3

instruments to manipulate a firm's performance. For regulators, it implies that increasing scrutiny or constraints over one specific form of manipulation technique does not eliminate manipulative activities altogether, but only changes managers' preferences for different strategies. 


\title{
Chapter 4
}

\section{Government Preferences, SEC's Enforcement Actions and Firms' Accounting Violations}

\begin{abstract}
I posit that the SEC's enforcement actions are influenced by government's preferences for firms that contribute to the government's policy of fostering employment conditions. Using a large sample of listed US firms for the period 1982 to 2012, I investigate whether the resource-constrained SEC reduces its enforcement actions for labor-intense firms, a proxy for a firm's contribution to employment conditions. I find that labor-intense firms are less likely to face an SEC enforcement action. Next, I also show that labor-intense firms are even less likely to face an SEC enforcement action in election years. All of these results hold after controlling for firms' accounting quality and two alternative explanations for firms' favorable treatment by the SEC, i.e., firms' location and firms' lobbying activities. Consistent with my hypotheses, these findings indicate that government preferences affect the SEC's enforcement actions. Finally, I find some evidence that labor-intense firms exploit this favorable treatment by engaging in more aggressive accounting choices. My results suggest that firms that contribute to government policies are rewarded by reduced SEC enforcement actions.
\end{abstract}




\subsection{Introduction}

Research in accounting and finance traditionally assumes that the Securities and Exchange Commission (SEC) is a neutral regulatory agency that allocates scarce resources to investigate those firms that are most likely to violate Generally Accepted Accounting Principles (GAAP), and uniformly enforces firms' compliance with those accounting standards (Dechow et al. 2011; Dechow et al. 1996, 1995). A number of recent studies, however, indicate that the SEC is significantly resource-constrained and prone to political pressure, and therefore undertakes investigations based on preferences (Correia 2009; Kedia and Rajgopal 2011; Yu and Yu 2011). For instance, Correia (2009) and Yu and Yu (2011) show that firms with political connections or that engage in lobbying are less likely to be convicted by the SEC. Kedia and Rajgopal (2011) find evidence consistent with the so called 'constrained cop' hypothesis. They show that the resource-constrained SEC is more likely to investigate firms located closer to its offices and interpret their findings as an indication that the SEC minimizes costs associated with its investigations.

While the above mentioned studies argue that the SEC's preferences are based on firms' attempts to influence the SEC or underlying conditions for the investigation, they do not take into account possible systematic preferences of the SEC based on operational characteristics of the firm. Yet, economists such as Stigler (1971) and Peltzman (1976) have long argued that regulations and regulators are influenced by the government. As the government decides on the resource allocations to regulatory agencies in the first place (Bealing 1994; Weingast 1984), the SEC, as a regulatory agency, is dependent on the government's budget decisions. In light of the recent evidence that the SEC is significantly resource-constrained (Kedia and Rajgopal 2011; Thomsen 2009), this dependency is potentially even stronger.

Following this argumentation, I investigate whether the government's preferences are likely to reflect in the SEC's decisions as to which firms to investigate. In particular, I study whether the SEC's enforcement actions are influenced by government's preferences for firms that contribute to government's policies. As the government's goal is to maximize political support, which comes in the form of votes, it responds to both constituent and special interest pressure by adjusting its political decisions and measures accordingly (Stigler 1971). Given that employment conditions are proven to systematically affect future electoral outcomes (Wolfers 2002; Kau et al. 1982; Hibbs 2006; MacRae 1977), the government has long favored a policy to promote these conditions by supporting not only large employers in absolute terms, but also smaller, labor-intense firms that contribute to future employment (Caves 1976; Adams and Brock 1987a; Audretsch 2003). Therefore, in this study, I use firms’ labor intensity as a 
proxy to identify firms that contribute to government's policies and investigate whether the resource-constrained SEC reduces its enforcement actions for labor-intense firms. ${ }^{55}$

SEC enforcement actions can be devastating for firms. In particular, sanctions directed by the SEC in combination with negative market reactions result in huge reputational and financial costs for both the firm and manager, and can ultimately lead to bankruptcy of the convicted firm (Karpoff et al. 2008a, 2008b; Feroz et al. 1991). As job losses are a direct consequence of bankruptcy, SEC enforcement actions do not only affect the economic wealth of government's constituents, e.g., a firm's employees, but also take down firms that are important for the government's policy of promoting employment. Avoiding bankruptcies of firms that employ a relatively larger number of people is thus beneficial for the government as it reduces signs of government's failure to foster employment. ${ }^{56}$ Therefore, the SEC and its Commissioners are likely to face political pressure from the government to spare labor-intense firms from enforcement actions.

Furthermore, as labor-intense firms represent the preferences of the government itself this political pressure is likely to be independent of firms' lobbying for their special interests (Yu and Yu 2011; Correia 2009; Adams and Brock 1987a). Thus, I argue that the SEC, which is constrained in terms of time, effort and enforcement budgets (Kedia and Rajgopal 2011; Thomsen 2009) implicitly incorporates this government influence in its decision processes as to which firms to investigate. As a consequence, the SEC is less likely to investigate labor-intense firms whose prosecution might ultimately increase prosecution costs or negatively impact future budget decisions due to the political pressure. This lower likelihood of investigation lowers regulatory enforcement and thus makes it less likely that labor-intense firms get convicted for a violation of GAAP.

To test whether the SEC reduces its enforcement actions for labor-intense firms, I use a sample of firms for the time period 1982 to 2012 that have been sanctioned by the SEC for violating GAAP as reported in Accounting and Auditing Enforcement Releases (AAERs) and all other public firms that did not receive an AAER over this period.

\footnotetext{
${ }^{55}$ Governments pursue various policies such as environmental, health care or educational policies. While the importance of these policies is likely to vary across time and is likely to be dependent on the government's partisanship, the policy of promoting employment is likely to be most important to every government as it is proven to systematically affect electoral outcomes (Hibbs 2006; MacRae 1977). Consequently, the government promotes this policy more than other policies, making it a powerful proxy for government's preferences.

56 An SEC enforcement action is not necessarily the reason for a firm's bankruptcy as firms that are subject to such actions might already have been on the verge of bankruptcy. In these instances an SEC enforcement action is not necessarily the cause of a firm's bankruptcy, but it might accelerate the process that leads to a firm's bankruptcy. Delaying such failure, however, might also benefit the government as it can avoid negative news about the current employment conditions (Brown and Dinç 2005). In addition, distressed firms that gain additional time by not being subject to an SEC enforcement action might use this time to avoid failure after all.
} 
Using a firm's labor intensity as a proxy for the firm's contribution to the government's policies, I investigate whether labor-intense firms face fewer SEC enforcement actions. I also include firms' lobbying efforts (Yu and Yu 2011) and distance to an SEC office (Kedia and Rajgopal 2011) in my model in order to control for the impact of these circumstances on the SEC's enforcement preferences.

Consistent with my hypothesis, I find evidence that labor-intense firms are less likely to be subject to an AAER. This finding indicates that firms that contribute to the government's policy of promoting employment face lower enforcement by the SEC. These results hold after controlling for a firm's accounting quality, location, and lobbying efforts, which provides evidence that these preferences are not driven by firms' lobbying activities, but instead are systematically based on firms' characteristics that support government's policies.

To test the robustness of these results, I further examine whether variations in government's sensitivity to constituents' interests result in variations of SEC enforcement actions against labor-intense firms. Prior research in political economy especially highlights the role of upcoming elections as a period in which the government is likely to take measures to ensure political support in the upcoming election (Brown and Dinc 2005; Kramer 1971). Thus, I argue that this higher sensitivity results in more political pressure on the SEC, resulting in even fewer enforcement actions against labor-intense firms. In line with this hypothesis, I find that the lower likelihood of SEC enforcement actions against labor-intense firms is even more pronounced in election years. Consequently, this finding provides further evidence that the government's preferences for firms that support government's policies reflect directly in SEC's enforcement actions.

One could argue, however, that labor-intense firms, which might be more important for the economy and are therefore under more scrutiny, have a higher accounting quality because of higher following by investors and analysts. Such a higher accounting quality would explain lower SEC investigations and convictions. Even though I include a firm's F-score (Dechow et al. 2011) as a control variable in all of my earlier tests to control for a firm's accounting quality, I run several additional regressions to investigate whether labor-intense firms have a better accounting quality and thus fewer SEC enforcement actions. ${ }^{57}$ Next to using all three specifications of the F-score as developed by Dechow et al. (2011), I use discretionary accruals based on the modified Jones model as in Dechow et al. (2011) and the Dechow and Dichev (2002) model, and the incidence of accounting restatements as proxies for a firm's accounting quality. I find consistent evidence across all proxies that labor-intense firms have a

\footnotetext{
57 The F-score developed by Dechow et al. (2011) is a scaled probability that can be used as a red flag or signal of the likelihood of earnings management or misstatement. Dechow et al. (2011) developed the F-score by systematically investigating financial characteristics of firms that have been subject to an AAER.
} 
lower accounting quality than their less labor-intense peers. This finding suggests that fewer SEC enforcement actions against labor-intense firms cannot be explained by these firms having a higher accounting quality. Instead, my results indicate that labor-intense firms exploit this preferential treatment by the SEC by engaging in more aggressive accounting choices.

Finally, I run several robustness tests to address potential concerns of my research design. First, I investigate whether labor-intense firms are less likely to receive a comment letter from the SEC. As comment letters are a potential trigger event for an SEC enforcement action, examining whether labor-intense firms are less likely to receive such letters can provide indications at which stage of the SEC investigation process the SEC adjusts its enforcement actions in accordance with government's policy to foster employment. I find that labor-intense firms are less likely to receive a comment letter, suggesting that the SEC allocates fewer resources to reviews of labor-intense firms, which might lead to fewer enforcement actions against these firms. Second, to address the concern that my measure of labor intensity reflects a firm's total labor intensity instead of a firm's US labor intensity, I obtain data on firms' US and non-US labor intensity from Compustat Segments and examine whether both US and non-US labor intensity are associated with a lower likelihood of being subject to an SEC enforcement action. For this small subset of my original sample, I find that most firms do not have employees outside of the US, suggesting that my measure of a firm's labor intensity is reflective of a firm's US labor intensity. In addition, I find that only a firm's US labor intensity is associated with a lower likelihood of being subject to an AAER, indicating that labor intensity is likely to measure government preferences instead of some underlying risk of engaging in fraudulent accounting choices.

I contribute to the accounting literature in the following ways. First, in line with a growing body of research (Kedia and Rajgopal 2011; Yu and Yu 2011; Correia 2009), my results suggest that the SEC is not neutral in its enforcement actions. Thus, contrary to the dominant assumption in archival accounting research, my study shows that firms in the same industry are not exposed to similar levels of enforcement (Kedia and Rajgopal 2011). Second, I find that the SEC's enforcement actions are systematically influenced by government's preferences. Accounting research has hitherto not examined whether preferences of the government drive SEC's enforcement efforts, although economists have long argued that regulations and regulators are influenced by the government (Stigler 1971). Instead, a small set of studies has focused on firms' attempts to impact SEC's enforcement actions via lobbying and political connections (Yu and Yu 2011). My study, however, shows that, in addition to such active attempts, the government itself imposes pressure on the SEC to ensure that this agency acts in accordance with government's political priorities. Third, by showing that firms adjust their accounting choices as a result of SEC's enforcement actions, my study sheds light on potentially adverse impacts that SEC's enforcement actions can have on firms' accounting quality. Finally, my study also contributes to the need expressed by 
accounting researchers for studies that enhance our understanding of the complex dynamics surrounding regulation and enforcement of these regulations (Bozanic et al. 2012; Canning and O’Dwyer 2013).

The remainder of the paper is organized as follows. Section 2 discusses prior research on political pressure on governmental agencies and develops the hypotheses. Section 3 presents the data and research method while Section 4 provides the empirical results and additional robustness checks. Section 5 concludes.

\subsection{Hypothesis Development}

\subsubsection{Government preferences for labor-intense firms}

Since the seminal studies of Stigler (1971) and Peltzman (1976), research in economics argues that politicians in general and the government in particular seek to maximize political support, which comes in the form of votes, and thus ensure that their actions promote this goal. In line with this theory, a pervasive body of research has since shown that the government indeed represents its constituents' interests to increase political support (Peltzman 1984, 1985, 1992; Hibbs 2006; Potrafke 2012; Mian et al. 2010; Kalt and Zupan 1984). Consequently, the government considers the economic interests of voters and interest groups in its actions. Hibbs (2006) and MacRae (1977) argue that constituents' support is to a large degree influenced by economic variables such as employment, inflation or the growth rate of private consumption. Furthermore, as empirical studies show that employment conditions significantly influence voters when deciding whether to re-appoint an incumbent government, employment has generally been a core interest of the government (Wolfers 2002; Kau et al. 1982; Hibbs 2006; MacRae 1977; Bertrand et al. 2007; Holbrook 1991; Conover et al. 1987, 1986; MacKuen et al. 1992). For instance, Holbrook (1991), who investigates presidential election outcomes for the years 1960 to 1984, finds that for every percentage point of unemployment, the president's party loses 1.2 percent of the vote.

As the employment conditions significantly affect future electoral outcomes, the government has the incentive to foster employment conditions in order to ensure political support (Caves 1976). Indeed, a huge body of research indicates that governments, independent of their partisanship (Potrafke 2012; Nordhaus 1975), promote employment. For instance, governments of both partisanships established policies to promote small businesses as these businesses are often more labor-intense than larger firms (Brock and Evans 1989) and are perceived to have the ability to generate jobs (Audretsch 2003; Davis et al. 1996). In particular, small businesses have been supported by government programs such as the Small Business Innovation Research (SBIR) program in the early 1980s in order to contribute to the employment 
conditions. ${ }^{58}$ More recently, the Jumpstart Our Business Startups Act or JOBS Act, which is also intended to support small US businesses, has been passed with bipartisan support (VanRoekel 2012). In addition, the government also promotes employment by supporting specific firms that contribute significantly to the overall employment conditions. In particular, firms that are perceived as being too big to fail receive government support in various forms such as import protection, regulatory delays, and subsidies in the form of tax favors and bailouts (Adams and Brock 2004, 1987b, 1987a, 1986). Chrysler, for instance, has been bailed out by the government to prevent huge job losses and destabilization of the entire manufacturing sector at the end of the 1970s and 2000s (Adams and Brock 1987a; Barnes 2009).

Therefore, the government has long favored a policy to promote employment conditions by supporting not only large employers in absolute terms, but also smaller businesses that employ a large number of people in relative terms and contribute to future employment. As a consequence, the government has preferences not just for large firms but also for smaller, labor-intense firms as they contribute to the overall employment conditions (Adams and Brock 2004, 1987b, 1987a, 1986; Caves 1976; Hillman et al. 1987; Audretsch 2003). As job losses are a direct consequence of bankruptcy, bankruptcy of labor-intense firms will result in relatively more job losses than bankruptcy of firms that are less labor-intense. Consequently, the government has incentives to protect labor-intense firms from events such as failure or bankruptcy that can interfere with the government's policy of promoting employment.

\subsubsection{SEC behavior under government preferences}

As outlined above, the government seeks to promote employment conditions to maximize political support and ensures that its actions promote this goal. To promote employment the government can choose to adjust regulations or induce pressure on regulators (Stigler 1971; Peltzman 1976). Therefore, the government is likely to impose pressure on regulators whose enforcement actions have a significant impact on employment conditions. SEC enforcement actions, for instance, have the potential to significantly interfere with the employment conditions the government aims to provide to its voters. Karpoff et al. (2008b), for instance, find that, in addition to the direct penalties, SEC's enforcement actions can lead to huge reputational penalties imposed by the market. ${ }^{59}$ As a result, about 34 percent of the firms do not survive the enforcement

\footnotetext{
58 The SBIR was an offshoot of the Small Business Investment Company (SBIC) program, which provided more than \$3 billion to young firms between 1958 and 1969 (Audretsch 2003).

59 In particular, the reputational penalties, i.e., the expected losses in the present value of future cash flows due to lower sales and higher contracting and financing costs, are over 7.5 times the sum of all penalties imposed through the legal and regulatory system (Karpoff et al. 2008b).
} 
process and thus file bankruptcy. ${ }^{60}$ On the other hand, firms that survive face a mean dollar loss of \$591.75 million from the SEC enforcement action (Karpoff et al. 2008b). Thus, an SEC enforcement action, whether or not it results in the firm's bankruptcy, can significantly interfere with the government's goal to promote employment, resulting in incentives for the government to impose pressure on the SEC.

The reason why the government's preferences are likely to reflect in the SEC's decisions as to which firms to investigate is the combination of SEC's resource constraints (Kedia and Rajgopal 2011; Thomsen 2009) and the fact that the government decides on the resource allocations to the SEC in the first place (Weingast 1984; Bealing 1994).

Thus, the SEC, as a regulatory agency, is dependent on the government's budget decisions. Kedia and Rajgopal (2011), for instance, show that the SEC budget between 1995 and 2009 is less than one percent of total stock market capitalization, indicating that the SEC is significantly resource-constrained. Next to government's control over the SEC's budget, the government has several additional instruments at its disposal that can potentially create incentives for regulators to act in accordance with the government's goal, i.e., the maximization of political support. First, as described by Arthur Levitt, former Chairman of the SEC (Levitt and Dwyer 2003), members of the government can actively intervene with an SEC investigation. Second, the government, i.e., the president with the advice and consent of the Senate, appoints SEC Commissioners and can thus impact which political views are represented in the SEC (Noll 1971; Weingast 1984; SEC 2013a). Finally, the government can sanction the SEC and its employees. For instance, the careers of SEC Commissioners and other key employees might depend on their political support. As a result, the SEC is likely to act in accordance with government's policy to foster employment and thus exercises judgment as to which firms to investigate.

This judgment can potentially occur at several steps of the SEC investigation process, which consists of several distinct stages and can ultimately lead to an AAER. ${ }^{61}$ The investigation process typically starts with a firm's conspicuous announcement, called trigger event, which can lead to an informal and confidential investigation by the SEC. If questionable activity is suspected, a formal investigation is initiated after which the Commission decides how the investigation proceeds. The process ends with an

\footnotetext{
60 An SEC enforcement action is not necessarily the reason for a firm's bankruptcy as firms that are subject to an AAER might already have been on the verge of bankruptcy. In these instances an SEC enforcement action is not necessarily the cause of a firm's bankruptcy, but it is likely to accelerate the process that leads to a firm's bankruptcy.

${ }^{61}$ For a more detailed description of the SEC enforcement process see Karpoff et al. (2008b) and Kedia and Rajgopal (2011).
} 
enforcement action such as an AAER. ${ }^{62}$ An SEC that is likely to adjust its enforcement actions in accordance with government's policy to foster employment has several possibilities to exercise judgment as to which firms to investigate during this process. For instance, the SEC can allocate less resources to general reviews or informal and confidential investigations of labor-intense firms. ${ }^{63}$ In addition, if another source puts forward claims against labor-intense firms, the SEC can pursue these claims less severely. In all of these instances, such a behavior of the SEC potentially reduces the likelihood that the SEC detects misbehavior of labor-intense firms. If the SEC starts a formal investigation of a labor-intense firm, the SEC Commissioners, as they decide how the investigation proceeds, can still overrule the recommendation of the SEC staff and thus reduce or even prevent enforcement actions against these firms.

In summary, the government has both the incentive and the means to impact the investigation process of the SEC. Therefore, I argue that the government's preference for labor-intense firms, to promote employment conditions, reflects in lower likelihood of SEC enforcement actions against these firms. This argumentation can be summarized in the following hypothesis:

\section{Hypothesis 1: Labor-intense firms are less likely to be subject to an AAER.}

\subsubsection{Government's pressure on SEC during election years}

Prior research in political economy especially highlights the role of upcoming elections as a period in which the government is likely to respond even more to the needs of its constituents to ensure political support in the upcoming election (Brown and Dinc 2005; Kramer 1971; Hibbing and Alford 1981). As Kinder and Kiewiet (1981, 1979) have emphasized, voters often use the current health of the economy as a signal of the incumbent's economic competence that will influence the voter's economic prosperity in the future. Therefore, it is of particular importance for the government to foster the employment conditions prior to elections. In line with that argument, a large literature on political business cycles, starting with Nordhaus (1975), has highlighted that the incumbent government is indeed willing to engage in potentially costly activities prior to elections to enhance the current employment conditions or avoid negative news with regard to these conditions. For instance, Alesina et al. (2000),

\footnotetext{
62 During the investigation period, the targeted firm may issue a press release indicating that it is the target of an SEC informal inquiry or formal investigation. However, usually the firm does not voluntarily disclose this information (Karpoff et al. 2008b; Kedia and Rajgopal 2011).

63 General reviews of company filings are conducted by the SEC's Division of Corporation Finance and may result in a comment letter if the Division believes that disclosure can be improved. According to Robert Sack, the former Chief Accountant of the Enforcement Division, these reviews are an important trigger event of an enforcement action as the SEC obtains about $50 \%$ of the leads from these reviews (Feroz et al. 1991).
} 
Borjas (1986) and Shleifer and Vishny (1994) show that the government prior to elections can induce pressure on state-owned firms to engage in excess employment and pay above-market wages in order to gain greater political support. Furthermore, studies by Cole (2009) and Dinç (2005) provide evidence that prior to elections the government provides subsidies via government-owned banks to the private sector as an additional mechanism to improve employment.

Next to inducing pressure on government-owned firms, studies have also shown that the government induces pressure on regulators to delay politically costly regulatory actions until after elections. For instance, Brown and Dinç (2005) investigate bank failures of the ten largest banks in 21 emerging market countries and find that failures are clustered after government elections. They interpret their findings as evidence that the government induces pressure on regulatory agencies to avoid politically costly regulatory interventions before elections. In a similar manner, Imai (2009) examines bank failures in Japan and finds that regulators delay declarations of insolvency in prefectures that support senior politicians of the ruling party.

Therefore, both political economy theory and empirical evidence indicate that the government is likely to place more pressure on the regulator prior to elections. Based on this, I argue that the SEC also faces more political pressure from the government prior to elections. This increased pressure, consequently, leads to relatively fewer enforcement actions against labor-intense firms prior to elections. Thus, I state the following hypothesis:

Hypothesis 2: Labor-intense firms are relatively less likely to be subject to an AAER in election years.

\subsection{Data and Research Method}

\subsubsection{SEC enforcement data}

To investigate the SEC's enforcement actions I use a sample of firms that have been subject to enforcement actions by the SEC for allegedly misstating their financial statements as reported in Accounting and Auditing Enforcement Releases (AAERs). Using the SEC's AAERs as a sample of misstatement firms has several advantages relative to other potential samples. First, the use of AAERs as a proxy for manipulation is a straightforward and consistent methodology. This methodology avoids potential biases induced in samples based on researchers' individual classification schemes and can be easily replicated by other researchers (Dechow et al. 2011). Second, in contrast to the Government Accountability Office (GAO) Financial Statement Restatement Database, AAERs span a larger time period, state the reporting periods that were misstated and are likely to only include events that occurred as a consequence of intentional misstatements rather than misinterpreting accounting rules (Plumlee and 
Yohn 2010; Dechow et al. 2011). Finally, using the SEC's AAERs also allows me to use the F-score, which is a potentially powerful proxy for a firm's accounting quality in this specific setting, as the F-score has been developed to predict AAERs (Dechow et al. 2011). Despite the advantages of using AAERs to identify accounting misstatements, there is one main disadvantage, which is common to many studies that also consider additional enforcement actions (e.g., Kedia and Rajgopal 2011). In particular, AAERs as well as other enforcement actions represent the end product of investigations as opposed to the initial investigations themselves. To test whether the government's preferences impact SEC's enforcement actions I would ideally like to study all investigations undertaken by the SEC. However, data on informal investigations that did not eventually convert into formal enforcement actions are not publicly available (Kedia and Rajgopal 2011). As a consequence, I cannot investigate at which stages of the enforcement process government's preferences for firms that contribute to its policies actually affect this very process. ${ }^{64}$

I obtain the data on AAERs from Dechow et al. (2011). The SEC investigation process that results in issuing an AAER against a firm typically starts with a conspicuous announcement, referred to as the trigger event, related to the firm that draws the SEC's scrutiny and can arise from a variety of sources (Karpoff et al. 2008b). ${ }^{65}$ The SEC can subsequently conduct an informal but confidential investigation of the target firm that may develop into a formal and public investigation if questionable activity is suspected; otherwise the SEC may drop the case. If a formal investigation is initiated the staff reviews books, trading data, witness testimony and other relevant information. The staff then makes an enforcement recommendation to the Commission, which decides how the SEC investigation proceeds. The SEC investigation can proceed in one of three ways based on the gravity of the perceived irregularity. If the SEC feels that the culpable firm or the individual has committed a criminal offence, the SEC turns the investigation over to the Department of Justice. If the SEC chooses to handle the disciplinary action itself, the SEC pursues the investigation through administrative or civil actions. A civil action is filed in federal court and an administrative action is the documentation of a discrepancy with a firm's accounting policy that does not warrant a

\footnotetext{
64 As a robustness test, I use SEC's comment letters, which might result from a general SEC review, and investigate whether labor-intense are less likely to receive such comment letters. As these letters might trigger an enforcement action, investigating the likelihood of receiving these letters provides some insights at which stage of the SEC investigation process the SEC adjusts its enforcement actions in accordance with government's policy to foster employment.

65 For instance, self-disclosures of malfeasance, restatements, auditor departures, unusual trading, investigations by other federal agencies such as the Department of Defense and Environmental Protection Agency, along with delayed SEC filings, management departures, whistleblower charges, and reviews by the SEC can all be potential sources of trigger events (Karpoff et al. 2008b). According to Robert Sack, the former Chief Accountant of the Enforcement Division, reviews by the SEC are an important trigger event as the SEC obtains about 50\% of the leads from these reviews (Feroz et al. 1991). Overall, however, there is no unambiguous information available which event has triggered a specific SEC enforcement action.
} 
civil suit action. All of these proceedings that involve an accountant or an auditor are designated as an Accounting and Auditing Enforcement Release (AAER) by the SEC, which is my measure of the SEC's enforcement actions.

The SEC has issued AAERs during or at the conclusion of an investigation since 1982. Therefore, the dataset I use in this study spans the time period 1982 to 2012 and consists of 3,403 AAERs; resulting in 1,297 firm misstatement events. After excluding AAERs that are unrelated to earnings misstatements or occur in financial industries, i.e., two-digit SIC codes 60-69, and matching the remaining misstatement events to firms' publicly available data in Compustat and the Center for Research in Security Prices (CRSP), I have a remaining sample of 694 firm-year observations with available data, representing AAERs against 306 distinct firms. Including my large sample of control firms, i.e., all non-AAER firms with available data, for the same time period, I arrive at an overall sample of 93,207 firm-year observations, representing 11,400 distinct firms.

\subsubsection{Methodology}

To test whether labor-intense firms are indeed less likely to receive an AAER I examine the likelihood of receiving an AAER using the following logistic regression model where subscript $i$ represents the firm and $t$ the year:

$$
\begin{aligned}
\text { AAER Dummy }_{\text {it }}=\beta_{0} & +\beta_{1} \text { Labor Intensity }_{i t}+\beta_{2} \mathrm{~F}-\text { score }_{i t}+\beta_{3} \text { Proximate }_{100_{i t}}+\beta_{4} \text { Lobbying }_{i t} \\
& +\beta_{5} \text { ROA }_{i t}+\beta_{6} \text { Big }_{\text {it }}+\beta_{7} \text { Market }- \text { to }- \text { Book }_{i t}+\beta_{8} \text { Leverage }_{i t} \\
& +\beta_{9} \text { Log Firm Age }_{i t}+\beta_{10} \text { Log Assets }_{\text {it }}+\delta_{11} \text { Industry Dummies } \\
& +\delta_{12} \text { Year Dummies }+e_{i t}
\end{aligned}
$$

The AAER DUMMY is an indicator variable that is equal to one in the years a firm has been convicted for allegedly misstating its financial statements as reported in Accounting and Auditing Enforcement Releases, and zero otherwise. This data has been obtained from Dechow et al. (2011), who collected the data from the Accounting and Auditing Enforcement Releases published by the Securities and Exchange Commission. This dataset allows me to identify the exact period in which the firm misstated its financial statements.

To test my first hypothesis, I use firm's labor intensity to proxy for a firm's contribution to government's policy of promoting employment. In particular, I measure LABOR INTENSITY as the ratio of the firm's total employees (Compustat item: EMP) scaled by current year's total average assets. ${ }^{66}$ To control for industry effects, I adjust this measure by subtracting the two-digit SIC code median-industry labor intensity to

\footnotetext{
66 Average total assets equals the sum of beginning and end of year total assets, i.e., (Compustat item: AT), divided by two.
} 
arrive at my final measure of a firm's LABOR INTENSITY. ${ }^{67}$ The higher this share, the more labor-intense a firm is relative to other firms. Thus, a firm with a higher $L A B O R$ INTENSITY contributes more to the government's policy of promoting employment. H1 predicts a negative coefficient on $\beta_{1}$, i.e., a higher labor intensity will be associated with a lower likelihood of receiving an AAER.

To test hypothesis 2 whether labor-intense firms are indeed even less likely to be subject to an AAER prior to elections, I adjust the logistic regression model for testing $\mathrm{H} 1$ in the following way:

AAER Dummy ${ }_{i t}=\beta_{0}+\beta_{1}$ Labor Intensity $_{i t}+\beta_{2}$ Election $_{\text {Year }}+\beta_{3}$ Labor Intensity $_{i t} *$ Election Year $_{t}$

$+\beta_{\mathrm{k}}$ Control Variables $\mathrm{it}_{\mathrm{t}}+\delta_{\mathrm{l}}$ Industry Dummies $+\delta_{\mathrm{m}}$ Year Dummies $+\mathrm{e}_{\mathrm{it}}$

ELECTION YEAR is a dummy variable that is one in all presidential election years during the time period 1982-2012 (i.e., 1984, 1988, 1992, 1996, 2000, 2004, 2008 and 2012), and zero otherwise. As presidential elections coincide with Congressional elections, these years represent higher scrutiny of voters towards its government. Thus, I use these years as my proxy for government's sensitivity towards its constituents' interests prior to elections. I interact this dummy variable with my firm-specific measure of LABOR INTENSITY. The underlying argument of $\mathrm{H} 2$ is that the government is willing to increase its pressure on the SEC to enhance the current employment conditions or avoid negative news with regard to these conditions as voters often use the current health of the economy as a signal of the government's competence to foster future employment. Thus, for testing $\mathrm{H} 2$ the point in time the market first learns about the start of an SEC investigation against labor-intense firms, instead of receiving an AAER per se, is important as the government can potentially benefit from a delay or further reduction of starting an investigation against these firms until after elections. To the extent that this point in time the market learns about the start of an SEC investigation cannot be controlled by the SEC as such investigations can be revealed by the media, other stakeholders or even the firm itself, the SEC is likely to reduce the enforcement actions against labor-intense firms. As information on the start of an SEC investigation is not publicly available and the release of an AAER lags the initial revelation of the misconduct by on average over 1,000 days (Karpoff et al. 2008b), I use the same dependent variable as for testing H1, denoted AAER DUMMY, which is one in the year the misstatement has occurred. H2 predicts a negative coefficient on $\beta_{3}$, i.e., labor intensity has greater impact on lowering the likelihood of being subject to an AAER in an election year compared to a non-election year.

\footnotetext{
${ }^{67}$ I use several alternative measures of labor intensity to control for the robustness of my results. In particular, I scale the number of employees by total book value of equity (Compustat item: CEQ) and by total market value of equity (Compustat item: CSHO x Compustat item: PRCC), respectively. Furthermore, I also rerun my models without adjusting these measures by industry-medians. My results are unaffected by applying these different measures.
} 
Firms that engage in less aggressive accounting choices are less likely to be subject to an AAER. To control for a firm's accounting quality, I use the F-score developed by Dechow et al. (2011). ${ }^{6}$ Dechow et al. (2011) investigate financial characteristics of misstating firms and develop a model to predict misstatements, i.e., AAERs. The output of this analysis is a scaled probability (F-score) that can be used as a red flag or signal of the likelihood of earnings management or misstatement (Dechow et al. 2011). In particular, Dechow et al. (2011) develop three different F-scores that include (1) only financial statement variables such as accruals, changes in ROA or changes in receivables (F-SCORE 1), (2) financial statement variables and off-balance sheet as well as nonfinancial variables such as the existence of operating leases ( $F$ SCORE 2), and (3) financial statement variables, off-balance sheet as well as nonfinancial variables and stock market-based variables such as market-adjusted stock return (F-SCORE 3). Thus, F-SCORE $X$ in my model either represents F-SCORE 1, FSCORE 2 or F-SCORE 3. The higher the resulting F-score, the higher is the likelihood of earnings misstatement. ${ }^{69}$

As Kedia and Rajgopal (2011) show that the SEC is more likely to investigate firms located closer to its offices, I also control for the distance between the county of a firm's headquarters and SEC offices in Washington, DC, New York City, NY, Miami, FL, Chicago, IL, Denver, CO, and Los Angeles, CA. I follow Kedia and Rajgopal (2011) and estimate the distance between the county of a firm's headquarters and SEC offices using the latitude and longitude of both counties and SEC offices obtained from the US Census Bureau Gazetter. ${ }^{70}$ Based on these distances I create a dummy, PROXIMATE 100, that is equal to one for all firms that are located within $100 \mathrm{~km}$ of the SEC office.

In addition, several studies find that firms that engage in lobbying or are politically connected can enjoy a favorable treatment by the SEC (Correia 2009; Yu and Yu 2011). I argue, however, that cross-sectional differences in SEC's enforcement actions are driven by government preferences instead of firms' active attempts to influence the SEC. To rule out that my results are driven by such attempts, I obtain data on firms' lobbying expenditures from the Center for Responsive Politics (CRP) (Correia 2009;

\footnotetext{
68 It is possible that the F-score does not only capture firm's accounting quality but also partly SEC's selection criteria (Dechow et al. 2011). From a firm's perspective, however, being subject to an SEC enforcement action is very costly (Karpoff et al. 2008b), making it beneficial for firms to avoid these characteristics. Therefore, the F-score is likely to mainly capture characteristics of firms that are more likely to misstate their financial statements as opposed to the SEC's selection criteria (Dechow et al. 2011).

${ }^{69}$ For a detailed explanation of the development of the F-score see Dechow et al. (2011).

70 In particular, I use the Haversine formula to calculate the distance between counties and SEC offices (Kedia and Rajgopal 2011). In 2007 the SEC elevated its district offices located in Boston, MA, Philadelphia, PA, Atlanta, GA, Fort Worth, TX, Salt Lake City, UT, and San Francisco, CA to regional offices and gave them responsibilities similar to their existing regional offices (Kedia and Rajgopal 2011). In order to increase the comparability of my results to those of Kedia and Rajgopal (2011) I consider only a firm's distance to the original regional offices. Considering these additional regional offices does, however, not affect my results.
} 
Blau et al. 2013; CRP 2013). The CRP compiles this data from 1998 onwards using quarterly lobbying disclosure reports filed with the Secretary of the Senate's Office of Public Records and includes lobbying expenditures for each firm. ${ }^{71}$ Based on this data I scale firm's lobbying expenditures by total average assets, denoted LOBBYING EXP, to control for a firm's lobbying activities relative to its size. I also create an indicator variable, $L O B B Y D U M M Y$, that is one if the lobbying expenditures are larger than zero, and zero otherwise. Thus, LOBBYING in my model either represents LOBBYING EXP or $L O B B Y$ DUMMY.

In accordance with prior studies that investigate determinants of firms' misstatements (Ettredge et al. 2008; Brazel et al. 2009), I also include several variables that control for the characteristics of a firm. First, I include a firm's two-digit SIC code median-adjusted return on assets, denoted ROA, to control for a firm's performance. Above average financial performance may indicate that the firm is achieving abnormally high performance through fraudulent reporting, or that the firm may have incentives to commit fraud in order to sustain their performance (Brazel et al. 2009). Next, I construct a dummy variable, denoted BIG 4, that is one for all firms audited by a Big 4 firm, and zero otherwise. As Big 4 auditors are of higher quality than non-Big 4 auditors (Palmrose 1988; Defond 1992), clients of the Big 4 are less likely to commit fraud. Consequently, employing a Big 4 auditor may lead to higher audit quality and reduce a firm's opportunity to engage in fraud (Brazel et al. 2009).

Furthermore, I use the MARKET-TO-BOOK ratio to control for a firm's growth expectations since Dechow et al. (1996), for instance, find that firms with higher growth opportunities are more likely to engage in earnings manipulation. A firm's LEVERAGE is also included to control for a firm's financial distress (Dechow et al. 1996; Brazel et al. 2009). Financially distressed firms may have a greater incentive to commit fraud than those that are not distressed. The natural logarithm of a firm's age, denoted as $L O G$ FIRM AGE, controls for the fact that fraud firms tend to be younger (Beneish 1997), which may be due to a greater incentive to commit fraud as a result of an initial public offering or other newly issued stock. Finally, to control for size I include the natural logarithm of a firm's total assets, LOG ASSETS. Table 1 provides an overview of my variables.

\footnotetext{
71 Therefore, all analyses that include lobbying expenditures as control variables are limited to the period 1998-2012.
} 


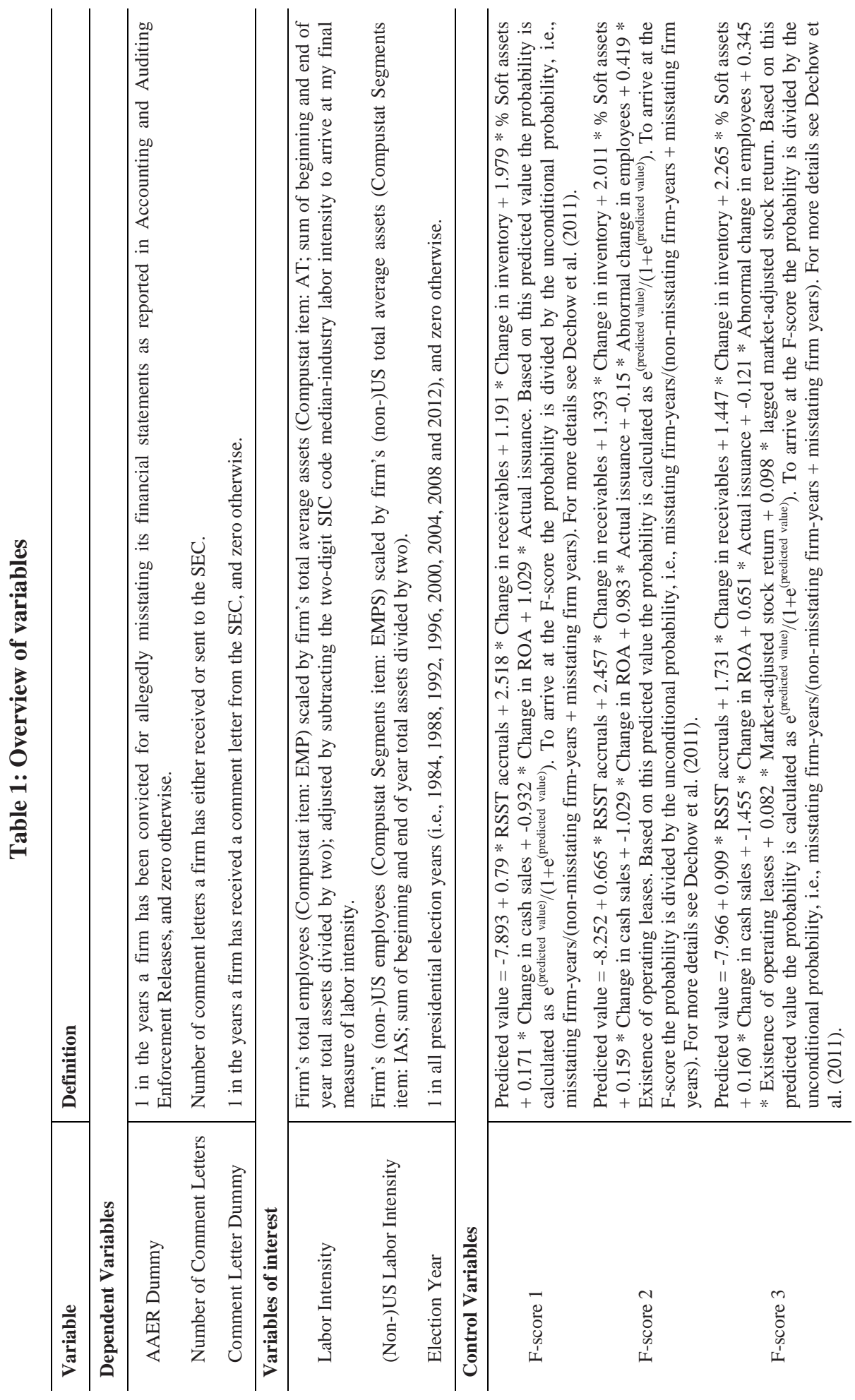



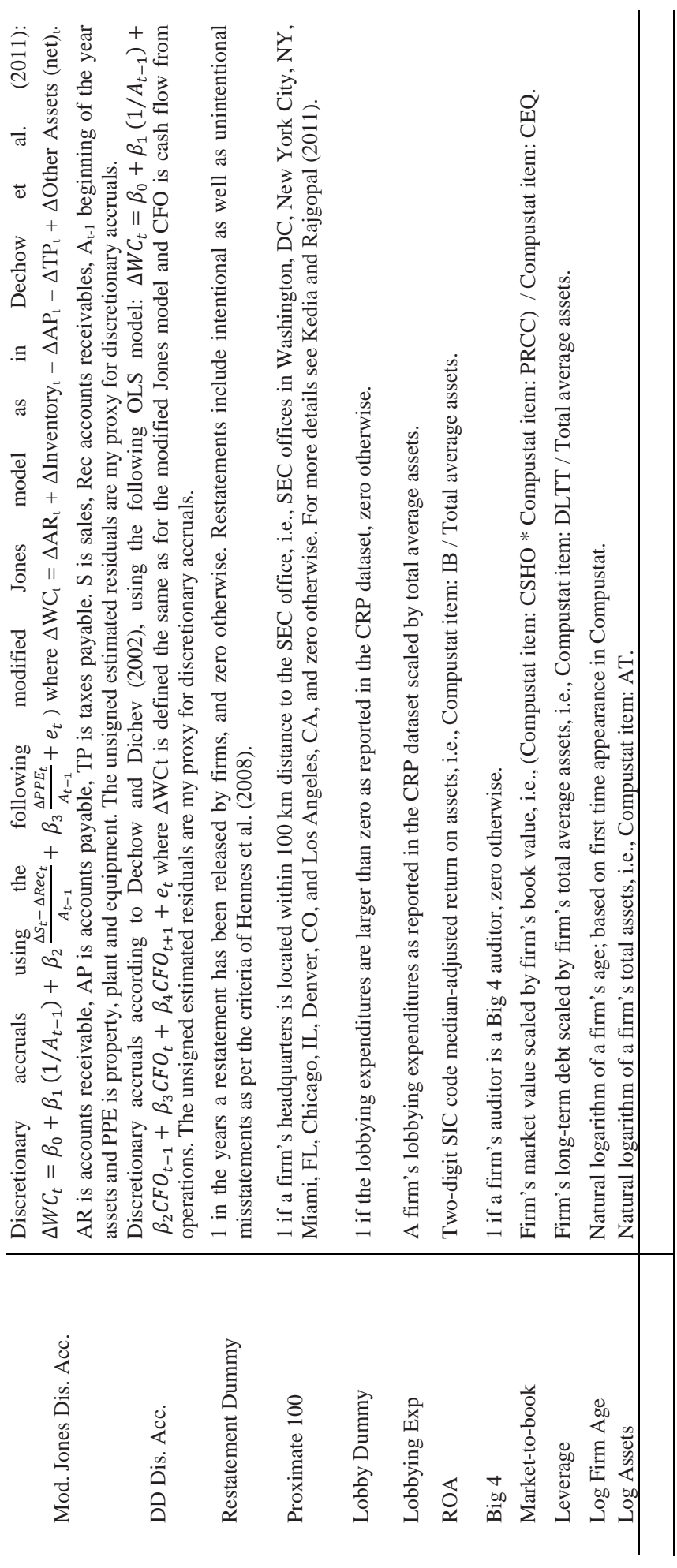


\subsubsection{Descriptive statistics}

Table 2 reports descriptive statistics of my sample, a comparison between more and less labor-intense firms, and a comparison of the AAER vs. non-AAER firms to better understand the differences between these different types of firms.

As reported in Table 2, Panel A the mean (median) firm in my sample has total average assets of $\$ 1,808$ million (\$141 million), 6,823 (837) employees, leverage of .179 (.119), a market-to-book ratio of 2.8 (1.8) and is 15 (10) years old. The skewness of these distributions suggests that my sample includes proportionately more small and younger firms. The majority of firms is audited by a Big 4 auditor (81.4\%) and 31.3\% of the firms are located within $100 \mathrm{~km}$ distance to a major SEC office. Furthermore, during the time period 1998-2012 16.2\% of the firms engage in lobbying, spending on average $\$ 71,621$.

Table 2, Panel B reports the differences between more and less labor-intense firms. I split the sample at the median value of labor intensity into two groups. The descriptives indicate that more labor-intense firms are significantly smaller, older, more profitable, employ a larger number of people and have less leverage. Labor-intense firms also engage in less lobbying, i.e., a smaller share of labor-intense firms engages in lobbying at all and the absolute lobbying amounts are lower. Furthermore, more laborintense firms have significantly higher F-scores, a larger share of them is located further away from an SEC office and does not have a Big 4 auditor; suggesting that laborintense firms potentially engage in more aggressive accounting choices.

Table 2, Panel $\mathrm{C}$ shows the differences between the firms that received an AAER and firms that did not. In particular, I find that firms that received an AAER differ significantly from firms that did not receive an AAER in all variables except for leverage. For instance, AAER firms have a higher F-score, are located closer to an SEC office, are more profitable, are more likely to be audited by a Big 4 auditor, have higher growth expectations as measured by the market-to-book ratio, are younger and larger. This is consistent with the perception that the SEC is more likely to target large firms and firms located closer to its offices (Kedia and Rajgopal 2011). I also find that a larger share of AAER firms engages in lobbying and that the absolute lobbying amounts are larger. In contrast, AAER firms' lobbying amounts relative to firm size are smaller. The descriptives also show that AAER firms employ more people as they are much bigger in size. However, AAER firms are significantly less labor-intense than their nonAAER peers. This finding provides preliminary support for $\mathrm{H} 1$. 
Table 2: Descriptive statistics

Panel A: Summary statistics for years 1982 to $2012^{\mathrm{a}}$

\begin{tabular}{ccccccccc}
\hline Variable & $\mathbf{N}$ & Mean & Std. & Min & 1st & Median & 3rd & Max \\
\hline Labor Intensity & 93,207 & 0.002 & .008 & -.011 & -.001 & 0 & .004 & .052 \\
Employees & 93,207 & 6.823 & 18.524 & .003 & .179 & .837 & 3.992 & 127.5 \\
F-score 1 & 93,207 & 1 & .727 & .120 & .484 & .819 & 1.284 & 4.287 \\
F-score 2 & 93,207 & 1 & .758 & .107 & .464 & .810 & 1.230 & 4.419 \\
F-score 3 & 93,207 & 1 & .809 & .130 & .480 & .847 & 1.387 & 4.624 \\
DD Dis. Acc. & 93,207 & 0.062 & 0.070 & 0 & 0.016 & 0.038 & 0.079 & 0.334 \\
Mod. Jones Dis. Acc. & 93,207 & 0.056 & 0.061 & 0 & 0.014 & 0.035 & 0.074 & 0.292 \\
Proximate 100 & 93,207 & .313 & .464 & 0 & 0 & 0 & 1 & 1 \\
Lobby Dummy & 55,913 & .162 & .368 & 0 & 0 & 0 & 0 & 1 \\
Lobbying Exp & 55,913 & 31.196 & 128.405 & 0 & 0 & 0 & 0 & 811.219 \\
Lobbying Amount & 55,913 & 71,621 & 284,129 & 0 & 0 & 0 & 0 & $1,740,000$ \\
ROA & 93,207 & -.057 & .228 & -1.16 & -.074 & 0 & .052 & .284 \\
Big 4 & 93,207 & .814 & .389 & 0 & 1 & 1 & 1 & 1 \\
Market-to-Book & 93,207 & 2.804 & 4.544 & -12.751 & 1.069 & 1.825 & 3.261 & 29.268 \\
Leverage & 93,207 & .179 & .199 & 0 & .003 & .119 & .292 & .898 \\
Firm Age & 93,207 & 14.92 & 14.08 & 2 & 5 & 10 & 20 & 71 \\
Assets & 93,207 & 1,808 & 5,790 & 2.12 & 32.79 & 140.98 & 738.16 & 41,959 \\
\hline
\end{tabular}

Notes to Table 2, Panel A:

${ }^{a}$ The table displays the summary statistics of the full sample for all variables over the period 1982-2012. See Table 1 for variable definitions.

Panel B: Statistics for more vs. less labor-intense firms ${ }^{b}$

\begin{tabular}{ccccc}
\hline Variable & $\mathbf{N}$ & $\begin{array}{c}\text { Higher labor } \\
\text { intensity (1) }\end{array}$ & $\begin{array}{c}\text { Lower labor } \\
\text { intensity (2) }\end{array}$ & Difference (1) - (2) \\
\hline Labor Intensity & 93,207 & .007 & -0.002 & $.009^{* * *}$ \\
Employees & 93,207 & 7.030 & 6.615 & $0.415^{* * *}$ \\
F-score 1 & 93,207 & 1.07 & .923 & $.147^{* * *}$ \\
F-score 2 & 93,207 & 1.07 & .927 & $.143^{* * *}$ \\
F-score 3 & 93,207 & 1.13 & .984 & $.146^{* * *}$ \\
DD Dis. Acc. & 93,207 & 0.065 & 0.059 & $0.006^{* * *}$ \\
Mod. Jones Dis. Acc. & 93,207 & 0.059 & 0.053 & $0.006^{* * *}$ \\
Proximate 100 & 93,207 & .308 & .318 & $-.01^{* * *}$ \\
Lobby Dummy & 55,913 & .124 & .197 & $-0.073^{* * *}$ \\
Lobbying Exp & 55,913 & 31.33 & 31.07 & 0.26 \\
Lobbying Amount & 55,913 & 40,486 & 100,746 & $-60,260^{* * *}$ \\
ROA & 93,207 & -.048 & -.067 & $.019^{* * *}$ \\
Big 4 & 93,207 & .785 & .844 & $-.059^{* * *}$ \\
Market-to-Book & 93,207 & 2.82 & 2.79 & .03 \\
Leverage & 93,207 & .174 & .184 & $-.010^{* * *}$ \\
Firm Age & 93,207 & 15.02 & 14.83 & $.19^{* * *}$ \\
Assets & 93,207 & 987 & 2,629 & $-1,642^{* * *}$
\end{tabular}

Notes to Table 2, Panel B:

b The table displays average values of the variables over the period 1982-2012 for two groups of firms: (i) more labor-intense firms; and (ii) less labor-intense firms. I constructed these groups by splitting the sample at the median value of the variable labor intensity. The table also displays the differences between the means of these variables. $* * *, * *$, and $*$ indicate the significance at the $1 \%, 5 \%$ and $10 \%$ level, respectively, of the 


\section{Chapter 4}

difference between the means of the more labor-intense firms sample as compared to the less labor-intense firms sample. See Table 1 for variable definitions.

Panel C: Statistics for AAER vs. non-AAER sample ${ }^{c}$

\begin{tabular}{cccccc}
\hline Variable & $\mathbf{N}$ & $\begin{array}{c}\text { AAER sample } \\
(\mathbf{1})\end{array}$ & $\mathbf{N}$ & $\begin{array}{c}\text { Non-AAER sample } \\
\mathbf{( 2 )}\end{array}$ & $\begin{array}{c}\text { Difference } \\
\mathbf{( 1 )}-\mathbf{( 2 )}\end{array}$ \\
\hline Labor Intensity & 694 & .0008 & 92,513 & 0.0024 & $-.0016^{* * *}$ \\
Employees & 694 & 12.35 & 92,513 & 6.783 & $5.567^{* * *}$ \\
F-score 1 & 694 & 1.47 & 92,513 & 1 & $.47^{* * *}$ \\
F-score 2 & 694 & 1.51 & 92,513 & 1 & $.51^{* * *}$ \\
F-score 3 & 694 & 1.61 & 92,513 & 1.06 & $.55^{* * *}$ \\
DD Dis. Acc. & 694 & 0.077 & 92,513 & 0.062 & $0.015^{* * *}$ \\
Mod. Jones Dis. Acc. & 694 & 0.067 & 92,513 & 0.056 & $0.011^{* * *}$ \\
Proximate 100 & 694 & .369 & 92,513 & .312 & $.057^{* * *}$ \\
Lobby Dummy & 509 & .202 & 55,404 & .162 & $0.04^{* *}$ \\
Lobbying Exp & 509 & 16.45 & 55,404 & 31.33 & $-14.88^{* * *}$ \\
Lobbying Amount & 509 & 113,658 & 55,404 & 71,235 & $42,423^{* * *}$ \\
ROA & 694 & -.029 & 92,513 & -.058 & $.029 * * *$ \\
Big 4 & 694 & .859 & 92,513 & .814 & $.044^{* * *}$ \\
Market-to-Book & 694 & 3.75 & 92,513 & 2.80 & $.954^{* * *}$ \\
Leverage & 694 & .188 & 92,513 & .179 & .009 \\
Firm Age & 694 & 13.87 & 92,513 & 14.93 & $-1.06^{* * *}$ \\
Assets & 694 & 3,243 & 92,513 & 1,798 & $1,445^{* * *}$ \\
\hline
\end{tabular}

Notes to Table 2, Panel C:

c The table displays average values of the variables over the period 1982-2012 for two groups of firms: (i) the AAER sample, i.e., firms that received an AAER; and (ii) the non-AAER sample, i.e., firms that did not receive an AAER; and the differences between the means of these variables. ${ }^{* * *}$, ${ }^{* *}$, and $*$ indicate the significance at the $1 \%, 5 \%$ and $10 \%$ level, respectively, of the difference between the means of the AAER sample as compared to the non-AAER sample. See Table 1 for variable definitions.

\subsection{Results}

\subsubsection{Test of $\mathrm{H1}$}

Table 3, Panel A shows the results of estimating equation 1, which examines the likelihood of being subject to an AAER. Consistent with $\mathrm{H} 1$, the negative and significant coefficient on the labor intensity $\left(\beta_{1}\right)$ in all of the models indicates that more labor-intense firms are less likely to receive an AAER. The coefficient estimate is not only statistically significant but also points to economic significance as reported in Table 3, Panel B. In particular, the likelihood of an SEC enforcement action for a firm in the bottom quartile of labor intensity in contrast to a firm in the top quartile increases by $11 \%$. These results indicate that the SEC is less likely to prosecute firms that contribute to the government's policy of promoting employment. This finding is robust to controlling for firms' lobbying activities, accounting quality and distance to an SEC office.

The control variables are largely in line with prior research. In particular, the positive and significant coefficients on all three types of F-score, i.e., model (1), (5) and 
(6), indicate that firms with a higher F-score are more likely to have misstated their financial statements and thus are more likely to receive an AAER (Dechow et al. 2011). I find for the majority of my models, i.e., all models except for model (2) and (3), a positive and significant coefficient on the PROXIMATE 100 dummy. Therefore, consistent with Kedia and Rajgopal (2011), I show that firms located closer to SEC's main offices are more likely to be investigated and thus receive an AAER. However, in the models (2) and (3), which include control variables for a firm's lobbying activities, the coefficient on the distance dummy is not significant. The negative but insignificant coefficient on the $L O B B Y$ DUMMY suggests that engaging in lobbying per se does not reduce the likelihood of being subject to an AAER. However, firms with higher lobbying expenditures relative to their size are less likely to be subject to an AAER, as indicated by the negative and significant coefficient on LOBBYING EXP. I also find, in line with prior research (Brazel et al. 2009), a negative and significant coefficient on the Big 4 dummy in four out of the six models, suggesting that clients of the Big 4 are less likely to commit fraud. Finally, I also find that larger and younger firms and firms with a larger growth potential are more likely to be subject to an AAER. 


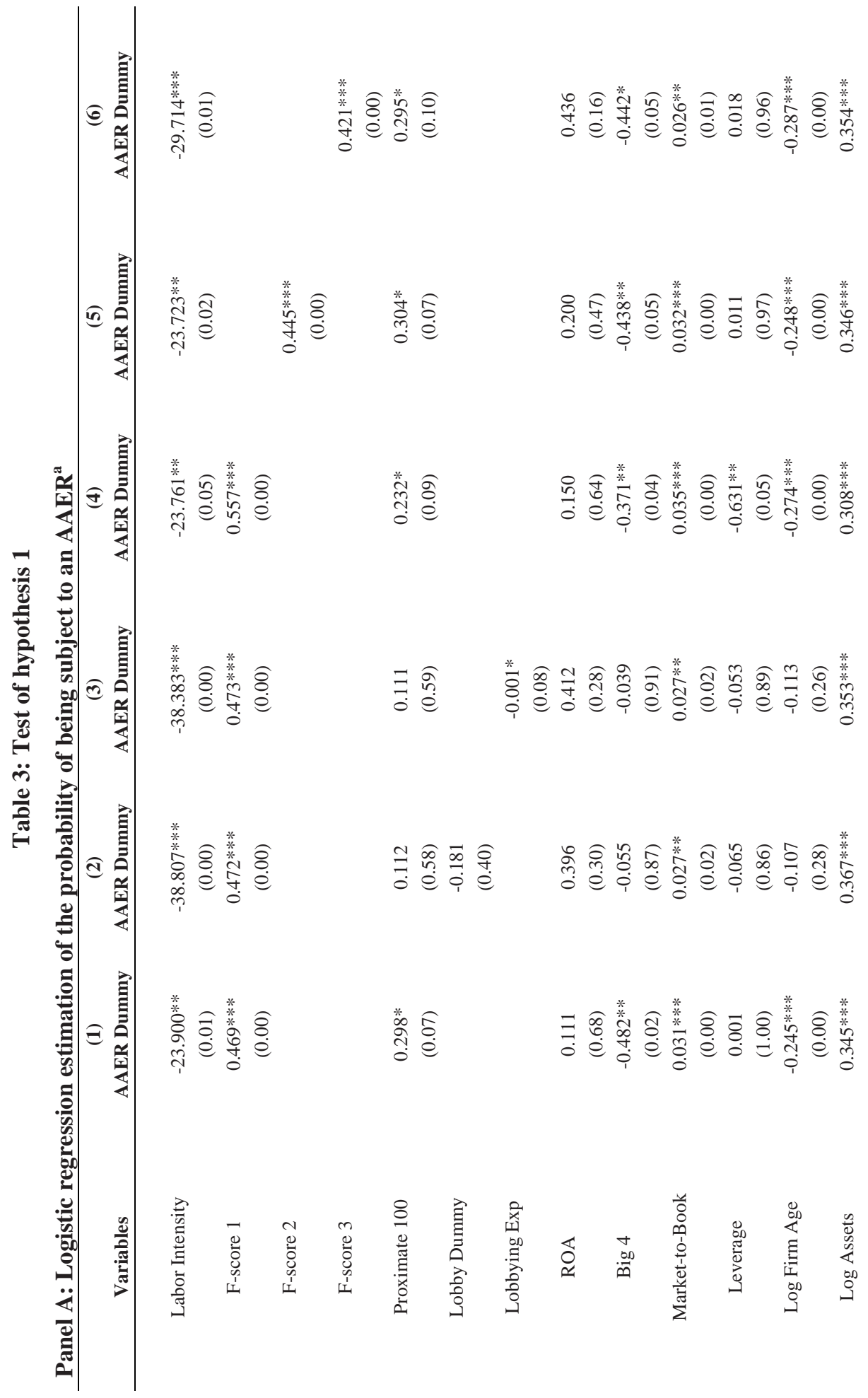




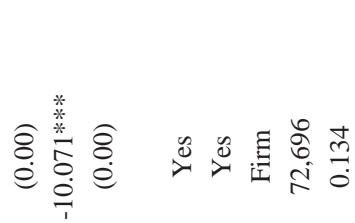

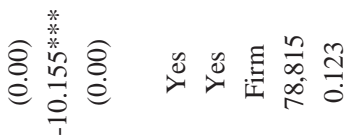

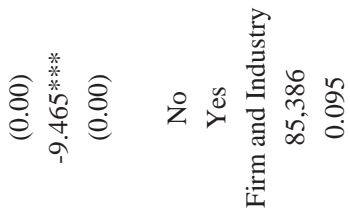

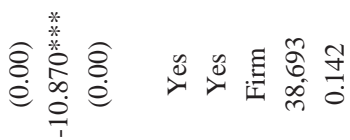

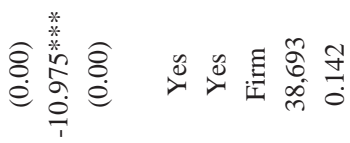

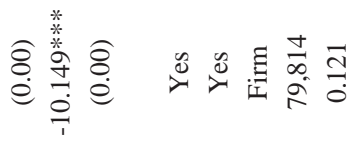

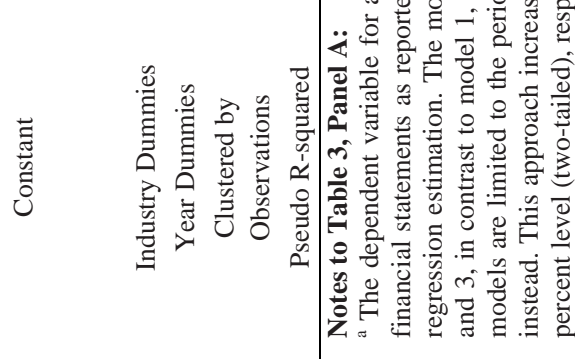

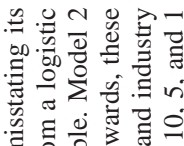

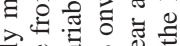

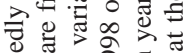

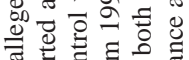

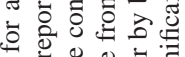

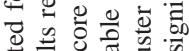

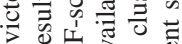

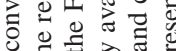

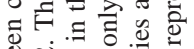

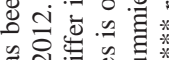

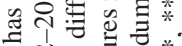

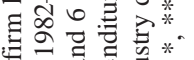

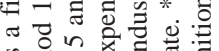

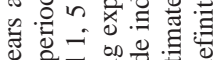

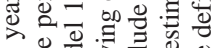

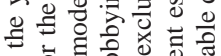

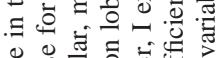

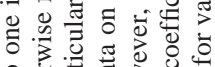

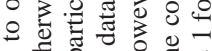

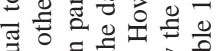
至요의

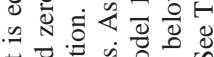

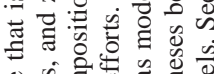

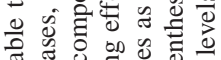

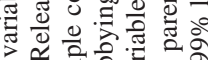

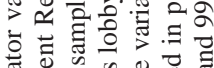

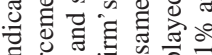

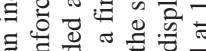

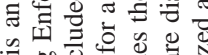

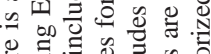

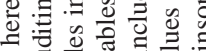

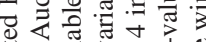

渮

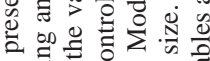

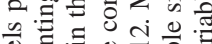

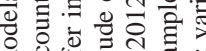

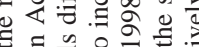

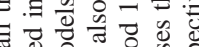

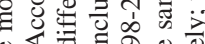

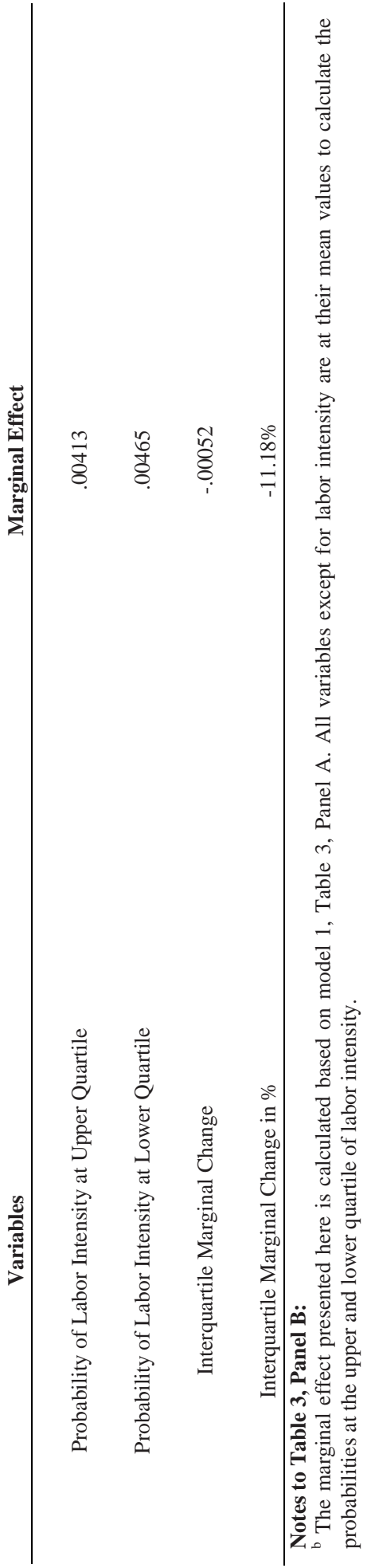




\subsubsection{Test of $\mathbf{H} 2$}

Table 4, Panel A presents the results of estimating the probability of being subject to an AAER in an election year to test H2. The results show a negative and significant coefficient on $\beta_{1}$, i.e., a firm's labor intensity, and $\beta_{3}$, i.e., the interaction term between the election year dummy and a firm's labor intensity, in all of my models. The coefficient estimates are not only statistically significant but also economically significant, as reported in Table 4, Panel B. In particular, the likelihood of an SEC enforcement action for a firm in the bottom quartile of labor intensity in contrast to a firm in the top quartile increases by $21 \%$ (9\%) in an election (non-election) year. ${ }^{72}$ These results thus indicate that labor-intense firms are even less likely to receive an AAER in an election year. As the coefficient on labor intensity stays significant in three out of four models the results suggest that labor-intense firms enjoy in general a favorable treatment by the SEC; and not just in election years. Moreover, the election year dummy is positive and significant in all models, suggesting that the SEC engages in more enforcement actions during election than non-election years. Overall, these findings provide more robust evidence that labor-intense firms face less SEC enforcement actions in response to government preferences. These results are thus consistent with $\mathrm{H} 2$ and indicate that labor-intense firms are even relatively less likely to be subject to an AAER in election years.

The results for the control variables remain largely unchanged to the results reported in Table 3, Panel A and are thus not discussed in detail.

\footnotetext{
72 Marginal effects for this interaction term are calculated by holding all variables except for a firm's labor intensity and the election year indicator at their mean (Greene 2010).
} 
Government Preferences, SEC's Enforcement Actions and Firms' Accounting Violations

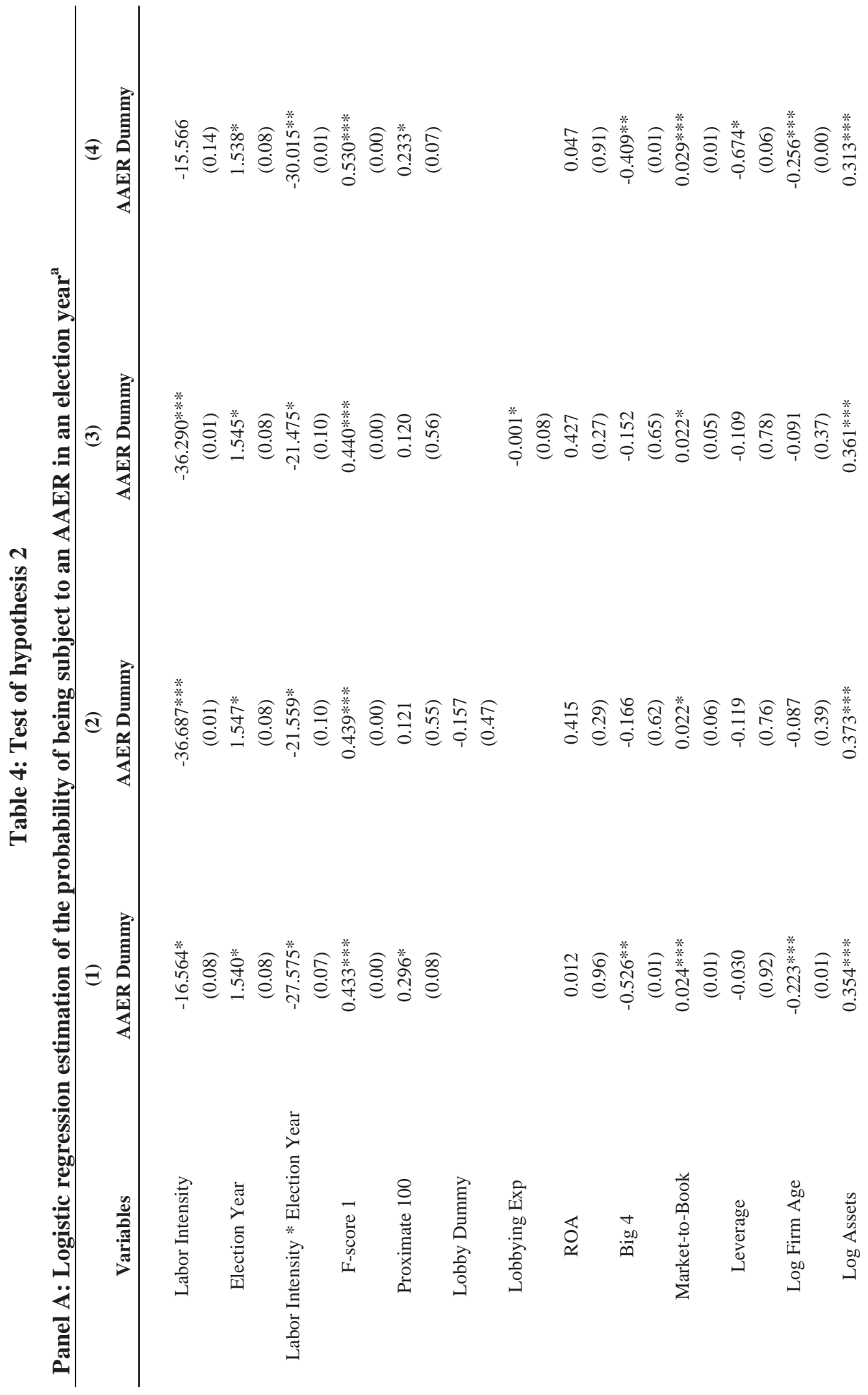




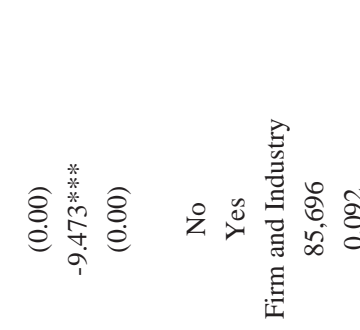

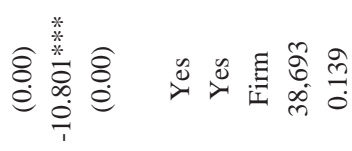

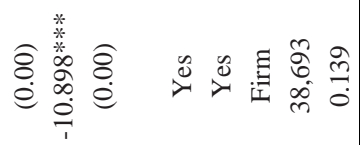

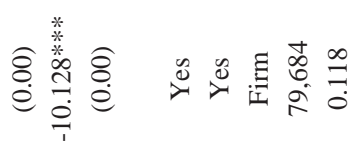

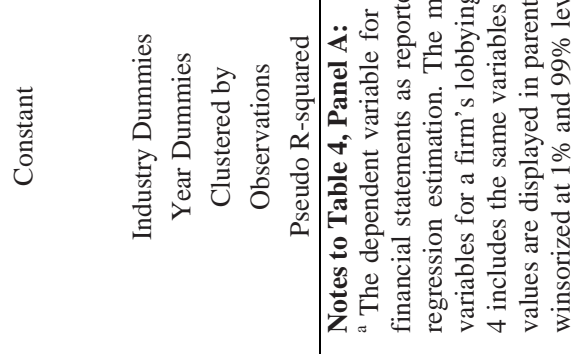

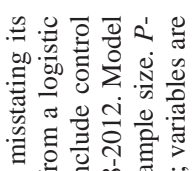

을.

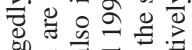

产语

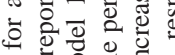

造品

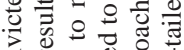

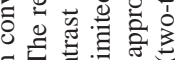

단.

ฮิ

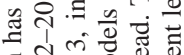

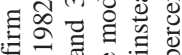

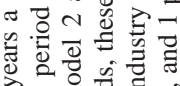

吅

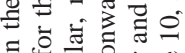

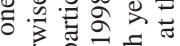

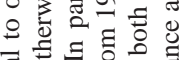

즐 흐의일

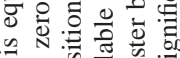

준

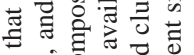

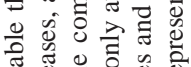

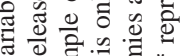

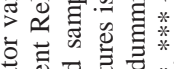

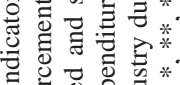

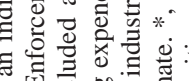

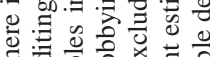

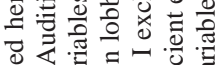

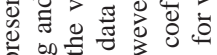

它

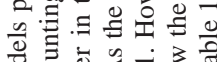

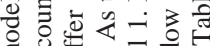

娄的过

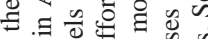

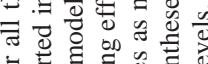

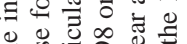

c i

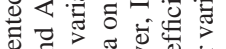

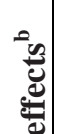

氖

$\frac{\sqrt[0]{\frac{0}{0}}}{\sqrt{\frac{\pi}{2}}}$

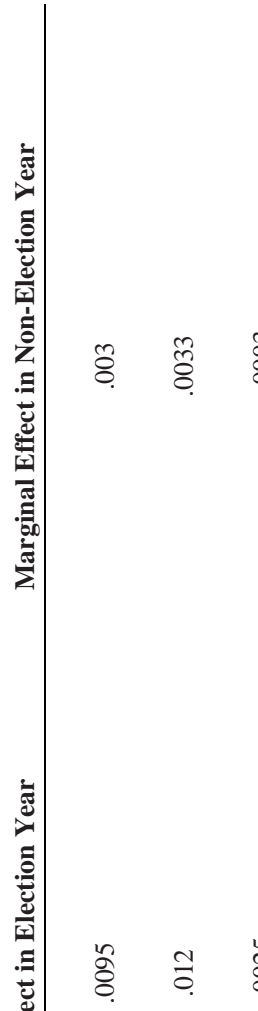

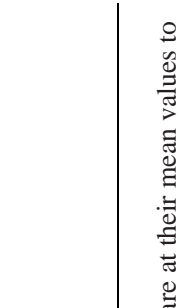

ठำ 힝

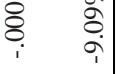

苛

这

窟

苛

훙

苛

ชั

递

뜜

ळें छ



胥

焉

을

空:

감

요

읍

둥

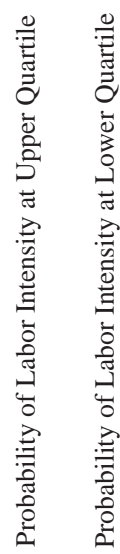




\subsubsection{Robustness and alternative tests}

\subsubsection{Accounting quality as alternative explanation for reduced SEC's enforcement actions against labor-intense firms}

A potential alternative explanation for fewer enforcement actions against laborintense firms is that these firms have a higher accounting quality than less labor-intense firms. In addition to controlling for firms' accounting quality in my main models, I therefore run the following ordinary least squares regression model and logistic regression model, respectively, where subscript $i$ represents the firm and $t$ the year:

$$
\begin{aligned}
\text { Accounting Quality }_{\text {it }} & =\beta_{0}+\beta_{1} \text { Labor Intensity }_{i t}+\beta_{2} \text { ROA }_{\text {it }}+\beta_{3} \text { Big } 4_{i t}+\beta_{4} \text { Market } \text { to }- \text { Book }_{\text {it }} \\
& +\beta_{5} \text { Leverage }_{i t}+\beta_{6} \text { Log Firm Age }_{i t}+\beta_{7} \text { Log Assets }_{i t}+\delta_{8} \text { Industry Dummies } \\
& +\delta_{9} \text { Year Dummies }+\mathrm{e}_{\mathrm{it}}
\end{aligned}
$$

ACCOUNTING QUALITY is measured using six different proxies. In particular, in three of the six models I use the three different types of F-scores as developed by Dechow et al. (2011). Recall that the F-score can be used as a red flag or signal of the likelihood of earnings management or misstatement (Dechow et al. 2011). In addition, I use two discretionary accruals models that have been widely used in prior literature. In particular, I use the modified Jones model (Dechow et al. 1995) and the Dechow and Dichev (2002) discretionary accrual model to measure accounting quality. Discretionary accruals are the difference between firms' actual accruals and the normal level of accruals. To determine the discretionary accruals, I first estimate the following modified Jones model (1991) cross-sectionally as in Dechow et al. (2011) for every two-digit industry-year $t$ with at least ten observations per industry-year:

$\Delta \mathrm{WC}_{\mathrm{t}}=\beta_{0}+\beta_{1}\left(1 / \mathrm{A}_{\mathrm{t}-1}\right)+\beta_{2} \frac{\Delta \mathrm{S}_{\mathrm{t}}-\Delta \mathrm{Rec}_{\mathrm{t}}}{\mathrm{A}_{\mathrm{t}-1}}+\beta_{3} \frac{\Delta \mathrm{PPE}_{\mathrm{t}}}{\mathrm{A}_{\mathrm{t}-1}}+\mathrm{e}_{\mathrm{t}}$

where $\Delta W C_{t}=\Delta A R_{t}+\Delta$ Inventory $-\Delta A P_{t}-\Delta T P_{t}+\Delta$ Other Assets (net) . $_{t} A R_{t}$ is accounts receivable, $A P_{t}$ is accounts payable, $T P_{t}$ is taxes payable. $S_{t}$ is sales, $\operatorname{Rec}_{t}$ accounts receivables, $A_{t-1}$ beginning of the year assets and $P P E_{t}$ is property, plant and equipment. The estimated absolute residuals are my proxy for discretionary accruals, denoted MOD. JONES DIS. ACC.

To determine the discretionary accruals according to Dechow and Dichev (2002), I estimate the following ordinary least squares model cross-sectionally for every two-digit industry-year $t$ with at least ten observations per industry-year:

$\Delta \mathrm{WC}_{\mathrm{t}}=\beta_{0}+\beta_{1}\left(1 / \mathrm{A}_{\mathrm{t}-1}\right)+\beta_{2} \mathrm{CFO}_{\mathrm{t}-1}+\beta_{3} \mathrm{CFO}_{\mathrm{t}}+\beta_{4} \mathrm{CFO}_{\mathrm{t}+1}+\mathrm{e}_{\mathrm{t}}$ 
where $\Delta W C_{t}$ is defined as above and CFO is cash flow from operations. The estimated absolute residuals are my proxy for discretionary accruals, denoted DD DIS. ACC. ${ }^{73}$

As a final measure of firms' accounting quality I obtain all restatements from the Government Accountability Office (GAO) Financial Statement Restatement Database, which covers the time period 1997-2006. I run model (3) as a logistic regression model where ACCOUNTING QUALITY is measured using restatements as an indicator variable that is equal to one in the years a restatement has been released by firms. Prior research suggests that a substantial number of restatements are due to unintentional errors rather than intentional misstatements (Hennes et al. 2008; Plumlee and Yohn 2010). I include both intentional as well as unintentional errors in my sample due to two reasons. First, restatements are an important trigger event for SEC enforcement actions (Kedia and Rajgopal 2011; Dechow et al. 2011). As a consequence, firms that do not enjoy a preferential treatment by the SEC might exercise more care in the preparation of their financial statements making it less likely that these firms make unintentional errors as well as intentional misstatements. Second, a large number of restatements due to intentional misstatements are initiated by regulatory action (Dechow et al. 2011). Thus, firms that enjoy a preferential treatment by the SEC and thus are likely to face fewer enforcement actions are potentially less likely to be required to restate their financials due to intentional misstatements.

Table 2, Panel A-C provides descriptive statistics on the discretionary accruals measures. In particular, Panel B shows that labor-intense firms have significantly higher levels of discretionary accruals, suggesting a lower accounting quality of these firms. More evidence in line with this preliminary evidence is presented in Table 5. The coefficient on labor intensity is positive and significant in all six models, consistently suggesting that the level of labor intensity is negatively associated with a firm's accounting quality.

While each of the accounting quality measures has its drawbacks (Price III et al. 2011; Dechow et al. 2011), in sum, these findings consistently suggest that labor-intense firms do not have a higher accounting quality which might explain fewer enforcement actions against these firms. Instead, the results consistently suggest that labor-intense firms exploit their preferential treatment by the SEC and engage in more aggressive accounting choices.

The coefficients on the control variables are similar to prior research. In particular, firms audited by a Big 4 auditor and older firms have a higher accounting quality; growth firms a lower accounting quality.

\footnotetext{
73 To address the possibility that labor-intense firms are more likely to manage their earnings downward, which potentially does not arise the same regulatory scrutiny as upward earnings management, I also use the signed residuals from both models as an alternative proxy for discretionary accruals. The results remain unchanged.
} 
Government Preferences, SEC's Enforcement Actions and Firms' Accounting Violations

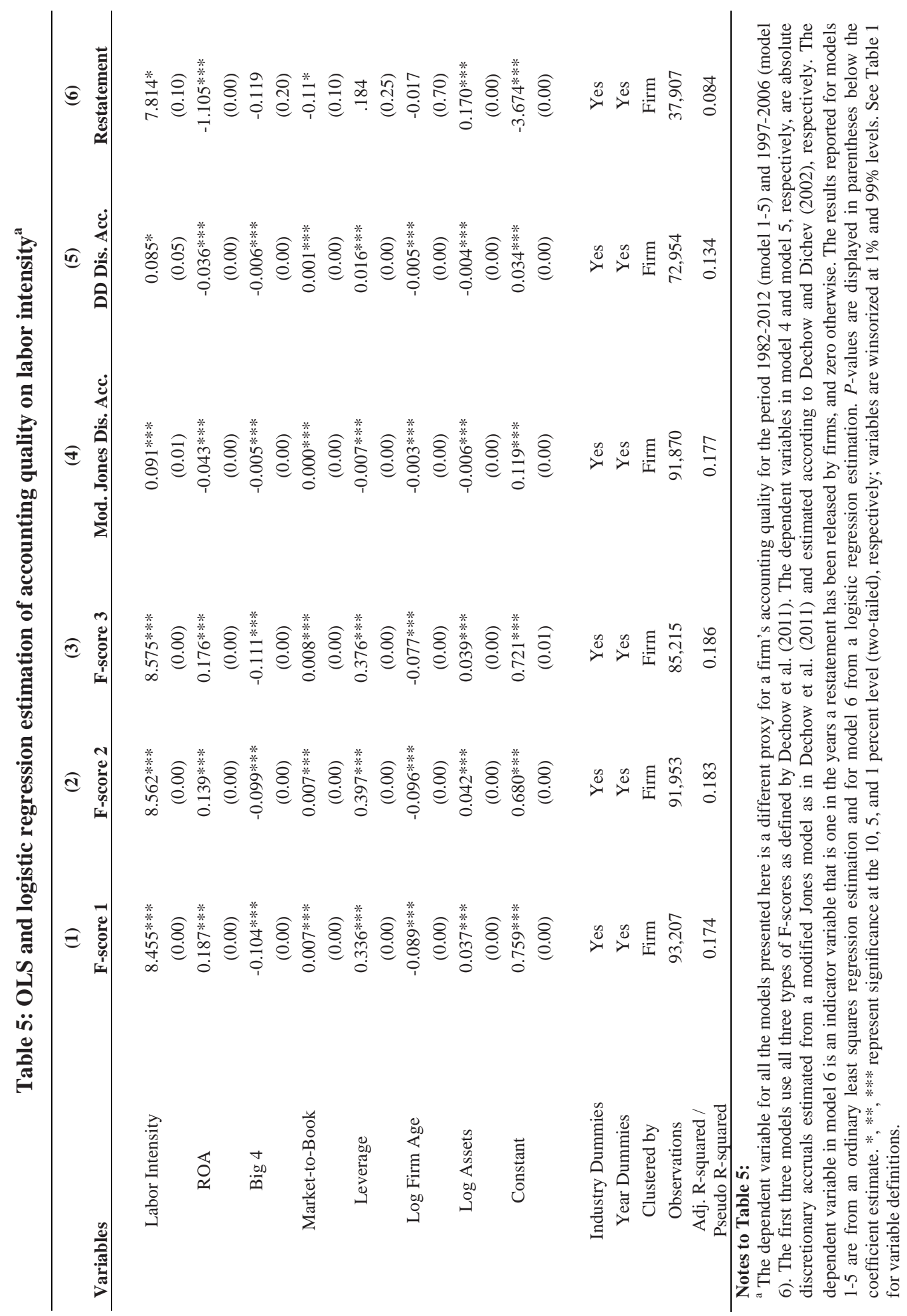




\subsubsection{US labor intensity versus non-US labor intensity}

To address the concern that my measure of labor intensity reflects a firm's total labor intensity instead of a firm's US labor intensity, I obtain data on firms' US and non-US number of employees and total average assets from Compustat Segments. As reporting the number of employees per geographical region is not required under SFAS 131, the information is only available for a relatively small subset of my original sample, i.e., 5086 firm-years representing 1217 individual firms. The descriptives of this subsample (untabulated) indicate that about $90 \%$ of the firms do not have employees and assets outside of the US, potentially, suggesting that using a firm's overall labor intensity is reflective of a firm's US labor intensity. In addition, for the subsample of firms that have both US and non-US employees the correlation between US and non-US labor intensity is .43 ( $<<0.01)$, between US and total labor intensity is $.80(\mathrm{p}<0.01)$ and between non-US and total labor intensity is .63 $(\mathrm{p}<0.01)$, indicating that the overall measure of labor intensity is reflective of firms' US employment.

Finally, the subsample of firms with US and non-US labor intensity allows me to further substantiate whether my proxy of government's preferences for employment, i.e., a firm's labor intensity, captures these preferences or is associated with some underlying omitted variable. In particular, I rerun model (1) but replace the firm's total labor intensity by its US and non-US labor intensity. As the government wants to foster US employment instead of non-US employment and thus has preferences for firms with a higher US labor intensity, I expect a negative and significant coefficient on US labor intensity but a non-significant coefficient on the non-US labor intensity.

The results of this test are shown in Table 6. The coefficient on US labor intensity but not on non-US labor intensity is negative and significant suggesting that a firm's US labor intensity influences regulatory actions by the SEC instead of non-US labor intensity.

Overall, the results of this additional test indicate that a majority of firms seem to mainly employ people in the US, the correlation of firms' US as well as non-US labor intensity is relatively high and that regulatory preferences seem to be related to US labor intensity. Thus, these results suggest that the bias introduced by using a firm's total labor intensity in my main tests is likely to work against me finding results for my hypotheses and also provide some additional evidence that labor intensity measures government preferences instead of an omitted firm characteristic related to a firm's accounting quality or risk of engaging in fraudulent accounting choices. However, given that firms that voluntarily report their number of employees in different geographic areas might not be representative of the overall sample, these results should be interpreted with caution. 
Table 6: Logistic regression estimation of the probability of being subject to an AAER with US vs. non-US labor intensity ${ }^{\mathrm{a}}$

(1)

Variables

US Labor Intensity

Non-US Labor Intensity

F-score 1

Proximate 100

Lobbying Exp

ROA

Big 4

Market-to-Book

Leverage

Log Firm Age

Log Assets

Constant

Industry Dummies

Year Dummies

Clustered by

Observations

Pseudo R-squared

AAER Dummy

$-48.329 * *$

$-19.675$

(0.55)

$0.482 * * *$

0.591

$-0.713$

0.020

(0.51)

0.809

$0.546 * * *$

$-10.551 * * *$

(0.00)

Yes

Yes

Firm

5,086

0.231

\footnotetext{
Notes to Table 6:

${ }^{a}$ The dependent variable for all the models presented here is an indicator variable that is equal to one in the years a firm has been convicted for allegedly misstating its financial statements as reported in Accounting and Auditing Enforcement Releases, and zero otherwise for the period 1999-2012. The results reported are from a logistic regression estimation. $P$-values are displayed in parentheses below the coefficient estimate. *, **, *** represent significance at the 10, 5, and 1 percent level (two-tailed), respectively; variables are winsorized at $1 \%$ and $99 \%$ levels. See Table 1 for variable definitions.
}

\subsubsection{Comment letters}

Finally, I conduct an additional test to provide more insights at what stages of the enforcement process government preferences are likely to influence SEC's enforcement actions. While my main tests use AAERs, which are the end product of investigations as 
opposed to the initial investigations themselves, I also run an additional test using SEC comment letters. The SEC's Division of Corporation Finance reviews company filings and sends comment letters to firms if it believes that these filings can be improved (SEC 2013b). The Division of Corporation Finance typically begins with a preliminary review of a firm's filings. ${ }^{74}$ Based on this preliminary review, the Division may decide to undertake a further review, which may result in a comment letter if the staff believes that disclosure can be improved. The company will typically respond by sending a letter to the SEC and there may be several rounds of correspondence until the SEC advises the company that the review of the filing is complete (Correia 2009). As the Division of Corporation Finance may refer cases to the Division of Enforcement, comment letters may trigger an enforcement action. Feroz et al. (1991) refer to a speech by Robert Sack, the former Chief Accountant of the Enforcement Division, who indicated that, in his opinion, the SEC obtains $50 \%$ of the leads from reviews of financial statements and securities offerings, suggesting that these reviews are an important trigger event of SEC's enforcement actions. A resource-constrained SEC that is likely to adjust its enforcement actions in accordance with government's policy to foster employment might also allocate fewer resources to reviews of labor-intense firms. As a consequence, labor-intense firms are less likely to receive a comment letter. In order to test whether labor-intense firms are indeed less likely to receive a comment and receive a lower number of comment letters, respectively, I use the following regression model where subscript $i$ represents the firm and $t$ the year:

Comment Letter $_{\text {it }}=\beta_{0}+\beta_{1}$ Labor Intensity $_{\text {it }}+\beta_{2} \mathrm{~F}-$ score $1_{\text {it }}+\beta_{3}$ Proximate $100_{\text {it }}$

$+\beta_{4}$ Lobbying $\operatorname{Exp}_{\text {it }}+\beta_{5} \mathrm{ROA}_{\text {it }}+\beta_{6}$ Big $4_{\text {it }}+\beta_{7}$ Market - to - Book $_{\text {it }}$

$+\beta_{8}$ Leverage $_{i t}+\beta_{9}$ Log Firm Age $_{i t}+\beta_{10}$ Log Assets $_{i t}+\delta_{11}$ Industry Dummies

$+\delta_{12}$ Year Dummies $+\mathrm{e}_{\mathrm{it}}$

COMMENT LETTER is either the number of letters exchanged between a company and the SEC or an indicator variable that is one in the years a firm received a comment letter from the SEC, and zero otherwise. The time period for this analysis is limited to the period 2004-2010 as comment and response letters are only publicly available from 2004 onwards. All other variables are defined as before.

The results of this additional test are shown in Table 7. I find that labor-intense firms are less likely to receive a comment letter and the total number of letters exchanged between the SEC and a labor-intense firm is also lower. This result suggests that the SEC allocates fewer resources to reviews of firms that contribute to government's policies. To the extent that these reviews are an important trigger event of an enforcement action, allocating fewer resources to reviews of labor-intense firms results in fewer investigations and enforcement actions by the Division of Enforcement.

\footnotetext{
74 The selection criteria for this preliminary review are not publicly disclosed. However, since the passage of the Sarbanes Oxley Act the SEC is required to undertake some level of review of a firm's filings at least once every three years (Kedia and Rajgopal 2011).
} 
In contrast, firms that have a higher F-score and thus potentially a lower accounting quality, firms that are located further away from the SEC office, and firms that engage in more lobbying are more likely to receive a comment letter and have a more extensive correspondence with the SEC. These latter findings suggest that the SEC is in general more likely to conduct reviews of firms that have a higher likelihood of misstating their financial statements.

\section{Table 7: Tobit and logistic regression estimation of the number of comment letters} and the probability of receiving a comment letter ${ }^{a}$

\begin{tabular}{|c|c|c|}
\hline Variables & $\begin{array}{c}\text { (1) } \\
\text { Number Comment Letters }\end{array}$ & $\begin{array}{c}\text { (2) } \\
\text { Comment Letter Dummy }\end{array}$ \\
\hline Labor Intensity & $\begin{array}{c}-5.530 * \\
(0.06)\end{array}$ & $\begin{array}{l}-2.084 * \\
(0.10)\end{array}$ \\
\hline F-score 1 & $\begin{array}{l}0.296 * * * \\
(0.00)\end{array}$ & $\begin{array}{c}0.104 * * * \\
(0.00)\end{array}$ \\
\hline Proximate 100 & $\begin{array}{c}-0.164^{* *} \\
(0.04)\end{array}$ & $\begin{array}{c}-0.075^{* *} \\
(0.04)\end{array}$ \\
\hline Lobbying Exp & $\begin{array}{c}0.001^{* *} \\
(0.01)\end{array}$ & $\begin{array}{c}0.000 * * * \\
(0.01)\end{array}$ \\
\hline ROA & $\begin{array}{c}-2.291 * * * \\
(0.00)\end{array}$ & $\begin{array}{c}-0.950 * * * \\
(0.00)\end{array}$ \\
\hline Big 4 & $\begin{array}{c}-0.777 * * * \\
(0.00)\end{array}$ & $\begin{array}{c}-0.308 * * * \\
(0.00)\end{array}$ \\
\hline Market-to-Book & $\begin{array}{c}0.023^{* * *} \\
(0.00)\end{array}$ & $\begin{array}{c}0.011^{* * *} \\
(0.00)\end{array}$ \\
\hline Leverage & $\begin{array}{c}0.520 * * * \\
(0.01)\end{array}$ & $\begin{array}{c}0.226 * * \\
(0.01)\end{array}$ \\
\hline Log Firm Age & $\begin{array}{l}0.219 * * * \\
(0.00)\end{array}$ & $\begin{array}{l}0.082 * * * \\
(0.00)\end{array}$ \\
\hline Log Assets & $\begin{array}{c}0.435 * * * \\
(0.00)\end{array}$ & $\begin{array}{c}0.182 * * * \\
(0.00)\end{array}$ \\
\hline Constant & $\begin{array}{c}-8.759 * * * \\
(0.00)\end{array}$ & $\begin{array}{c}-3.481^{* * *} \\
(0.00)\end{array}$ \\
\hline Industry Dummies & Yes & Yes \\
\hline Year Dummies & Yes & Yes \\
\hline Clustered by & Firm & Firm \\
\hline Observations & 21,038 & 21,038 \\
\hline Pseudo R-squared & 0.067 & 0.125 \\
\hline
\end{tabular}

\section{Notes to Table 7:}

${ }^{a}$ The dependent variable for model 1 is the number of comment letters a firm has either received or sent to the SEC, and for model 2 an indicator variable that is equal to one in the years a firm has received a comment letter to the SEC, and zero otherwise. As data on comment letters is only publicly available from 2004 
onwards, these models are limited to the period 2004-2010. The results of model 1 are from a Tobit regression estimation; and for model 2 from a logistic regression estimation. $P$-values are displayed in parentheses below the coefficient estimate. $* * *, * * *$ represent significance at the 10,5 , and 1 percent level (two-tailed), respectively; variables are winsorized at $1 \%$ and $99 \%$ levels. See Table 1 for variable definitions.

\subsection{Conclusions}

The traditional assumption in accounting and finance is that the SEC is a neutral regulatory agency that investigates those firms that are most likely to violate GAAP. Yet, economists have long argued that regulators such as the SEC are influenced by the government. As the government's goal is to maximize political support, which is largely affected by the employment conditions, it is likely to have preferences for firms that contribute to the government's policy of promoting employment. Thus, I investigate whether the SEC, as a consequence of government pressure, reduces its enforcement actions for labor-intense firms, a proxy for a firm's contribution to employment conditions. My results indicate that labor-intense firms are less likely to face an SEC enforcement action, after controlling for firms' accounting quality, location and lobbying efforts. I further exploit the variation in government's sensitivity to voters' interests in election years to provide more robust evidence that labor-intense firms face less SEC enforcement actions due to government preferences for these firms. I find that labor-intense firms are even less likely to receive an AAER in election years, after controlling for two alternative explanations for firms' favorable treatment by the SEC, i.e., firms' location and lobbying activities.

I also investigate whether labor-intense firms' lower likelihood of being subject to an AAER can be explained by the accounting quality of these firms. A higher accounting quality would explain lower SEC investigations and convictions. I find, however, evidence that labor-intense firms have a lower accounting quality than their less labor-intense peers, suggesting that fewer SEC enforcement actions against laborintense firms cannot be explained by those firms' higher accounting quality. Instead my results indicate that labor-intense firms exploit this preferential treatment by the SEC by engaging in even more aggressive accounting choices.

My study has several limitations. First, AAERs only represent the end product of SEC's enforcement actions as opposed to the initial investigations themselves. Thus, I can only describe at which stages of the SEC enforcement process government's preferences can affect the outcome of this process, i.e., receipt of an AAER, but cannot conclusively state at which stage exactly such preferences impact the enforcement process. However, by investigating the likelihood of receiving an SEC comment letter as an additional test, I find evidence that labor-intense firms are less likely to receive a comment letter, suggesting that the resource-constrained SEC allocates fewer resources to reviews of firms that contribute to government's policies. Second, my study ignores that also the terms of SEC Commissioners are limited to five years and thus SEC Commissioners themselves might have incentives to impact the enforcement preferences of the SEC around the end of their terms. Future research could explore 
whether Commissioner's incentives affect the enforcement preferences. Finally, my measures of accounting quality have limitations. For instance, it can be argued that higher discretionary accruals do not reflect fraudulent misstatements that might eventually lead to an AAER, but simply an exploitation of leeway in accounting standards. However, given the consistency of my results across several noisy accounting quality measures, I provide some evidence that labor-intense firms have on average a lower accounting quality than their less labor-intense peers.

Overall, my results indicate that the SEC is not a neutral regulatory agency, but systematically incorporates the government's preferences in its enforcement actions, regardless of firms' active lobbying activities. To the extent that these firms exploit this preferential treatment by engaging in more aggressive accounting choices, my study sheds light on a problematic consequence of government's pressure on the SEC. Future research could explore other types of firms that the government has preferences for and the costs and benefits arising out of this preferential treatment in greater detail. 



\section{Chapter 5}

\section{Conclusion}

The traditional assumption in the accounting literature is that regulatory agencies such as the SEC investigate firms that are most likely to violate regulations and enforce firms' compliance with these regulations. However, economists have long argued that regulators can be captured by the industry they are supposed to regulate or can be influenced by the government (Stigler 1971). Next to economic theories, recent fraud scandals have further increased public concerns that regulators are not effective in their enforcement of regulations.

This dissertation investigates underlying motives for differences in regulatory scrutiny across different types of firms operating in different institutional settings. As regulatory behavior also affects managers' manipulation choices, this dissertation also sheds light on how managers make different manipulation choices depending on the regulatory scrutiny they face.

In particular, chapter 2 and 3 investigate the behavior of regulators in the healthcare industry and hospital managers' reactions to these behaviors, while chapter 4 focuses on regulatory preferences of the SEC and managers' reactions to these preferences. All of these studies contribute towards a better understanding of regulatory behavior and firms' reactions to such behavior. This chapter provides a summary of the findings of each study, their limitations as well as their contributions and implications. An outlook on potential future research concludes this dissertation.

\subsection{Summary}

The first study of this dissertation, presented in chapter 2, empirically investigates whether regulators in the healthcare sector are less likely to enforce regulations for nonprofit firms that have higher performance on social goals. It further examines whether these organizations, in light of this lower regulatory enforcement, use upcoding as a tool to subsidize their social goals.

Based on "regulatory capture" theory (Stigler 1971), this study develops the case that differences in regulatory scrutiny may serve the benefit of a larger group of stakeholders and might reflect regulators' preferences about how to maximize social welfare. Nonprofit firms' objective is not only to meet a zero-profit goal, but also to improve the welfare of a broad group of constituents (Hoerger 1991; Newhouse 1970; Pauly 1987). In the healthcare sector nonprofit hospitals, for instance, pursue social goals such as providing medical education and care to the uninsured (Clement et al. 1994). As the financial support nonprofits obtain to pursue these social goals is limited 
(Chen et al. 2009), nonprofit hospitals are likely to explore alternative mechanisms to generate additional resources. One such mechanism to supplement the cost of pursuing social goals is upcoding, a form of overbilling where an ailment is classified as more severe than it actually is.

In line with this argumentation, it is posited that health care regulators recognize that nonprofit hospitals pursue costly social goals, which are implicitly supported by regulators' reduced enforcement of firms with higher social performance as such reduced enforcement allows these firms to obtain higher average prices. As such preferences can be revealed in the process of regulatory enforcement, it is argued that nonprofit hospital managers that pursue social goals react to this differentiated enforcement of regulation by engaging in higher levels of upcoding. The results confirm the predictions developed in this study, showing that hospitals with higher performance on social goals are less likely to be convicted for upcoding and use upcoding to subsidize the cost of social objectives such as charity care and medical education.

The second study of this dissertation investigates the role of upcoding as a type of revenue manipulation in firms' performance management activities. This study builds on the first study of this dissertation, in which revenue manipulation via upcoding has been identified as a powerful manipulation tool, which allows firms to increase revenues without (1) altering operations, (2) affecting costs directly or (3) facing the need to reverse in the future. More precisely, the second study examines how managers make trade-off decisions between revenue manipulation and accrual-based earnings management and real activities manipulation.

Whereas studies have started to examine how firms make choices between AEM and RAM depending on the costs associated with these strategies (Zang 2012; Badertscher 2011), the role of revenue manipulation via overbilling practices in such manipulation choices has not yet been investigated. As fraud scandals suggest that firms' performance manipulation tools are not limited to AEM and RAM, studying the trade-off decisions between these three manipulation tools provides a more complete picture of managers' manipulation choices.

In addition, this study identifies operational and financial circumstances as well as scrutiny from different regulators that make the application of each of these three strategies costly. Therefore, it is likely that managers will trade off between these three different strategies depending on the specific constraints they are facing.

The results of the second study confirm that managers trade off between these three activities, indicating that the use of RM as an alternative manipulation tool directly decreases the hospital's need to apply RAM and AEM. In addition, the results suggest that the trade-off decisions are driven by the operational constraints the hospital is facing. Overall, the results suggest that organizations that have the opportunity to engage in revenue manipulation are likely to make different trade-off decisions in their performance manipulation choices than organizations that have only RAM and AEM at their disposal. 
The third study of this dissertation extends the analysis of regulatory behavior from the healthcare sector to a large sample of listed firms and focuses on the role of government in affecting the behavior of regulatory agencies. In particular, it investigates whether government's preferences for firms that contribute to the government's policy of fostering employment are likely to reflect in the SEC's decisions as to which firms to investigate. Thus, this study examines the role that government has on inducing pressure on the enforcement actions of the SEC, as one specific regulatory agency, and also provides insights in how firms that are subject to such preferential treatment adjust their reporting behavior.

Even though research in accounting and finance traditionally assumes that the SEC is a neutral regulatory agency that investigates those firms that are most likely to violate GAAP, economists such as Stigler (1971) and Peltzman (1976) have long argued that regulations and regulators are influenced by the government. To maximize political support the government responds to both constituent and special interest pressure by adjusting its political decisions and measures accordingly (Stigler 1971). As the employment conditions are proven to systematically affect future electoral outcomes (Hibbs 2006), the government pursues a policy of promoting these conditions by supporting not only large employers in absolute terms, but also smaller, labor-intense firms that contribute to future employment (Adams and Brock 1987b; Audretsch 2003; Caves 1976).

The reason for government's pressure on SEC's enforcement actions is that these enforcement actions can take down firms that are important for the government's policy of promoting employment. As a consequence, the SEC and its Commissioners are likely to face political pressure from the government to spare labor-intense firms from enforcement actions. The government has several measures such as decision rights over the SEC's budget and the nomination of SEC Commissioners at its disposal to impose its preferences on the SEC's decisions as to which firms to investigate. As a result, the SEC is likely to act in accordance with government's policy to foster employment and thus exercises judgment as to which firms to investigate.

In line with this argumentation, the results provide evidence that labor-intense firms are less likely to be subject to SEC's enforcement actions. To test the robustness of these results, the study further examines whether a government's higher sensitivity to constituents' interests in election years further decreases the likelihood of enforcement actions against labor-intense firms. The results confirm this hypothesis providing further evidence that government's preferences for firms that support government's policies reflect directly in SEC's enforcement actions. All of these results hold after controlling for firms' accounting quality and two alternative explanations for firms' favorable treatment by the SEC, i.e., firms' location and lobbying activities. In addition, the study also provides evidence that labor-intense firms do not have a higher accounting quality, which would explain fewer SEC investigations and convictions. Instead, the results 
indicate that labor-intense firms exploit this preferential treatment by the SEC by engaging in more aggressive accounting choices.

\subsection{Limitations}

Even though considerable attention has been devoted to the empirical research design in each of the three studies, several limitations apply. As the studies presented in chapter 2 and 3 both investigate upcoding in the healthcare sector, they have some limitations in common. First, in both studies a hospital's upcoding level is investigated using only one respectively three DRG families. Including more DRG families in these analyses would indeed provide more complete results, but will greatly increase the complexity of the analyses because interactions between these DRG families have to be accounted for. In addition, to the extent that all DRG families used in these analyses are known for being prone to upcoding for over a decade, the analyses provide a conservative proxy for a hospital's upcoding behavior. An additional concern is related to the measurement of upcoding or inappropriate billing. To determine upcoding, two measures are used to control for the patient health status, i.e., Charlson index and mortality rate, which control for the underlying patient characteristics. However, even after controlling for these underlying patient characteristics, it cannot be conclusively stated that every case where there is a higher proportion of DRGs in the top of the DRG family is indeed upcoding. Finally, the analyses focus only on hospitals located in California. However, the results should be generalizable to other countries that use DRG-type reimbursement systems such as Australia, Germany, the Netherlands, and the United Kingdom.

In addition to the limitations already mentioned, the study presented in chapter 3 is subject to additional limitations. First, the possibility to manipulate revenues as described in this study might not be a feasible manipulation strategy for all types of firms. However, fraud scandals in various industries suggest that many firms have the possibility to manipulate revenues via overbilling, which is a similar mechanism as upcoding (Koppel 2006). Second, the study focuses only on upcoding as an alternative manipulation strategy of hospitals and ignores additional potential manipulation mechanism such as kickbacks or overtreatment of patients (GAO 2000). Finally, the analysis focuses on for-profit hospitals whose operations and related manipulation incentives might differ to firms in other industries. However, prior research indicates that for-profit hospitals face similar manipulation incentives than firms in other industries.

The third study also has several limitations. First, AAERs only represent the end product of SEC's enforcement actions as opposed to the initial investigations themselves. Thus, the analyses cannot directly test at which stages of the SEC enforcement process government's preferences affect the enforcement process. However, as the study also finds that labor-intense firms are less likely to receive a comment letter, which is an important trigger event for an enforcement action, the study 
can provide some evidence that the resource-constrained SEC allocates fewer resources to general reviews of firms that contribute to government's policies. Second, the study ignores that also the terms of SEC Commissioners are limited to five years and thus SEC Commissioners themselves might have incentives to impact the enforcement preferences of the SEC around the end of their terms. Finally, the measures of accounting quality have limitations. For instance, it can be argued that higher discretionary accruals do not reflect fraudulent misstatements that might eventually lead to an AAER, but simply an exploitation of leeway in accounting standards. However, given the consistency of the results across several noisy accounting quality measures, the study provides some evidence that labor-intense firms have on average a lower accounting quality than their less labor-intense peers.

\subsection{Contributions, Implications and Future Research}

All three studies contribute to the accounting literature as well as have implications for firms' managers, shareholders, policy makers and other stakeholders such as regulatory agencies or financial market intermediaries. In particular, the first study contributes to the accounting literature as it enhances the understanding of the complex social considerations surrounding regulation and its enforcement by showing that regulators reduce their enforcement for firms that perform activities that increase societal welfare. Accounting literature has not yet examined whether social preferences of the regulator drive enforcement efforts. Second, it provides evidence that in nonprofit settings, revenue manipulation via upcoding could be driven by a desire to crosssubsidize social goals. Finally, upcoding has been identified as a powerful method for revenue manipulation. The study further has policy implications as it suggests that regulators are likely to take the motives for financial manipulation into consideration while making decisions about which firms to pursue. In addition, the results identify upcoding as one potential reason for the high costs of health care in the US relative to other countries.

One of the main contributions of the second study is that it provides a more complete picture of the types of performance management tools that firms use to manipulate their performance. This is important to get to more definitive conclusions about the application and effect of the various performance management strategies (Fields et al. 2001). As it also provides additional insights on the costs that determine managers' decisions to choose one of the three performance manipulation tools over the other, it helps to further understand which manipulation strategy firms choose depending on their operational environment.

The findings of this study also inform regulators, auditors and investors that they should be aware of alternative, powerful instruments to manipulate financial performance, which can hardly be detected from financial reporting numbers. Especially for auditors of hospitals' financial statements the findings of the study suggest that it might be important to incorporate the potential performance manipulation resulting 
from upcoding into their auditing processes in order to conduct a more thorough analysis of the hospitals' reported figures. This study also provides a set of conditions that auditors of medical claims should incorporate in their assessment of which hospitals to investigate and can thus contribute to improve the detection of upcoding.

The third study contributes to a growing body of research (Correia 2009; Kedia and Rajgopal 2011; Yu and Yu 2011) which shows that the SEC is not neutral in its enforcement actions. In addition to prior studies which either focused on firms' active attempts to impact SEC's enforcement actions via lobbying and political connections or on the underlying resource constraints of the SEC, the findings of this study suggest that SEC's enforcement actions are systematically influenced by government's preferences independent of these alternative explanations. Finally, the study provides evidence that firms adjust their accounting choices as a result of the preferential treatment by the SEC. Thus, these findings inform regulators such as the SEC about potential adverse effects of their preferential treatment.

This dissertation provides a multitude of research possibilities to further improve the understanding of the interplay between regulatory behavior and firms' manipulation choices.

The first study of this dissertation provides evidence that social preferences of the regulator drive enforcement efforts. It would be fruitful to explore this issue in other industries. For example, research could explore whether firms that signal the importance of non-monetary goals such as environmental sustainability or employee learning obtain some leniency from regulators such as tax authorities. Future studies could also investigate whether firms can actually mislead regulatory agencies about their social behavior to reduce regulatory scrutiny. From a social welfare perspective, it would also be helpful to investigate whether upcoding to meet the cost of providing indigent people with health care or providing medical education is actually preferable.

Recently, the US healthcare systems has been subject to a significant regulatory overhaul stemming from the passage of the Affordable Care Act (ACA). As one of the main goals of the ACA is to lower the number of uninsured by expanding public and private insurance coverage, future studies could investigate how that regulatory change affects hospitals need to apply upcoding to cross-subsidize social goals. ${ }^{75}$ In addition, future studies could shed more light on potentially competing incentives of the regulator such as social preferences versus preferences for promotion, which could potentially be achieved with a strong enforcement track record.

The second study provides evidence that upcoding is a powerful manipulation tool that decreases the need to apply RAM and AEM. However, to the extent that more and more resources are devoted to detect upcoding, future studies could investigate how

\footnotetext{
75 The Congressional Budget Office (CBO) estimates that the legislation will reduce the number of uninsured residents by about 30 million, still leaving over 20 million residents uninsured (CBO 2012).
} 
these efforts affect hospitals' trade-off decisions. In addition, overbilling as a mechanism to manipulate revenues is likely to be present in several other industries. It would thus be interesting to investigate whether the findings are generalizable to other industries in which such possibility to manage revenues exists.

The findings of the third study suggest that firms that contribute to government's policy of fostering employment are less likely to be subject to SEC's enforcement actions. Future research could investigate whether the SEC Commissioners whose terms are limited to five years might have their own incentives to impact the enforcement preferences of the SEC around the end of their terms. As the third study also provides evidence that firms that enjoy a preferential treatment have a lower accounting quality, several questions arise. First, it would be worthwhile to explore the reaction of intermediaries such as auditors to such preferential treatment. For instance, auditors might decrease their audit fees as they assess the risk of inspection as lower than for other clients or increase their fees as the risk of fraudulent accounting choices increases. Second, it would be interesting to explore the career consequences for managers that do not exploit the preferential treatment by the SEC. Overall, it would also be helpful to understand whether such government capture of the regulatory process actually increases or decreases social welfare. Finally, future research could explore other types of firms that the government has preferences for and how it affects the work of different regulators.

Overall, many drivers of regulatory preferences and firms' reactions to such preferences are still unknown, providing many opportunities for future research. 



\section{References}

Abarbanell, J., and R. Lehavy. 2003. Can Stock Recommendations predict Earnings Management and Analysts’ Earnings Forecast Errors? Journal of Accounting Research 41 (1):1-31.

Adams, W., and J. W. Brock. 1986. Corporate power and economic sabotage. Journal of Economic Issues 20 (4):919-940.

Adams, W., and J. W. Brock. 1987a. Bigness and social efficiency: A case study of the US auto industry. In Corporations and Society, edited by A. S. Miller and W. Samuels. Westport, Conn.: Greenwood Press.

Adams, W., and J. W. Brock. 1987b. Corporate Size and the Bailout Factor. Journal of Economic Issues 21 (1):61-85.

Adams, W., and J. W. Brock. 2004. The Bigness Complex: Industry, Labor, and Government in the American Economy: Stanford University Press.

Aggarwal, R. K., M. E. Evans, and D. Nanda. 2011. Nonprofit Boards: Size, Performance and Managerial Incentives. Journal of Accounting and Economics 53 (1-2):466-487.

Alesina, A., R. Baqir, and W. Easterly. 2000. Redistributive public employment. Journal of Urban Economics 48 (2):219-241.

Alexander, J. A., and S. Y. I. H. D. Lee. 2006. Does Governance Matter? Board Configuration and Performance in Not-for-Profit Hospitals. Milbank Quarterly 84 (4):733-758.

Allen, E. J., C. R. Larson, and R. G. Sloan. 2013. Accrual reversals, earnings and stock returns. Journal of Accounting and Economics 56 (1):113-129.

Altman, E. I. 1968. Financial Ratios, Discriminant Analysis and the Prediction of Corporate Bankruptcy. The Journal of Finance 23 (4):589-609.

Altman, E. I., and A. Saunders. 1997. Credit Risk Measurement: Developments over the last 20 Years. Journal of Banking \& Finance 21 (11):1721-1742.

Armstrong, M., and D. E. Sappington. 2007. Recent Developments in the Theory of Regulation. Handbook of Industrial Organization 3:1557-1700.

Arora, A. 1996. Testing for Complementarities in Reduced-Form Regressions: A Note. Economics Letters 50 (1):51-55.

Arora, A., and A. Gambardella. 1990. Complementarity and External Linkages: The Strategies of the Large Firms in Biotechnology. The Journal of Industrial Economics 38 (4):361-379.

Arrow, K. J. 1963. Uncertainty and the Welfare Economics of Medical Care. The American Economic Review 53 (5):941-973.

Athey, S., and S. Stern. 1998. An Empirical Framework for Testing Theories about Complementarity in Organizational Design.Working paper

Audretsch, D. B. 2003. Standing on the shoulders of midgets: The US Small Business Innovation Research program (SBIR). Small Business Economics 20 (2):129-135.

Baber, W. R., S. H. Kang, and Y. Li. 2011. Modeling Discretionary Accrual Reversal and the Balance Sheet as an Earnings Management Constraint. The Accounting Review 86 (4):1189-1212.

Badertscher, B. A. 2011. Overvaluation and the Choice of Alternative Earnings Management Mechanisms. The Accounting Review 86 (5):1491-1518.

Barnes, P. 2009. Taxpayers Have \$80.3B Invested in Detroit, cited 11/06/2013. Available from http://archive.is/3G13v.

Barth, M. E., J. A. Elliott, and M. W. Finn. 1999. Market Rewards associated with Patterns of Increasing Earnings. Journal of Accounting Research 37 (2):387-413.

Barton, J., and P. J. Simko. 2002. The Balance Sheet as an Earnings Management Constraint. Accounting Review 77 (s-1):1-27.

Bealing, W. E. 1994. Actions speak louder than words: An institutional perspective on the Securities and Exchange Commission. Accounting, Organizations and Society 19 (7):555-567.

Bealing, W. E., M. W. Dirsmith, and T. Fogarty. 1996. Early regulatory actions by the SEC: An institutional theory perspective on the dramaturgy of political exchanges. Accounting, Organizations and Society 21 (4):317-338.

Becker, D., D. Kessler, and M. McClellan. 2005. Detecting Medicare Abuse. Journal of Health Economics 24 (1):189-210 


\section{References}

Beneish, M. D. 1997. Detecting GAAP violation: Implications for assessing earnings management among firms with extreme financial performance. Journal of Accounting and Public Policy 16 (3):271309.

Bertrand, M., F. Kramarz, A. Schoar, and D. Thesmar. 2007. Politicians, Firms and the Political Business Cycle: Evidence from France.Working paper

Blau, B. M., T. J. Brough, and D. W. Thomas. 2013. Corporate lobbying, political connections, and the bailout of banks. Journal of Banking \& Finance 37 (8):3007-3017.

Blount, L. L., and R. S. Gold. 1999. False Claim Allegations Over Unspecified vs. Other Specified Bacteria: Analysis of DRG 79 Issues. Healthcare Management Advisors.

Borjas, G. J. 1986. The earnings of state government employees in the United States. Journal of Urban Economics 19 (2):156-173.

Bowen, R. M., L. DuCharme, and D. Shores. 1995. Stakeholders' implicit claims and accounting method choice. Journal of Accounting and Economics 20 (3):255-295.

Bozanic, Z., M. W. Dirsmith, and S. Huddart. 2012. The social constitution of regulation: The endogenization of insider trading laws. Accounting, Organizations and Society 37 (7):461-481.

Brazel, J. F., K. L. Jones, and M. F. Zimbelman. 2009. Using nonfinancial measures to assess fraud risk. Journal of Accounting Research 47 (5):1135-1166.

Breusch, T. S., and A. R. Pagan. 1980. The Lagrange Multiplier Test and Its Applications to Model Specification in Econometrics. The Review of Economic Studies 47 (1):239-253.

Brickley, J. A., and R. L. Van Horn. 2002. Managerial Incentives in Nonprofit Organizations: Evidence from Hospitals. The Journal of Law and Economics 45:227-249.

Brock, W. A., and D. S. Evans. 1989. Small business economics. Small Business Economics 1 (1):7-20.

Brown, C. O., and I. S. Dinc. 2005. The politics of bank failures: Evidence from emerging markets. The Quarterly Journal of Economics 120 (4):1413-1444.

Burgstahler, D., and I. Dichev. 1997. Earnings Management to avoid Earnings Decreases and Losses. Journal of Accounting and Economics 24 (1):99-126.

Burgstahler, D., and M. Eames. 2006. Management of Earnings and Analysts' Forecasts to Achieve Zero and Small Positive Earnings Surprises. Journal of Business Finance \& Accounting 33 (5-6):633-652.

Canning, M., and B. O’Dwyer. 2013. The dynamics of a regulatory space realignment: Strategic responses in a local context. Accounting, Organizations and Society 38 (3):169-194.

Caves, R. E. 1976. Economic models of political choice: Canada's tariff structure. Canadian Journal of Economics 9 (2):278-300.

Caylor, M. L. 2010. Strategic Revenue Recognition to achieve Earnings Benchmarks. Journal of Accounting and Public Policy 29 (1):82-95.

CBO. 2012. Estimates for the insurance coverage provisions of the Affordable Care Act updated for the recent Supreme Court decision

Charlson, M. E., P. Pompei, K. L. Ales, and C. R. MacKenzie. 1987. A New Method of Classifying Prognostic Comorbidity in Longitudinal Studies: Development and Validation. Journal of Chronic Diseases 40 (5):373-383.

Chen, H. F., G. J. Bazzoli, and H. M. Hsieh. 2009. Hospital Financial Conditions and the Provision of Unprofitable Services. Atlantic Economic Journal 37 (3):259-277.

Clement, J. P., D. G. Smith, and J. R. Wheeler. 1994. What do we want and what do we get from Not-forProfit Hospitals? Hospital \& Health Services Administration 39 (2):159-178.

Clune, W. H. 1983. Political Model of Implementation and Implications of the Model for Public Policy, Research, and the Changing Roles of Law and Lawyers. Iowa Law Review 69:47.

CMS. 2004. Fiscal Year 2004 Improper Medicare Fee-For-Service Payment Report

CMS. 2008. CMS issues Improper Payment Rates for Medicare, Medicaid, and Schip

CMS. 2010. Acute Care Hospital Inpatient Prospective Payment System

Cohen, D. A., A. Dey, and T. Z. Lys. 2008. Real and Accrual-Based Earnings Management in the Pre- and Post-Sarbanes-Oxley Periods. The Accounting Review 83 (3):757-787.

Cohen, D. A., and P. Zarowin. 2010. Accrual-Based and Real Earnings Management Activities around Seasoned Equity Offerings. Journal of Accounting and Economics 50 (1):2-19.

Cole, S. 2009. Fixing market failures or fixing elections? Agricultural credit in India. American Economic Journal: Applied Economics 1 (1):219-250.

Conover, P. J., S. Feldman, and K. Knight. 1986. Judging inflation and unemployment: The origins of retrospective evaluations. The Journal of Politics 48 (3):565-588.

Conover, P. J., S. Feldman, and K. Knight. 1987. The personal and political underpinnings of economic forecasts. American Journal of Political Science:559-583.

Cooper, D. J., and K. Robson. 2006. Accounting, professions and regulation: Locating the sites of professionalization. Accounting, Organizations and Society 31 (4):415-444. 
Correia, M. 2009. Political connections, SEC enforcement and accounting quality.Working paper

Covaleski, M. A., M. W. Dirsmith, and J. E. Michelman. 1993. An Institutional Theory Perspective on the DRG Framework, Case-mix Accounting Systems and Health-care Organizations. Accounting, Organizations and Society 18 (1):65-80.

Crennen, C. 2013. Major cases involving upcoding by hospitals, cited 06/05/2013. Available from http://medicarefalseclaims.com/?page_id=358.

CRP. 2013. Center for Responsive Politics, cited 11/12/2013. Available from http://www.OpenSecrets.org/lobby/.

Culpan, R., and J. Trussel. 2005. Applying the agency and stakeholder theories to the Enron debacle: An ethical perspective. Business and Society Review 110 (1):59-76.

Dafny, L. 2005. How Do Hospitals Respond to Price Changes? The American Economic Review 95 (5):15251547.

Dafny, L., and D. Dranove. 2009. Regulatory Exploitation and Management Changes: Upcoding in the Hospital Industry. Journal of Law and Economics 52 (2):223-250.

Davis, S. J., J. Haltiwanger, and S. Schuh. 1996. Small business and job creation: Dissecting the myth and reassessing the facts. Small Business Economics 8 (4):297-315.

Dechow, P. M., and I. D. Dichev. 2002. The quality of accruals and earnings: The role of accrual estimation errors. The Accounting Review 77 (s-1):35-59.

Dechow, P. M., W. Ge, C. R. Larson, and R. G. Sloan. 2011. Predicting Material Accounting Misstatements. Contemporary Accounting Research 28 (1):17-82.

Dechow, P. M., and D. J. Skinner. 2000. Earnings Management: Reconciling the Views of Accounting Academics, Practitioners, and Regulators. Accounting Horizons 14 (2):235-250.

Dechow, P. M., R. G. Sloan, and A. P. Sweeney. 1995. Detecting Earnings Management. The Accounting Review 70 (2):193-225.

Dechow, P. M., R. G. Sloan, and A. P. Sweeney. 1996. Causes and consequences of earnings manipulation: An analysis of firms subject to enforcement actions by the SEC. Contemporary Accounting Research 13 (1):1-36.

Defond, M. L. 1992. The association between changes in client firm agency costs and auditor switching. Auditing: A Journal of Practice \& Theory 11 (1):16-31.

DeFond, M. L., and K. R. Subramanyam. 1998. Auditor changes and discretionary accruals. Journal of Accounting and Economics 25 (1):35-67.

Degeorge, F., J. Patel, and R. Zeckhauser. 1999. Earnings Management to Exceed Thresholds. Journal of Business 72 (1):1-33.

Demski, J. S., and D. E. Sappington. 1987. Hierarchical Regulatory Control. The Rand Journal of Economics:369-383.

Dichev, I., J. Graham, C. R. Harvey, and S. Rajgopal. 2012. Earnings Quality: Evidence from the Field.Working paper

Dinç, I. S. 2005. Politicians and banks: Political influences on government-owned banks in emerging markets. Journal of Financial Economics 77 (2):453-479.

DOJ. 2012. The False Claims Act: A Primer

Edelman, L. B. 1992. Legal ambiguity and symbolic structures: Organizational mediation of civil rights law. American Journal of Sociology 97:1531-1576.

Edelman, L. B., and M. C. Suchman. 1997. The legal environments of organizations. Annual Review of Sociology 23:479-515.

Edelman, L. B., C. Uggen, and H. S. Erlanger. 1999. The endogeneity of legal populations: Grievance procedures or rational myth. American Journal of Sociology 105:406-454.

Eldenburg, L., F. B. Gaertner, and T. Goodman. 2012. The Influence of Ownership and Compensation Practices on Charitable Activities.Working paper

Eldenburg, L., K. A. Gunny, K. W. Hee, and N. Soderstrom. 2011. Earnings Management Using Real Activities: Evidence from Nonprofit Hospitals. The Accounting Review 86 (5):1605-1630.

Eldenburg, L., B. E. Hermalin, M. S. Weisbach, and M. Wosinska. 2004. Governance, Performance Objectives and Organizational Form: Evidence from Hospitals. Journal of Corporate Finance 10 (4):527-548.

Eldenburg, L., and R. Krishnan. 2003. Public versus Private Governance: A Study of Incentives and Operational Performance. Journal of Accounting and Economics 35 (3):377-404.

Eldenburg, L. G., and R. Krishnan. 2008. The Influence of Ownership on Accounting Information Expenditures. Contemporary Accounting Research 25 (3):739-772.

Ettredge, M. L., L. Sun, P. Lee, and A. A. Anandarajan. 2008. Is earnings fraud associated with high deferred tax and/or book minus tax levels? Auditing: A Journal of Practice \& Theory 27 (1):1-33. 


\section{References}

Farrell, K. A., and D. A. Whidbee. 2003. Impact of Firm Performance Expectations on CEO Turnover and Replacement Decisions. Journal of Accounting and Economics 36 (1):165-196.

Feroz, E., K. J. Park, and V. Pastena. 1991. The financial and market effects of the SEC's accounting and auditing enforcement releases. Journal of Accounting Research 29:107-142.

Fields, T. D., T. Z. Lys, and L. Vincent. 2001. Empirical Research on Accounting Choice. Journal of Accounting and Economics 31 (1):255-307.

Fischer, P. E., and R. E. Verrecchia. 2000. Reporting bias. The Accounting Review 75 (2):229-245.

Folland, S., A. C. Goodman, and M. Stano. 1997. The Economics of Health and Health Care. Vol. 11. New Jersey: Prentice Hall.

Frank, R. G., and D. S. Salkever. 1994. Nonprofit Organization in the Health Sector. The Journal of Economic Perspectives 8 (4):129-144.

GAO. 2000. Medicare Improper Payments

Grabner, I., and F. Moers. 2013. Management control as a system or a package? Conceptual and empirical issues. Accounting, Organizations and Society 38 (6):407-419.

Graham, J. R., C. R. Harvey, and S. Rajgopal. 2005. The Economic Implications of Corporate Financial Reporting. Journal of Accounting and Economics 40 (1-3):3-73.

Greene, W. 2010. Testing hypotheses about interaction terms in nonlinear models. Economics Letters 107 (2):291-296.

Gunny, K. A. 2010. The Relation Between Earnings Management Using Real Activities Manipulation and Future Performance: Evidence from Meeting Earnings Benchmarks. Contemporary Accounting Research 27 (3):855-888.

Hansmann, H. B. 1980. The Role of Nonprofit Enterprise. The Yale Law Journal 89 (5):835-901.

Harris, J. E. 1979. Pricing rules for hospitals. The Bell Journal of Economics 10:224-243.

Hausman, J. A. 1978. Specification Tests in Econometrics. Econometrica: Journal of the Econometric Society 46 (6):1251-1271.

Healy, P. M. 1985. The Effect of Bonus Schemes on Accounting Decisions. Journal of Accounting and Economics 7 (1-3):85-107.

Healy, P. M., and J. M. Wahlen. 1999. A Review of the Earnings Management Literature and Its Implications for Standard Setting. Accounting Horizons 13 (4):365-383.

Heese, J., R. Krishnan, and F. Moers. 2014. The interplay between regulator preferences and organizational motives for revenue manipulation. Working paper

Hennes, K. M., A. J. Leone, and B. P. Miller. 2008. The importance of distinguishing errors from irregularities in restatement research: The case of restatements and CEO/CFO turnover. The Accounting Review 83 (6):1487-1519.

HHS. 2011. Overview of the uninsured in the United States: A summary of the 2011 current population survey

Hibbing, J. R., and J. R. Alford. 1981. The electoral impact of economic conditions: who is held responsible? American Journal of Political Science 25 (3):423-439.

Hibbs, D. A. 2006. Voting and the Macroeconomy. In The Oxford Handbook of Political Economy, edited by B. R. Weingast and D. A. Wittman: Oxford University Press, 565-586.

Hillman, A. L., E. Katz, and J. Rosenberg. 1987. Workers as insurance: Anticipated government assistance and factor demand. Oxford Economic Papers 39 (4):813-820.

Hirth, R. A. 1997. Competition between For-Profit and Nonprofit Health Care Providers: Can it help achieve Social Goals? Medical Care Research and Review 54 (4):414-438.

Hoerger, T. J. 1991. Profit Variability in For-Profit and Not-For-Profit Hospitals. Journal of Health Economics 10 (3):259-289.

Holbrook, T. M. 1991. Presidential elections in space and time. American Journal of Political Science 35 (1):91-109.

Hsia, R. Y. J., and Y. C. Shen. 2011. Rising Closures Of Hospital Trauma Centers Disproportionately Burden Vulnerable Populations. Health Affairs 30 (10):1912-1920.

Imai, M. 2009. Political influence and declarations of bank insolvency in Japan. Journal of Money, Credit and Banking 41 (1):131-158.

Jaspen, B. 1998. An Off Year for Consolidations. Modern Healthcare 28:40-48.

Jones, J. J. 1991. Earnings Management during Import Relief Investigations. Journal of Accounting Research 29 (2):193-228.

Kalt, J. P., and M. A. Zupan. 1984. Capture and ideology in the economic theory of politics. The American Economic Review 74 (3):279-300.

Karpoff, J. M., D. S. Lee, and G. S. Martin. 2008a. The consequences to managers for financial misrepresentation. Journal of Financial Economics 88 (2):193-215. 
Karpoff, J. M., D. S. Lee, and G. S. Martin. 2008b. The cost to firms of cooking the books. Journal of Financial and Quantitative Analysis 43 (3):581-612.

Kau, J. B., D. Keenan, and P. H. Rubin. 1982. A general equilibrium model of congressional voting. The Quarterly Journal of Economics 97 (2):271-293.

Kedia, S., and S. Rajgopal. 2011. Do the SEC's enforcement preferences affect corporate misconduct? Journal of Accounting and Economics 51 (3):259-278.

Kinder, D. R., and D. R. Kiewiet. 1979. Economic discontent and political behavior: The role of personal grievances and collective economic judgments in congressional voting. American Journal of Political Science 23 (3):495-527.

Kinder, D. R., and D. R. Kiewiet. 1981. Sociotropic politics: The American case. British Journal of Political Science 11 (2):129-161.

Klein, C. C., and G. Sweeney. 1999. Regulator Preferences and Utility Prices: Evidence from Natural Gas Distribution Utilities. Energy Economics 21 (1):1-15.

Kole, S., and K. Lehn. 1997. Deregulation, the Evolution of Corporate Governance Structure, and Survival. The American Economic Review 87 (2):421-425.

Koppel, N. 2006. Lawyer's Charge Opens Window on Bill Padding. The Wall Street Journal.

Kothari, S., A. J. Leone, and C. E. Wasley. 2005. Performance Matched Discretionary Accrual Measures. Journal of Accounting and Economics 39 (1):163-197.

Kothari, S., K. Ramanna, and D. J. Skinner. 2010. Implications for GAAP from an analysis of positive research in accounting. Journal of Accounting and Economics 50 (2):246-286.

Kramer, G. H. 1971. Short-term fluctuations in US voting behavior: 1896-1964. American Political Science Review 65 (1):131-143.

Kwoka, J. E. 1985. The Herfindahl Index in Theory and Practice. Antitrust Bull 30:915-948.

Laffont, J.-J., and D. Martimort. 1999. Separation of Regulators against Collusive Behavior. The Rand Journal of Economics 30 (2):232-262.

Laffont, J.-J., and J. Tirole. 1991. The politics of government decision-making: A theory of regulatory capture. The Quarterly Journal of Economics 106 (4):1089-1127.

Lambert, R. A., and D. F. Larcker. 1995. The Prospective Payment System, Hospital Efficiency, and Compensation Contracts for Senior-Level Hospital Administrators. Journal of Accounting and Public Policy 14 (1):1-31.

Leone, A. J., and R. L. Van Horn. 2005. How do Nonprofit Hospitals Manage Earnings? Journal of Health Economics 24 (4):815-837.

Levitt, A., and P. Dwyer. 2003. Take on the street: How to fight for your financial future: Vintage Books.

MacKuen, M. B., R. S. Erikson, and J. A. Stimson. 1992. Peasants or bankers? The American electorate and the US economy. American Political Science Review 86 (3):597-611.

MacRae, C. D. 1977. A political model of the business cycle. The Journal of Political Economy 85 (2):239263.

Marciukaityte, D., and J. C. Park. 2009. Market Competition and Earnings Management.Working paper

Markarian, G., and J. Santalo. 2009. Product Market Competition, Information and Earnings Management.Working paper

Marquardt, C. A., and C. I. Wiedman. 2004. How Are Earnings Managed? An Examination of Specific Accruals. Contemporary Accounting Research 21 (2):461-491.

Mian, A., A. Sufi, and F. Trebbi. 2010. The Political Economy of the US Mortgage Default Crisis. The American Economic Review 100 (5):1967-1998.

MNT. 2006. Tenet Healthcare to sell 11 hospitals to help cover cost of settlement, cited 03/21/2014. Available from http://www.medicalnewstoday.com/releases/46409.php.

Morrisey, M. A., G. J. Wedig, and M. Hassan. 1996. Do Nonprofit Hospitals Pay Their Way? Health Affairs 15 (4):132-144.

Naughton, M. C. 1989. Regulatory Preferences and Two-Part Tariffs: The Case of Electricity. Southern Economic Journal 55 (3):743-758.

Newhouse, J. P. 1970. Toward a Theory of Nonprofit Institutions: An Economic Model of a Hospital. The American Economic Review 60 (1):64-74.

Noll, R. G. 1971. Reforming regulation: An evaluation of the Ash Council proposals. Vol. 837: Brookings Institution Washington, DC.

Nordhaus, W. D. 1975. The political business cycle. Review of economic Studies 42 (2):169-190.

Norton, E. C., and D. O. Staiger. 1994. How Hospital Ownership affects Access to Care for the Uninsured. The Rand Journal of Economics 25:171-185.

OIG, H. 1998. Using Software to Detect Upcoding of Hospital Bills

OIG, H. 2001a. Improper Fiscal Year 2000 Medicare Fee-For-Service Payments 


\section{References}

OIG, H. 2001b. Medicare Hospital Prospective Payment System: How DRG Rates Are Calculated and Updated

OIG, H. 2005. The Orange Book

Palmrose, Z.-V. 1988. An Analysis of Auditor Litigation and Audit Service Quality. Accounting Review 63 (1):55-73.

Pauly, M. V. 1987. Nonprofit Firms in Medical Markets. The American Economic Review 77 (2):257-262.

Peltzman, S. 1976. Toward a more general Theory of Regulation. Journal of Law and Economics 19:211-240.

Peltzman, S. 1984. Constituent interest and congressional voting. Journal of Law and Economics 27:181-210.

Peltzman, S. 1985. An Economic Interpretation of the History of Congressional Voting in the Twentieth Century. The American Economic Review.

Peltzman, S. 1992. Voters as fiscal conservatives. The Quarterly Journal of Economics 107 (2):327-361.

Pizzini, M. J. 2006. The Relation between Cost-system Design, Managers’ Evaluations of the Relevance and Usefulness of Cost Data, and Financial Performance: An empirical Study of US Hospitals. Accounting, Organizations and Society 31 (2):179-210.

Plumlee, M., and T. L. Yohn. 2010. An analysis of the underlying causes attributed to restatements. Accounting Horizons 24 (1):41-64.

Plummer, E., D. P. Mest, and J. E. Core. 2001. Evidence on the Management of Earnings Components. Journal of Accounting Auditing and Finance 16 (4):301-330.

Potrafke, N. 2012. Political cycles and economic performance in OECD countries: Empirical evidence from 1951-2006. Public Choice 150 (1-2):155-179.

Preston, A. M. 1992. The Birth of Clinical Accounting: A Study of the Emergence and Transformations of Discourses on Costs and Practices of Accounting in U.S. Hospitals. Accounting, Organizations and Society 17 (1):63-100.

Price III, R. A., N. Y. Sharp, and D. A. Wood. 2011. Detecting and predicting accounting irregularities: A comparison of commercial and academic risk measures. Accounting Horizons 25 (4):755-780.

Psaty, B. M., R. Boineau, L. H. Kuller, and R. V. Luepker. 1999. The Potential Costs of Upcoding for Heart Failure in the United States. The American Journal of Cardiology 84 (1):108-109.

Raith, M. 2003. Competition, Risk and Managerial Incentives. American Economic Review 93:1425-1436.

Rashbaum, W. K. 2012. Company Admits It Bilked Clients on Big Projects, cited 06/08/2013. Available from http://www.nytimes.com/2012/04/25/nyregion/lend-lease-expected-to-admit-to-fraudscheme.html?pagewanted=all\&_r=0.

Reinhardt, U. E. 2006. The Pricing of US Hospital Services: Chaos behind a Veil of Secrecy. Health Affairs 25 (1):57-69.

Richardson, S. A., R. G. Sloan, M. T. Soliman, and I. Tuna. 2005. Accrual reliability, earnings persistence and stock prices. Journal of Accounting and Economics 39 (3):437-485.

Roychowdhury, S. 2006. Earnings Management through Real Activities Manipulation. Journal of Accounting and Economics 42 (3):335-370.

Samuelson, P. A., and W. D. Nordhaus. 2004. Economics. 19th ed: McGraw-Hill.

Sapolsky, H. M. 1986. Prospective Payment in Perspective. Journal of Health Politics, Policy and Law 11 (4):633-645.

Schipper, K. 1989. Commentary on Earnings Management. Accounting Horizons 3 (4-5):91-102.

Schmidt, K. M. 1997. Managerial Incentives and Product Market Competition. The Review of Economic Studies 64 (2):191-213.

SEC. 2013a. Current SEC Commissioners, cited 10/15/2013 2013. Available from http://www.sec.gov/about/commissioner.shtml.

SEC. 2013b. What we do, cited 10/03/2013 2013. Available from http://www.sec.gov/about/whatwedo.shtml.

Shleifer, A. 2004. Does Competition Destroy Ethical Behavior? American Economic Review 94 (2):414-418.

Shleifer, A., and R. W. Vishny. 1994. Politicians and firms. The Quarterly Journal of Economics 109 (4):9951025.

Silverman, E., and J. Skinner. 2004. Medicare Upcoding and Hospital Ownership. Journal of Health Economics 23 (2):369-389.

Sloan, R. G. 1993. Accounting Earnings and Top Executive Compensation. Journal of Accounting and Economics 16 (1-3):55-100.

Soderstrom, N. 1993. Hospital Behavior under Medicare Incentives. Journal of Accounting and Public Policy 12 (2):155-185.

Steinbusch, P. J. M., J. B. Oostenbrink, J. J. Zuurbier, and F. J. M. Schaepkens. 2007. The Risk of Upcoding in Casemix Systems: A Comparative Study. Health Policy 81 (2-3):289-299.

Stigler, G. J. 1971. The Theory of Economic Regulation. The Bell Journal of Economics and Management Science 2 (1):3-21. 
Stubben, S. R. 2010. Discretionary Revenues as a Measure of Earnings Management. The Accounting Review 85 (2):695-717.

TAF. 2007. Fraud Statistics - 1986-2007

Thomas, J. 2011. Power Scandal Exposed. Seven News, cited 06/08/2013. Available from http://au.news.yahoo.com/today-tonight/money/article/-/10241945/TT_Power_scandal_exposed__12092011_files/.

Thomsen, L. 2009. Testimony of Linda Chatman Thomsen before the United States Senate Committee on Banking, Housing and Urban Affairs concerning investigations and examinations by the Securities and Exchange Commission and issues raised by the Bernard L. Madoff Investment Securities Matter

Tinaikar, S., and S. Xue. 2009. Product Market Competition and Earnings Management: Some International Evidence.Working paper

Trueman, B., and S. Titman. 1988. An Explanation for Accounting Income Smoothing. Journal of Accounting Research 26:127-139.

VanRoekel, S. 2012. The JOBS Act: Encouraging Startups, Supporting Small Businesses, cited 11/06/2013. Available from http://www.whitehouse.gov/blog/2012/04/05/jobs-act-encouraging-startupssupporting-small-businesses.

Watts, R. L., and J. L. Zimmerman. 1978. Towards a positive theory of the determination of accounting standards. The Accounting Review 53 (1):112-134.

Weingast, B. R. 1984. The congressional-bureaucratic system: A principal agent perspective (with applications to the SEC). Public Choice 44 (1):147-191.

Weingast, B. R., and M. J. Moran. 1983. Bureaucratic discretion or congressional control? Regulatory policymaking by the Federal Trade Commission. The Journal of Political Economy 5:765-800.

Weisbrod, B. A. 1977. The Voluntary Nonprofit Sector. Massachusetts: Lexington Books

Weisbrod, B. A. 1988. The Nonprofit Economy. Cambridge: Harvard University Press.

Wennberg, J. E., and M. M. Cooper. 1999. The Quality of Medical Care in the United States: A Report on the Medicare Program. The Dartmouth Atlas of Health Care. Chicago, IL: American Hospital Association Press.

Wilson, J. Q. 1980. The politics of regulation. New York: Basic.

Wilson, J. Q. 1989. Bureaucracy: What government agencies do and why they do it. New York: Basic Books.

Winter, A., and J. Pettengill. 2003. Relationships among Medicare Inpatient, Overall Medicare and Total Margins for Hospitals. Washington, D.C.: Medicare Payment Advisory Commission.

Wolfers, J. 2002. Are voters rational?: Evidence from gubernatorial elections: Graduate School of Business, Stanford University.

Woo, C. Y. 1983. Evaluation of the Strategies and Performance of Low ROI Market Share Leaders. Strategic Management Journal 4 (2):123-135.

Wooldridge, J. M. 2002. Econometric Analysis of Cross Section and Panel Data. 2nd ed. Boston: The MIT Press.

Yermack, D. 1996. Higher Market Valuation of Companies with a Small Board of Directors. Journal of Financial Economics 40 (2):185-211.

Yetman, M. H., and R. J. Yetman. 2013. Do Donors Discount Low Quality Accounting Information? The Accounting Review 88 (3):1041-1067.

Yu, F., and X. Yu. 2011. Corporate lobbying and fraud detection. Journal of Financial and Quantitative Analysis 46 (6):1865.

Zang, A. 2012. Evidence on the Trade-Off between Real Activities Manipulation and Accrual-Based Earnings Management. The Accounting Review 87 (2):675-703.

Zellner, A. 1962. An Efficient Method of Estimating Seemingly Unrelated Regressions and Tests for Aggregation Bias. Journal of the American Statistical Association 57 (298):348-368.

Zuckerman, S., J. Hadley, and L. Iezzoni. 1994. Measuring hospital efficiency with frontier cost functions. Journal of Health Economics 13 (3):255-280. 



\section{Curriculum Vitae}

Jonas Heese was born on September 26, 1984, in Erkelenz, Germany. He holds a Dipl.-Betriebswirt as well as B.A. (with First Class Honors) degree in business administration with majors in Accounting, Finance and Marketing from the University of Cooperative Education Mannheim, Germany, and the Open University London, UK, respectively. He also holds a M.Sc. (cum laude) degree in international business administration with a major in Accounting from Maastricht University, The Netherlands. In May 2010 he joined the Department of Accounting \& Information Management at Maastricht University as a Ph.D. candidate. During his doctoral studies, Jonas has been a visiting scholar at Michigan State University and the University of Melbourne.

He presented his work at various international conferences, including the American Accounting Association Annual Meeting (2013, 2014), the American Accounting Association Management Accounting Mid-Year Meeting (2013, 2014), the Conference on New Directions in Management Accounting (2012), the European Accounting Association Annual Meeting (2013, 2014) and Doctoral Consortium (2013), the Global Management Accounting Research Symposium (2012, 2013, 2014). He also presented his work as an invited speaker at university seminars, including Aalto University, Bocconi University, Erasmus University, Harvard Business School, London School of Economics and Political Science, Michigan State University (2011, 2014), Monash University, Nanyang Technological University, University of Arizona, University of Melbourne, University of Miami, University of Queensland, University of Technology at Sydney, University of Western Australia. In 2013 Jonas was selected as the EAA Representative at the AAA Doctoral Consortium. As of July 2014, Jonas is an Assistant Professor at the Accounting \& Management Unit at Harvard Business School. 
